\title{
The environmental risks of neonicotinoid pesticides: a review of the evidence post 2013
}

\author{
Thomas James Wood ${ }^{1}$ • Dave Goulson ${ }^{2}$
}

Received: 1 February 2017 / Accepted: 9 May 2017 /Published online: 7 June 2017

(C) The Author(s) 2017. This article is an open access publication

\begin{abstract}
Neonicotinoid pesticides were first introduced in the mid-1990s, and since then, their use has grown rapidly. They are now the most widely used class of insecticides in the world, with the majority of applications coming from seed dressings. Neonicotinoids are water-soluble, and so can be taken up by a developing plant and can be found inside vascular tissues and foliage, providing protection against herbivorous insects. However, only approximately $5 \%$ of the neonicotinoid active ingredient is taken up by crop plants and most instead disperses into the wider environment. Since the mid-2000s, several studies raised concerns that neonicotinoids may be having a negative effect on nontarget organisms, in particular on honeybees and bumblebees. In response to these studies, the European Food Safety Authority (EFSA) was commissioned to produce risk assessments for the use of clothianidin, imidacloprid and thiamethoxam and their impact on bees. These risk assessments concluded that the use of these compounds on certain flowering crops poses a high risk to bees. On the basis of these findings, the European Union adopted a partial ban on these substances in May 2013. The purpose of the present paper is to collate and summarise scientific evidence published since 2013 that investigates the impact of neonicotinoids on nontarget organisms. Whilst much of the recent work has focused on the impact of neonicotinoids on bees, a growing body of
\end{abstract}

Responsible editor: Philippe Garrigues

Thomas James Wood

woodtho4@msu.edu

1 Department of Entomology, Michigan State University, East Lansing, MI 48824, USA

2 School of Life Sciences, The University of Sussex, Falmer, East Sussex BN1 9QG, UK evidence demonstrates that persistent, low levels of neonicotinoids can have negative impacts on a wide range of free-living organisms.

Keywords Neonicotinoids $\cdot$ Neonicotinoid pesticides · European Food Safety Authority · Non-target organisms . Residues $\cdot$ Invertebrates $\cdot$ Bees $\cdot$ Freshwater habitats

\section{Introduction}

Neonicotinoid pesticides were first introduced in the 1990s, and since then, they have become the most widely used class of insecticide in the world (Jeschke et al. 2011; Casida and Durkin 2013). This increase in popularity largely occurred from the early 2000s onwards (Fig. 1). This increase in use has largely been driven by the adoption of seed treatments. Neonicotinoids are water-soluble, and so a small quantity applied to a seed will dissolve when in contact with water and be taken up by the roots of the developing plant. Once inside the plant, it becomes systemic and is found in vascular tissues and foliage, providing protection against herbivorous insects. This prophylactic use of neonicotinoids has become extremely widespread - for example, between 79 and $100 \%$ of maize hectares in the USA in 2011 were treated with a neonicotinoid seed dressing (Douglas and Tooker 2015).

However, only approximately $5 \%$ of the neonicotinoid active ingredient is taken up by crop plants (Sur and Stork 2003) and most instead disperses into the wider environment (Goulson 2014). In recent years, numerous authors have raised concerns about the impact neonicotinoids may have on non-target organisms. Neonicotinoids released in dust abraded by seed drilling machinery were implicated in mass poisonings of honeybees in Germany and Italy (Pistorius et al. 2009; Bortolotti et al. 2009); neonicotinoids were found in 


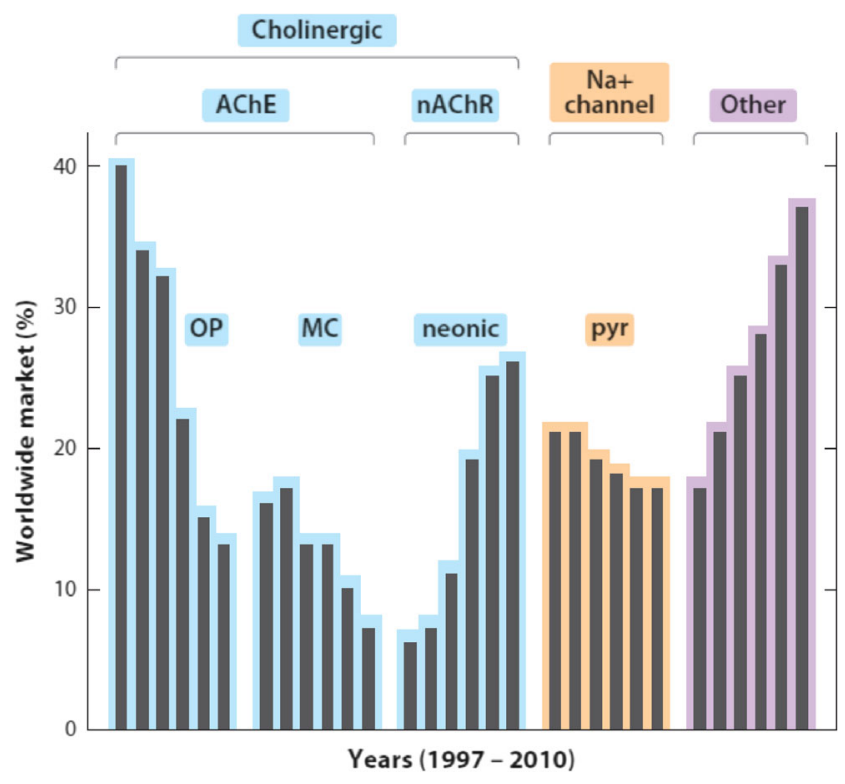

Fig. 1 Changes in use of insecticide classes between 1997 and 2010 showing decreases for organophosphates (OPs), methylcarbamates (MCs) and pyrethroids (pyr) and increases for neonicotinoids (neonic) and other compounds. Abbreviations: AChE acetylcholinesterase; $n A C h R$ nicotinic acetylcholine receptor. Reproduced from Casida and Durkin (2013)

agricultural soils (Bonmatin et al. 2005) and also in the pollen and nectar of treated crops (Bonmatin et al. 2007). In 2012, two high-profile studies were published that showed exposure to neonicotinoids in pollen and nectar could have serious effects on honeybee navigation and individual survival (Henry et al. 2012) and bumblebee colony development and queen production (Whitehorn et al. 2012). In response to the growing body of work, the European Food Safety Authority (EFSA), the body with regulatory oversight for agricultural chemicals, was commissioned to produce a risk assessment on the three most widely used agricultural neonicotinoids (clothianidin, imidacloprid and thiamethoxam) and the risk that they posed to bees (EFSA 2013a, b, c). On the basis of the available evidence, EFSA recommended a moratorium on the use of neonicotinoids on treated crops which was accepted and implemented by the European Commission of the European Union (EU) at the end of 2013.

This moratorium is currently being re-evaluated. One of the specified objectives was to allow further research on the impact of neonicotinoids on bees in order to inform subsequent regulatory decisions. Since 2013, a great number of studies have been published that consider the impact of neonicotinoids on bees and also a wide range of other non-target taxa (Fig. 2). Using data from Web of Science, studies on neonicotinoids (search term neonicotinoid*) published during the years 2013-2016 represent $52.4 \%$ of all papers on neonicotinoid since 1995 . The proportion is even greater for more specialised studies, such as neonicotinoids and bees (neonicotinoid* + bee*, 59.4\%), neonicotinoids and residues (neonicotinoid* + residue, $60.9 \%$ ), neonicotinoids and water (neonicotinoid* + water, $61.7 \%$ ) and neonicotinoids and soil (neonicotinoid* + soil, 63.7\%). Many large reviews of neonicotinoids' impacts on non-target organisms have also been published, for example Nuyttens et al. (2013) on neonicotinoid contaminated dust, Godfray et al. (2014, 2015) on the risks neonicotinoids pose to pollinators, Bonmatin et al. (2015) on environmental fate of and exposure to neonicotinoids, Pisa et al. (2015) and Gibbons et al. (2015) on the impacts of neonicotinoids on non-target terrestrial organisms and Morrissey et al. (2015) on contamination of aquatic ecosystems with neonicotinoids and their impact on aquatic organisms.

The purpose of this review is to consider the scientific evidence published since 2013 that covers the impact of neonicotinoids on wild non-target organisms (therefore excluding the domesticated honeybee) and to bring it together into one place to aid informed decision-making. It is not a formal risk assessment, though comparisons will be made with the knowledge base used in the EFSA risk assessments specifically and that which was known in 2013 more generally. The findings will be of interest to those considering the wider impact of neonicotinoid pesticide use when assessing their future use in agricultural environments.

\section{Evidence for exposure to neonicotinoid pesticides}

\section{Risk of exposure for non-target organisms from neonicotinoids applied directly to crops}

Due to their systemic nature, neonicotinoids applied to crops by any application method (e.g. seed dressing, foliar spray, soil drench) will be taken up by crop tissues and can subsequently be found in all parts of the treated plant (Simon-Delso et al. 2015). The EFSA (2013a, b, c) reports identify and discuss a number of exposure pathways through which bees can be exposed to neonicotinoids, where the risk of exposure is dependent on application rate, application type and crop type. However, knowledge about the extent and significance of these pathways was poor. Since then, a large number of studies have been published further documenting neonicotinoid exposure from treated crops. Important reviews include Nuyttens et al. (2013), Godfray et al. (2014), Long and Krupke (2015) and Bonmatin et al. (2015).

\section{Risk of exposure from pollen and nectar of treated flowering crops}

Using data from 30 (clothianidin), 16 (thiamethoxam) and 29 (imidacloprid) outdoor studies and known highest and lowest maximum application rates for seed dressings authorised in the EU, EFSA (2013a, b, c) calculated expected residue rates in pollen and nectar of the studied crops (Table 1). Levels are variable, but all are within one order of magnitude. Levels in pollen are consistently higher than levels in nectar. Godfray 
Fig. 2 Number of studies published in scientific journals on neonicotinoids in each year. Open circles, "neonicotinoid*"; filled diamonds, "neonictotinoid* + bee*"; filled circle,

"neonicotinoid* + residue"; open triangle, "neonicotinoid* + water"; filled triangle, "neonicotinoid* + soil". Data from Web of Science

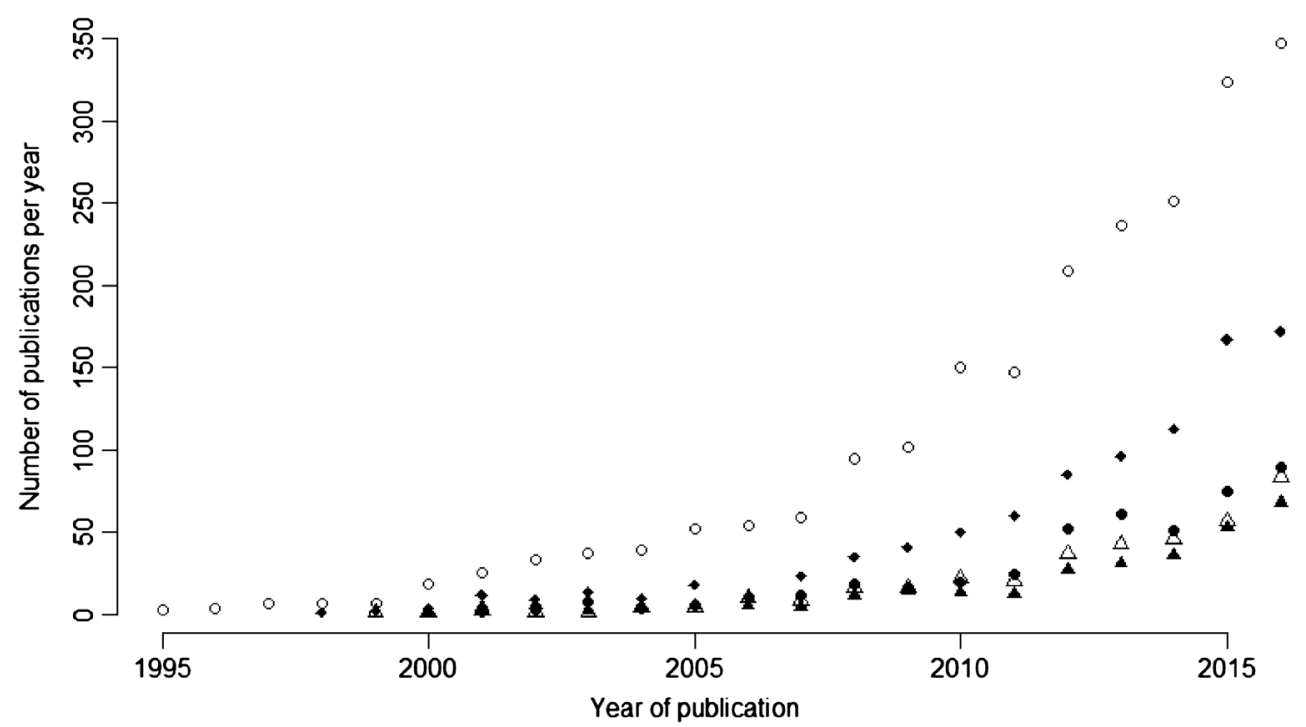

et al. (2014) reviewed 20 published studies to calculate an arithmetic mean maximum level of $1.9 \mathrm{ppb}$ for nectar and $6.1 \mathrm{ppb}$ for pollen in treated crops, in line with the EFSA findings.

Since 2014, a number of studies have been published which report neonicotinoid concentrations in the pollen and nectar of neonicotinoid-treated flowering crops. These results have been approximately in line with the concentrations reported by EFSA and Godfray et al. In oilseed rape treated with thiamethoxam, Botías et al. (2015) found average concentrations of $3.26 \mathrm{ng} / \mathrm{g}$ of thiamethoxam, $2.27 \mathrm{ng} / \mathrm{g}$ of clothianidin and $1.68 \mathrm{ng} / \mathrm{g}$ of thiacloprid in the pollen. Oilseed rape nectar contained similar average concentrations of $3.20 \mathrm{ng} / \mathrm{g}$ of thiamethoxam, $2.18 \mathrm{ng} / \mathrm{g}$ of clothianidin and $0.26 \mathrm{ng} / \mathrm{g}$ of thiacloprid. Xu et al. (2016) found average levels of clothianidin in oilseed rape of $0.6 \mathrm{ng} / \mathrm{g}$. No pollen samples were taken. In maize pollen, Stewart et al. (2014) found average thiamethoxam and clothianidin levels between the limit of detection (LOD) of 1 to $5.9 \mathrm{ng} / \mathrm{g}$ across a range of seed treatments. $\mathrm{Xu}$ et al. (2016) found average clothianidin concentration of $1.8 \mathrm{ng} / \mathrm{g}$ in maize pollen. Additionally, Stewart et al. (2014) found no neonicotinoid residues in soybean flowers or cotton nectar.

Several studies published since 2013 have used free flying bees to experimentally demonstrate that proximity to treated flowering crops increases their exposure to neonicotinoids (Table 2). Using honeybees, neonicotinoid concentrations in pollen taken from foragers returning to nests placed next to untreated flowering crops ranged from 0 to $0.24 \mathrm{ng} / \mathrm{g}$ compared to pollen from nests next to treated flowering crops which ranged from 0.84 to $13.9 \mathrm{ng} / \mathrm{g}$. There have been fewer studies of bumblebees, and hence, the sample size is much smaller, with concentrations of neonicotinoids in pollen from untreated areas ranging from $<0.1$ to $<0.3 \mathrm{ng} / \mathrm{g}$ compared to $0.4-0.88 \mathrm{ng} / \mathrm{g}$ for
Table 1 Summary of expected residues in pollen and nectar of various neonicotinoid-treated flowering crops calculated by EFSA from the review of outdoor field trials

\begin{tabular}{|c|c|c|c|c|c|c|}
\hline \multirow[t]{2}{*}{ Crop } & \multirow[t]{2}{*}{ Pesticide } & \multirow{2}{*}{$\begin{array}{l}\text { Application rates } \\
\text { (g a.s./ha) }\end{array}$} & \multicolumn{2}{|c|}{ Residues in pollen (ng/g) } & \multicolumn{2}{|c|}{ Residues in nectar (ng/g) } \\
\hline & & & Minimum & Maximum & Minimum & Maximum \\
\hline Oilseed rape & Clothianidin & $25-80$ & 5.95 & 19.04 & 5 & 16 \\
\hline Sunflower & Clothianidin & 27 & & 3.29 & & 0.324 \\
\hline Maize & Clothianidin & $25-125$ & 7.38 & 36.88 & $n / a$ & $n / a$ \\
\hline Oilseed rape & Imidacloprid & $10-52.5$ & 1.56 & 8.19 & 1.59 & 8.35 \\
\hline Sunflower & Imidacloprid & $24-35$ & & 3.9 & & 1.9 \\
\hline Maize & Imidacloprid & $54-268$ & 3.02 & 15.01 & $n / a$ & $n / a$ \\
\hline Cotton & Imidacloprid & $75-100$ & 3.45 & 4.6 & 3.45 & 4.6 \\
\hline Oilseed rape & Thiamethoxam & $8-33.6$ & 4.592 & 19.29 & 0.648 & 2.72 \\
\hline Sunflower & Thiamethoxam & $16.4-20.8$ & 2.378 & 3.02 & 0.59 & 0.75 \\
\hline Maize & Thiamethoxam & $63-101$ & 13.419 & 21.513 & $n / a$ & $n / a$ \\
\hline
\end{tabular}

No nectar values are available for maize as this plant does not produce nectar. Blanks are where no minimum values were stated 


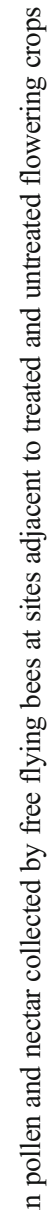

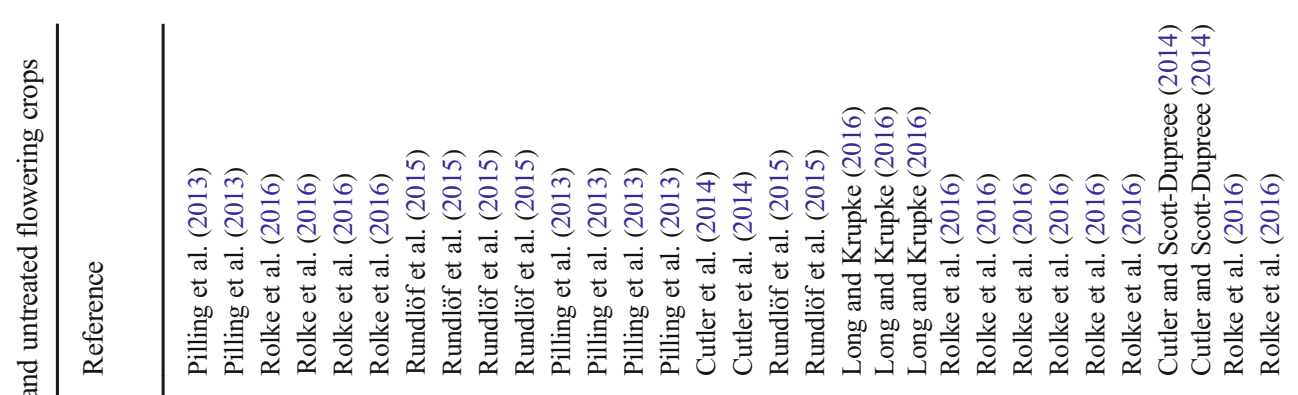

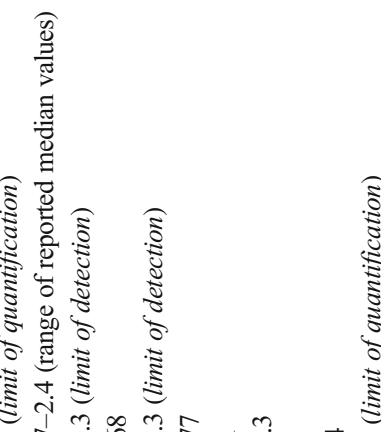<smiles>C[C@@H]1C[C@H]2C[C@H]1C2</smiles>

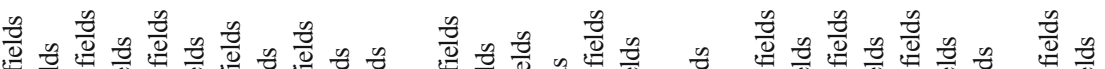

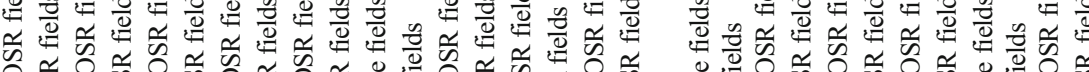

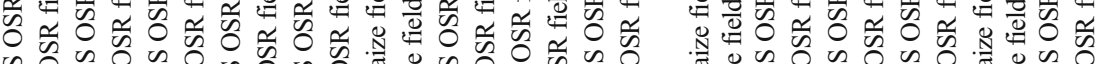

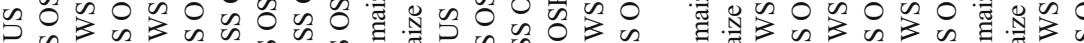

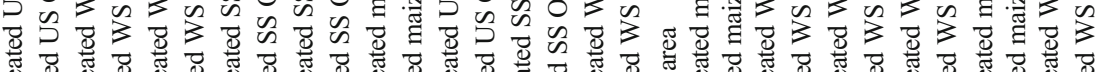

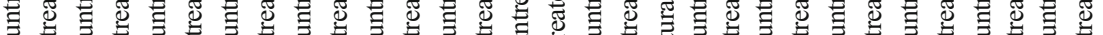

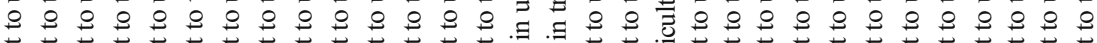

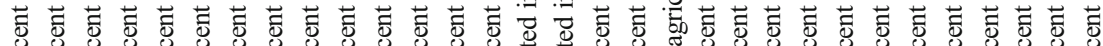

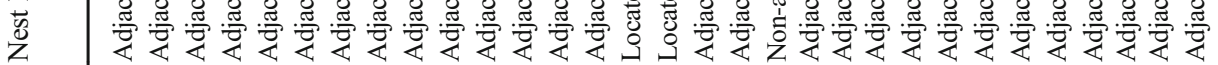

-

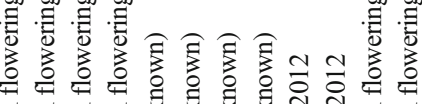

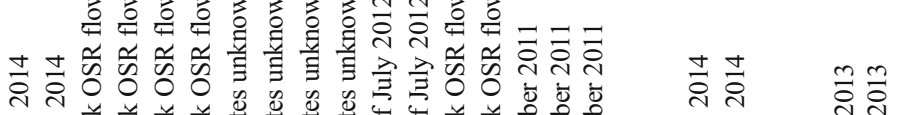

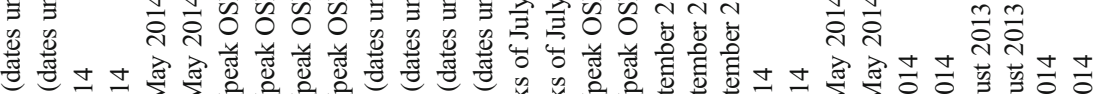

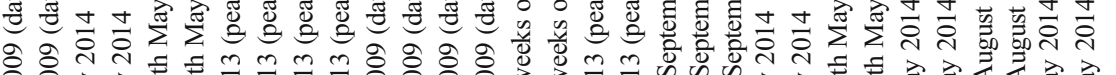

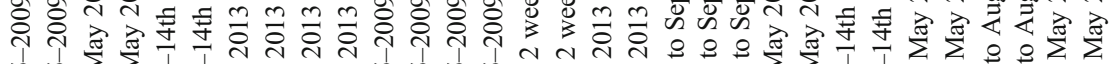

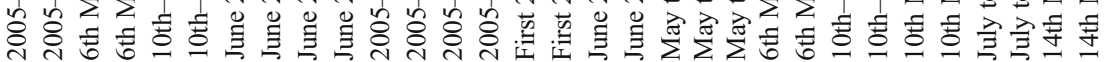

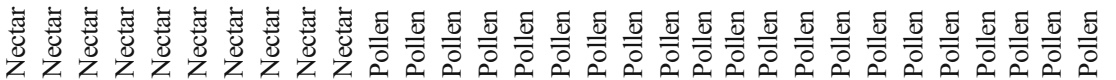


nests placed next to treated areas. The only available study looking at solitary bee-collected pollen found Osmia bicornis collecting $<0.3 \mathrm{ng} / \mathrm{g}$ in untreated areas and $0.88 \mathrm{ng} / \mathrm{g}$ in treated areas. Similar trends are found in the nectar results, though fewer studies are available. Rolke et al. (2016) found neonicotinoid concentrations of $0.68-0.77 \mathrm{ng} / \mathrm{mL}$ in honeybee collected nectar samples from apiaries adjacent to neonicotinoid-treated oilseed rape, compared to $<0.3 \mathrm{ng} / \mathrm{mL}$ from apiaries adjacent to untreated oilseed rape. However, Rundlöf et al. (2015) found concentrations of $5.4 \mathrm{ng} / \mathrm{mL}$ in bumblebee collected nectar and $10.3 \mathrm{ng} / \mathrm{mL}$ in honeybee collected nectar taken from bees originating from nests placed adjacent to treated oilseed rape compared to $0-0.1 \mathrm{ng} / \mathrm{mL}$ from bees from nests adjacent to untreated oilseed rape.

This level of variation of up to one order of magnitude in neonicotinoid concentrations found in bee-collected pollen and nectar in different studies is substantial. The detected levels in pollen and nectar presumably depend significantly on the dose and mode of treatment, the studied crop, the season, the location, the soil type, the weather, time of day samples are collected, and so on. Even different crop varieties can result in significant variation in the residue content of pollen and nectar (Bonmatin et al. 2015). Because pollen samples taken from a series of bees will be from a mixture of different plants, most of which will not be crop plants, the neonicotinoid residues in crop pollen will be diluted by untreated, non-crop pollen. However, for the reported studies, the higher neonicotinoid concentrations are within an order of magnitude of the $6.1 \mathrm{ng} / \mathrm{g}$ in pollen and $1.9 \mathrm{ng} / \mathrm{mL}$ in nectar values calculated by Godfray et al. (2014). Additionally, in all cases, the concentrations of neonicotinoids in pollen and nectar were higher at sites adjacent to neonicotinoid-treated flowering crops than at sites adjacent to untreated crops. The available evidence shows that proximity to treated flowering crops increases the exposure of bees to neonicotinoid pesticides. The recent evidence for concentrations found in flowering crops is approximately in line with the levels reported by EFSA (2013a, b, c).

\section{Risk from non-flowering crops and cropping stages prior to flowering}

The EFSA studies state that some of the crops on which clothianidin is authorised as a seed-dressing do not flower, are harvested before flowering or do not produce nectar or pollen, and therefore, these crops will not pose any risk to bees via this route of exposure. Whilst non-flowering crops are clearly not a source of exposure through produced pollen and nectar, they do represent a source of neonicotinoids that can dissipate into the wider environment (discussed in the "Risk of exposure for non-target organisms from neonicotinoids persisting in the wider environment" section).
Additionally, treated crops of any type represent additional pathways of neonicotinoid exposure to other organisms.

Depending on crop species and consequent seed size, neonicotinoid-treated seeds contain between 0.2 and $1.25 \mathrm{mg}$ of active ingredient per seed (Goulson 2013). For a granivorous grey partridge weighing $390 \mathrm{~g}$, based on typical treatment rates, Goulson calculated that it would need to consume around five maize seeds, six sugar beet seeds or 32 oilseed rape seeds to receive a nominal $\mathrm{LD}_{50}$. Based on US Environmental Protection Agency (EPA) estimates that around $1 \%$ of sown seed is accessible to foraging vertebrates at recommended sowing densities, Goulson calculated that sufficient accessible treated seed would be present to deliver a $\mathrm{LD}_{50}$ to $\sim 100$ partridges per hectare sown with maize or oilseed rape. Given that grey partridges typically consume around $25 \mathrm{~g}$ of seed a day, there is the clear potential for ingestion of neonicotinoids by granivorous animals, specifically birds and mammals. However, whilst some experimental studies have been conducted to investigate mortality and sublethal effects of treated seeds on birds (see the "Sensitivity of birds and bats to neonicotinoids" section), no studies are available that demonstrate consumption of treated seed by farmland birds under field conditions or quantify relative consumption of treated versus untreated seed to better understand total exposure via this route.

In addition to insect herbivores, developing seedlings treated with neonicotinoids are predated by molluscan herbivores which can be serious pests of arable crops. Because neonicotinoids have relatively low efficacy against molluscs, Douglas et al. (2015) investigated neonicotinoid residues in the slug Deroceras reticulatum, a major agricultural pest, using neonicotinoid seed-treated soybean in both laboratory and field studies. Total neonicotinoid concentrations from samples of field collected slugs feeding on treated soybean were as high as $500 \mathrm{ng} / \mathrm{g}$ with average levels over $100 \mathrm{ng} / \mathrm{g}$ after 12 days of feeding. No neonicotinoids were detected in slugs feeding on untreated control plants. After 169 days, no neonicotinoids were detected in either control or treated slugs. In the laboratory, slugs consuming soybean seedlings incurred low mortality of between 6 and 15\% depending on the strength of the seed treatment. In laboratory experiments, slugs were exposed to the ground beetle Chlaenius tricolour after feeding on soybean. C. tricolour is a typical predatory beetle found in agro-ecosystems and is known to be an important predator of slugs. For beetles that consumed slugs, $61.5 \%$ ( $n=16 / 26$ ) of those from the neonicotinoid treatment subsequently showed signs of impairment compared to none of those in the control treatment $(n=0 / 28)$. Of the 16 that showed impairment, seven subsequently died. A similar result was found by Szczepaniec et al. (2011) who found that the application of imidacloprid to elm trees caused an outbreak of spider mites Tetranychus schoenei. This increase was as a result of a reduction in the density of their predators which 
incurred increased mortality after ingesting imidaclopridcontaining prey items. Many beneficial predatory invertebrates feed on pests of crops known to be treated with neonicotinoids, but to date no other studies have assessed whether neonicotinoids are transmitted to these predators through direct consumption of crop pests in agro-ecosystems.

Additionally, flowering crops in a non-flowering stage can also pose a potential threat to natural enemy populations. The soybean aphid parasitoid wasp Aphelinus certus is an important parasite of the soybean aphid Aphis glycines. Frewin et al. (2014) gave A. certus access to laboratory populations of aphids feeding on control and neonicotinoid-treated soybean plants. A. certus parasitised a significantly smaller proportion of aphids on treated plants than on untreated plants. Frewin et al. hypothesise two potential reasons for this effect-firstly that exposure to neonicotinoid residues within aphid hosts may have increased mortality of the immature parasitoid or the parasitism combined with residues may have increased aphid mortality. Secondly, A. certus may avoid parasitising pesticide-poisoned aphids. Aphelinus species are known to use internal cues to determine host suitability, and it is possible that they may use stress- or immune-related aphid hormones to judge host suitability. Given that a key part of biological control of insect pests using parasitic wasps is to increase the parasitoid abundance early in the season, the reduction in the parasitism rate caused by neonicotinoid seed treatment could potentially impair the ability of $A$. certus to control soybean aphid. It is not known if $A$. certus emerging from contaminated hosts will incur lethal or sublethal effects which may further impair this ability.

Non-flowering neonicotinoid crops present possible exposure routes through direct consumption of treated seed or consumption of seedling plants that may result in the transmission of neonicotinoids to higher trophic levels, including beneficial insects that offer a level of pest control through predatory behaviour. As the EFSA reports did not consider the impact of neonicotinoids on non-bees, no comparison can be made here.

\section{Risk of exposure from the drilling of treated seed and subsequent dust drift}

Numerous studies (12 listed by Godfray et al. 2014) prior to 2013 identified that neonicotinoids present in seed dressings can be mechanically abraded during the drilling process and can subsequently be emitted as dust. This dust can contain very high levels of neonicotinoids, up to $240,000 \mathrm{ng} / \mathrm{g}$ under certain conditions (see the review by Nuyttens et al. 2013). Acute contact with this dust can in certain cases result in the mass poisoning of honeybees (e.g. Pistorius et al. 2009; Bortolotti et al. 2009). Concentrations of neonicotinoids in dust created during sowing and the total volume released into the air depend on application rate, seed type, seed treatment quality (including additions of seed lubricants such as talcum powder), seed drilling technology and environmental conditions. Girolami et al. (2013) demonstrated that the dust cloud created by seed drills is an ellipsoidal shape approximately $20 \mathrm{~m}$ in diameter. Using cage experiments, a single pass of a drilling machine was sufficient to kill all honeybees present. The use of tubes designed to direct exhaust air towards the ground did not substantially increase bee survival rate. Neonicotinoid concentrations of up to $4000 \mathrm{ng} / \mathrm{g}$ were detected in honeybees with an average concentration of $300 \mathrm{ng} / \mathrm{g}$. Similar concentrations were detected in bees exposed to both unmodified and modified drills.

On the basis of the available evidence, the EFSA reports (2013a, b, c) concluded that maize produces the highest dust drift deposition, whilst for sugar beet, oilseed rape and barley seeds the dust drift deposition was very limited. No information was available for other crops, and given that seed type is an important factor determining neonicotinoid release, extrapolation to other crops is highly uncertain. A high acute risk was not excluded for bees foraging or flying in adjacent crops during the sowing of maize, oilseed rape and cereals. In practice, this assessment indicates that forager honeybees or other pollinators flying adjacent to the crop are at high risk (e.g. via direct contact to dust) and may be able to carry considerable residues back to the hive (for social bees). Bees present further away or foraging upwind during the sowing will be considerably less exposed. The reports conclude that the aforementioned assessments do not assess potential risk to honeybees from sublethal effects of dust exposure. No information on neonicotinoid residues in nectar in the adjacent vegetation following dust drift was available.

In recent years, various types of improved seed drills have been adopted that direct air from the drills towards the soil, reducing the dust drift effect by up to $95 \%$ (see Manzone et al. 2015). Air deflectors have become mandatory for certain products in the Netherlands, France, Belgium and Germany (Godfray et al. 2014). Bonmatin et al. (2015) and Long and Krupke (2015) reviewed existing literature on the exposure of pollinators and other non-target organisms to contaminated dust from seed drilling machines. The authors conclude that despite attention by regulators they consider dust drift to be a likely cause of environmental neonicotinoid contamination, in particular when best practice is not followed.

Recent studies continue to detect neonicotinoids in the tissues of wildflowers surrounding agricultural fields immediately after planting. Stewart et al. (2014) detected average neonicotinoid concentrations of $9.6 \mathrm{ng} / \mathrm{g}$ in whole wildflowers collected from field margins adjacent to fields planted with maize $(n=18)$, cotton $(n=18)$ and soybean $(n=13)$. The samples were collected a few days after sowing (typically within 3 days), with the highest concentration of $257 \mathrm{ng} / \mathrm{g}$ collected adjacent to a maize field sown the previous day with thiamethoxam-treated seed. Detailed data on concentrations 
adjacent to each crop type are not available. No samples were taken from vegetation adjacent to crops sown without a neonicotinoid seed dressing. Rundlöf et al. (2015) collected flowers and leaves from wild plants growing adjacent to treated and untreated oilseed rape fields 2 days after sowing. Adjacent to the treated fields, neonicotinoid concentrations were lower than in the previous study at $1.2 \mathrm{ng} / \mathrm{g}$, but this was higher than the control fields where no neonicotinoids were detected.

\section{Risk of exposure from guttation fluid}

Some plants secrete small volumes of liquid (xylem sap) at the tips of leaves or other marginal areas, often referred to as guttation droplets. Six published studies and an EFSA review found extremely high neonicotinoid concentrations in guttation droplets of up to four to five orders of magnitude greater than those found in nectar, particularly when plants are young (see Godfray et al. 2014). Using a clothianidin concentration of $717,000 \mathrm{ng} / \mathrm{g}$ and an acute oral toxicity of $3.8 \mathrm{ng} / \mathrm{bee}$ for clothianidin (see the "Direct lethality of neonicotinoids to adult wild bees" section), EFSA (2013a) calculated that a honeybee would only need to consume $0.005 \mu$ to receive an $\mathrm{LD}_{50}$. Given that honeybee workers can carry between 1.4 and $2.7 \mathrm{~mL}$ of water a day, there is the clear potential for lethal exposure via this route. The risk assessments for thiamethoxam and imidacloprid were similar (EFSA 2013b, c). However, on the basis of experimental trials, the EFSA reports conclude that whilst guttation droplets were frequently produced, honeybees were rarely seen collecting water from them and therefore the risk should be considered low.

Few studies have looked at neonicotinoid exposure via guttation droplets since 2013. In the one available study, Reetz et al. (2015) assessed thiamethoxam concentrations in oilseed rape guttation droplets and measured residues in individual honeybee honey sacs. The authors note that targeted observations of water-foraging honeybees in the field are nearly impossible, and so returning honeybees from apiaries placed out adjacent to treated oilseed rape crops were instead collected in the autumns of 2010 and 2011 when seedling oilseed rape crops were producing guttation droplets. Oilseed rape produced guttation droplets containing between 70 and $130 \mathrm{ng} / \mathrm{mL}$ clothianidin at the cotyledon stage. Out of 436 honey sacs, neonicotinoids were only detected in 62 samples at concentrations between 0.1 and $0.95 \mathrm{ng} / \mathrm{mL}$. However, because there was no behavioural observation, it is not possible to state the origin of this contamination with certainty; neonicotinoids are also present in waterbodies and the nectar of wild flowers (see the "Risk of exposure for non-target organisms from neonicotinoids persisting in the wider environment" section). As such, there is still little evidence documenting the extent to which honeybees or other insects collect or are otherwise exposed to neonicotinoids through contact with guttation droplets.

\section{Risk of exposure for non-target organisms from neonicotinoids persisting in the wider environment}

In identifying routes of exposure for honeybees, the EFSA reports discussed the possibility of neonicotinoid residues in flowering arable weeds growing in fields with treated crops. This route of exposure was considered to be negligible as weeds would not be present in the field when the crop is sown and considerable uptake via weed plant roots was considered to be unlikely as the substance is concentrated around the treated seed. However, the reports note that potential uptake into flowering weeds cannot be ruled out for granular neonicotinoid applications, highlighting a data gap for this issue.

The persistence of neonicotinoids in soil, water and wild plants is of potentially serious concern. If these pesticides are able to move into habitats surrounding agricultural fields, the range of organisms that they could affect is much greater than simply crop-visiting invertebrates. If these pesticides last for extended periods in the wider environment, then neonicotinoid exposure may be chronic, rather than an acute exposure associated with the sowing of treated seeds.

Since April 2013, much empirical data has been produced documenting the fate of residual neonicotinoids in the wider environment after application. Key review publications are Bonmatin et al. (2015) and Morrissey et al. (2015).

\section{Persistence of neonicotinoids in soil}

Although neonicotinoids applied through a seed dressing are designed to be taken up into the target crop plant, only 1.6$20 \%$ of the active ingredient is absorbed, with the majority remaining in the soil (Sur and Stork 2003; Goulson 2014; Bonmatin et al. 2015). A small proportion is dispersed through dust created whilst drilling (see the "Risk from nonflowering crops and cropping stages prior to flowering" section). Neonicotinoids can bind to soil with the strength of the binding dependent on various factors. Neonicotinoids are water soluble (see the "Persistence of neonicotinoids in water and transport mechanisms for contamination of aquatic systems" section) and may leach from soils if water is present. Leaching is lower and sorption is higher in soils with a high content of organic material (Selim et al. 2010). In a recent comparison of soil types, Mörtl et al. (2016), Fig. 3) found that clothianidin and thiamethoxam leached readily from sandy soils. Clay soils showed higher retention of neonicotinoids, but the greatest retention was seen for loam soils. Correspondingly, the highest residual neonicotinoid concentrations were found in loam soils.

Whilst several studies have assessed dissipation half-life times $\left(\mathrm{DT}_{50}\right)$ of neonicotinoids in soil, much of this work was 


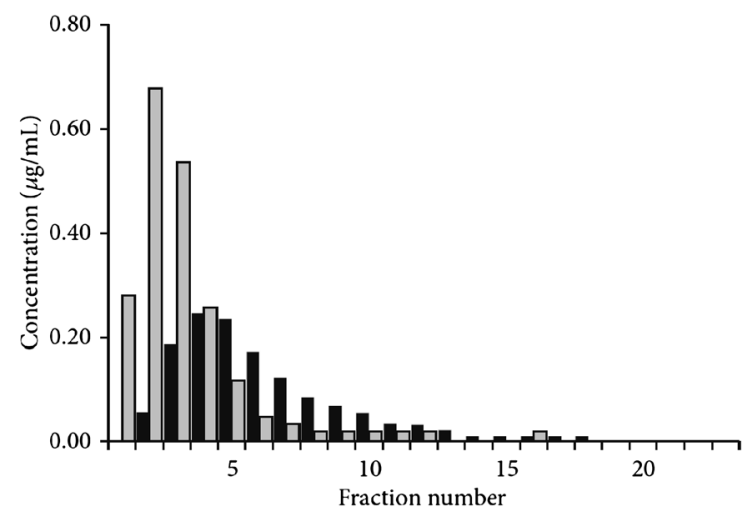

(a)

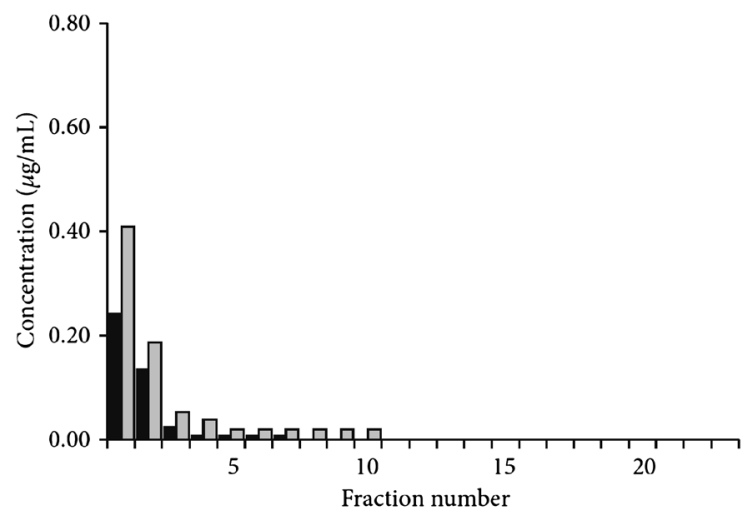

(c)

Fig. 3 Elution profiles of clothianidin and thiamethoxam upon absorption on soils. Concentrations of clothianidin (black columns) and thiamethoxam (grey columns) measured in aqueous eluates from soil columns of a sand, b clay and $\mathbf{c}$ loam soils. Eluates from $\mathbf{d}$ pumice

conducted before the recent interest in the potentially deleterious effect of neonicotinoids on wider biodiversity. A review of available $\mathrm{DT}_{50}$ times from field and laboratory studies conducted between 1999 and 2013 was reviewed by Goulson (2013). Reported $\mathrm{DT}_{50} \mathrm{~S}$ are highly variable and typically range from 200 to in excess of 1000 days for imidacloprid, 7-353 days for thiamethoxam and 148-6931 days for clothianidin. DT $_{50} \mathrm{~s}$ appear to be shorter for the nitro-substituted neonicotinoids, at 374 days for thiacloprid and $31-450$ days for acetamiprid. $\mathrm{DT}_{50}$ values of over 1 year would suggest the likelihood of neonicotinoid accumulation in the soil, assuming continuous input. However, these reported values are highly variable. At the time the EFSA reports were written, only one field study was available that assessed neonicotinoid accumulation in the soil over multiple years with continued neonicotinoid input. Bonmatin et al. 2005 screened 74 samples of farmland soil from France for imidacloprid. Imidacloprid concentrations were higher in soils which had been treated in two consecutive years than those soils which had only received one treatment, suggesting the possibility of imidacloprid accumulation in the soil. However, as the study only looked at soils treated for a maximum of 2 years, it is not clear whether residues would continue to increase. Two studies had been completed by 2013 but were

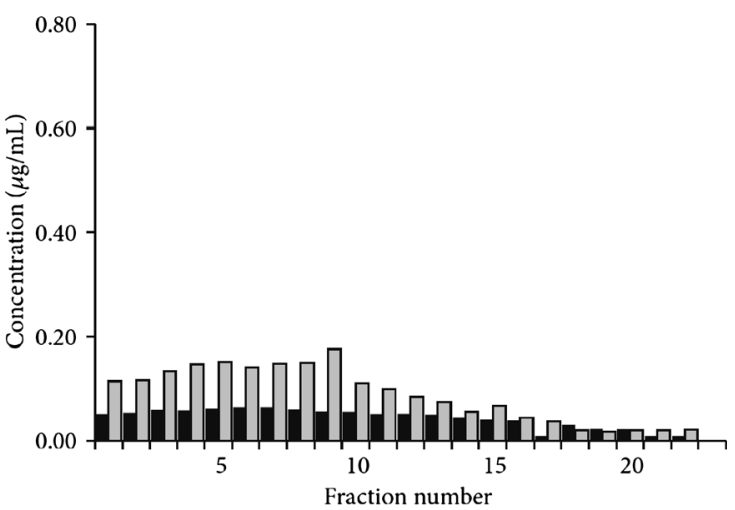

(b)

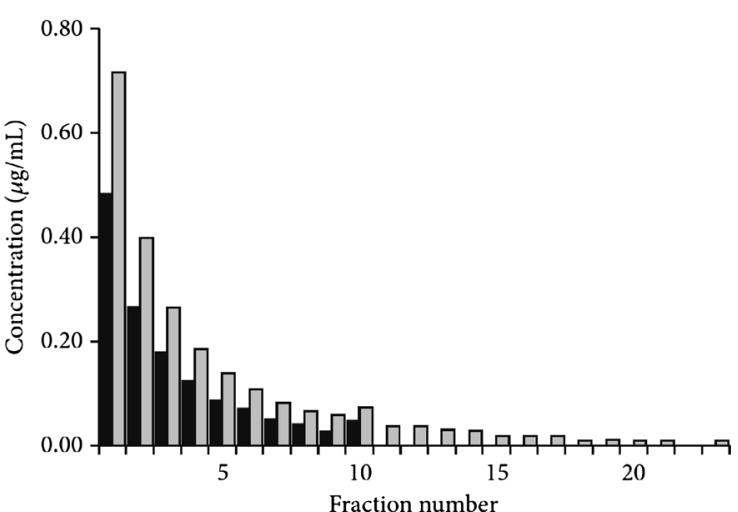

(d)

columns are shown as a control. Concentrations in 10-mL fractions of the eluate are shown in micrograms per millilitre, as a function of the fraction number. Reproduced from Mörtl et al. (2016)

not widely disseminated. These studies were carried out by Bayer and assessed levels of imidacloprid in soil over 6 years for seed-treated barley in the UK (Placke 1998a) and spray application to orchard soils in Germany (Placke 1998b). Goulson (2013) reviewed this data and argued that the studies show accumulation of neonicotinoids in soils over time, with some indication that concentrations may begin to plateau after about 5 years. However, since the trials were terminated after 6 years, it is not clear whether levels would have continued to increase.

Since 2013, a number of studies have been published which have measured neonicotinoid levels in agricultural soils, have calculated $\mathrm{DT}_{50} \mathrm{~S}$ of neonicotinoids in real-world soils and have measured accumulation in the soil using extensive field trials and field sampling. Data on field-realistic neonicotinoid samples are summarised in Table 3. Jones et al. (2014) measured neonicotinoid concentrations in centre and edge soil samples from 18 fields across 6 English counties. Samples were collected in the spring of 2013, prior to crop planting. Imidacloprid (range $<0.09-10.7 \mathrm{ng} / \mathrm{g}$ ), clothianidin (range $<0.02-13.6 \mathrm{ng} / \mathrm{g}$ ) and thiamethoxam (range $<0.02-1.5 \mathrm{ng} / \mathrm{g}$ ) were detected. Residues from the centre of the fields were higher than for the edge of the fields (average imidacloprid 1.62 against $0.76 \mathrm{ng} / \mathrm{g}$, average clothianidin 4.89 against $0.84 \mathrm{ng} / \mathrm{g}$ and average thiamethoxam 


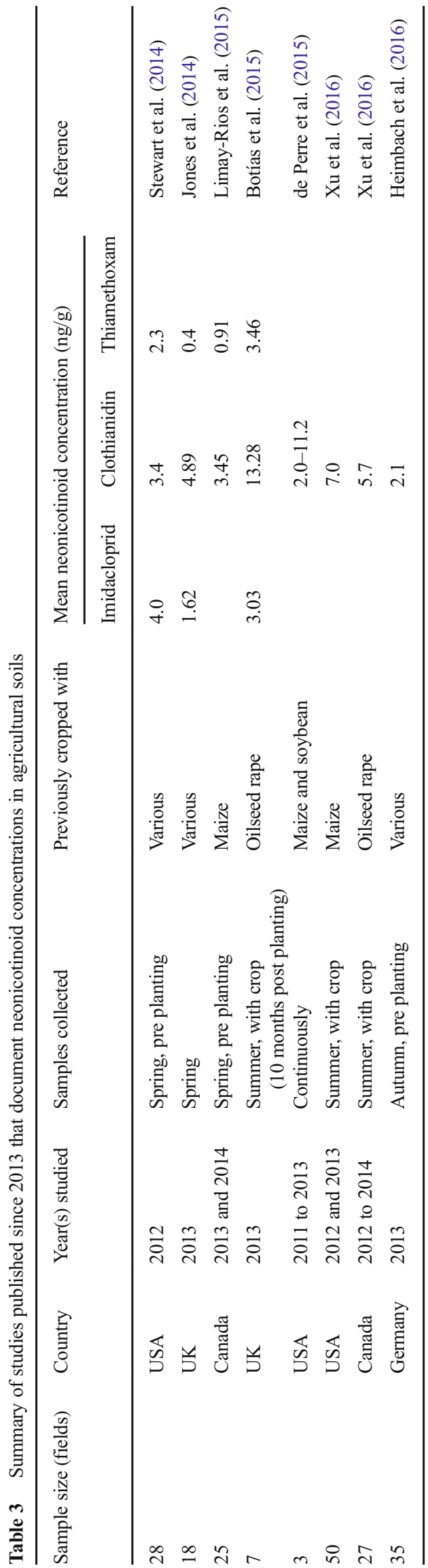

0.40 against $0.05 \mathrm{ng} / \mathrm{g}$ ). Neonicotinoids not previously applied in the previous 3 years (predominantly imidacloprid) were detected in 14 of the 18 fields. Limay-Rios et al. (2015) analysed soil samples collected in the springs of 2013 and 2014 from 25 agricultural fields in Ontario, Canada, before crops were sown and found average concentrations of $3.45 \mathrm{ng} / \mathrm{g}$ of clothianidin and $0.91 \mathrm{ng} / \mathrm{g}$ thiamethoxam, with a total average neonicotinoid concentration of $4.36 \mathrm{ng} / \mathrm{g}$, similar to the findings of Jones et al. (2014).

Botías et al. (2015) analysed soil samples from seven winter-sown oilseed rape and five winter-sown wheat fields collected in summer 2013, 10 months after the crops were sown. Samples were collected from field centres (oilseed rape only) and field margins (oilseed rape and winter wheat). Imidacloprid (range $\leq 0.07-7.90 \mathrm{ng} / \mathrm{g}$ ), clothianidin (range $0.41-28.6 \mathrm{ng} / \mathrm{g}$ ), thiamethoxam (range $\leq 0.04-9.75 \mathrm{ng} / \mathrm{g}$ ) and thiacloprid (range $\leq 0.01-0.22 \mathrm{ng} / \mathrm{g}$ ) were detected. Residues from the centre of the oilseed rape fields were higher than for the edge of the oilseed rape fields (average imidacloprid 3.03 against $1.92 \mathrm{ng} / \mathrm{g}$, average clothianidin 13.28 against $6.57 \mathrm{ng} /$ $\mathrm{g}$, average thiamethoxam 3.46 against $0.72 \mathrm{ng} / \mathrm{g}$ and average thiacloprid 0.04 against $\leq 0.01 \mathrm{ng} / \mathrm{g}$ ). Whilst these values are higher than those measured by Jones et al. (2014) and LimayRios et al. (2015), they are within an order of magnitude at their greatest difference.

Hilton et al. (2015) presented previously private data from 18 industry trials conducted between 1995 and 1998 for thiamethoxam applied to bare soils, grass and a range of crops (potatoes, peas, spring barley, winter barley, soybean, winter wheat and maize). Thiamethoxam $\mathrm{DT}_{50} \mathrm{~s}$ ranged between 7.1 and 92.3 days, with a geometric mean of 31.2 days (arithmetic mean 37.2 days). Across different application methods and environmental conditions, thiamethoxam declined to $<10 \%$ of its initial concentration within 1 year. de Perre et al. (2015) measured soil clothianidin concentrations over 2011 to 2013, with clothianidin-treated maize sown in the springs of 2011 and 2013. Maize seeds were sown with seed dressings of 0.25 and $0.50 \mathrm{mg} /$ seed (Fig. 4). At the lower-concentration seed dressing, clothianidin residues in the soil ranged from approximately $2 \mathrm{ng} / \mathrm{g}$ before planting to $6 \mathrm{ng} / \mathrm{g}$ shortly after planting. At the higher seed dressing, clothianidin average residues ranged from $2 \mathrm{ng} / \mathrm{g}$ before planting to $11.2 \mathrm{ng} / \mathrm{g}$ shortly after planting. For the seed treatment of $0.5 \mathrm{mg} / \mathrm{seed}$, de Perre et al. (2015) calculated a $\mathrm{DT}_{50}$ for clothianidin of 164 days. For the lower treatment of $0.25 \mathrm{mg} / \mathrm{seed}$, a DT $\mathrm{DT}_{50}$ of 955 days was calculated, though this model explained a much lower proportion of the data than the model for the $0.5 \mathrm{mg} / \mathrm{seed}$ data.

Schaafsma et al. (2016) calculated clothianidin $\mathrm{DT}_{50} \mathrm{~s}$ in maize fields in Ontario, Canada, in 2013 and 2014, including data published in Schaafsma et al. (2015). Soil samples were collected from 18 fields in the spring before crop planting. Average neonicotinoid concentrations (clothianidin and thiamethoxam aggregated) were $4.0 \mathrm{ng} / \mathrm{g}$ in 2013 and 


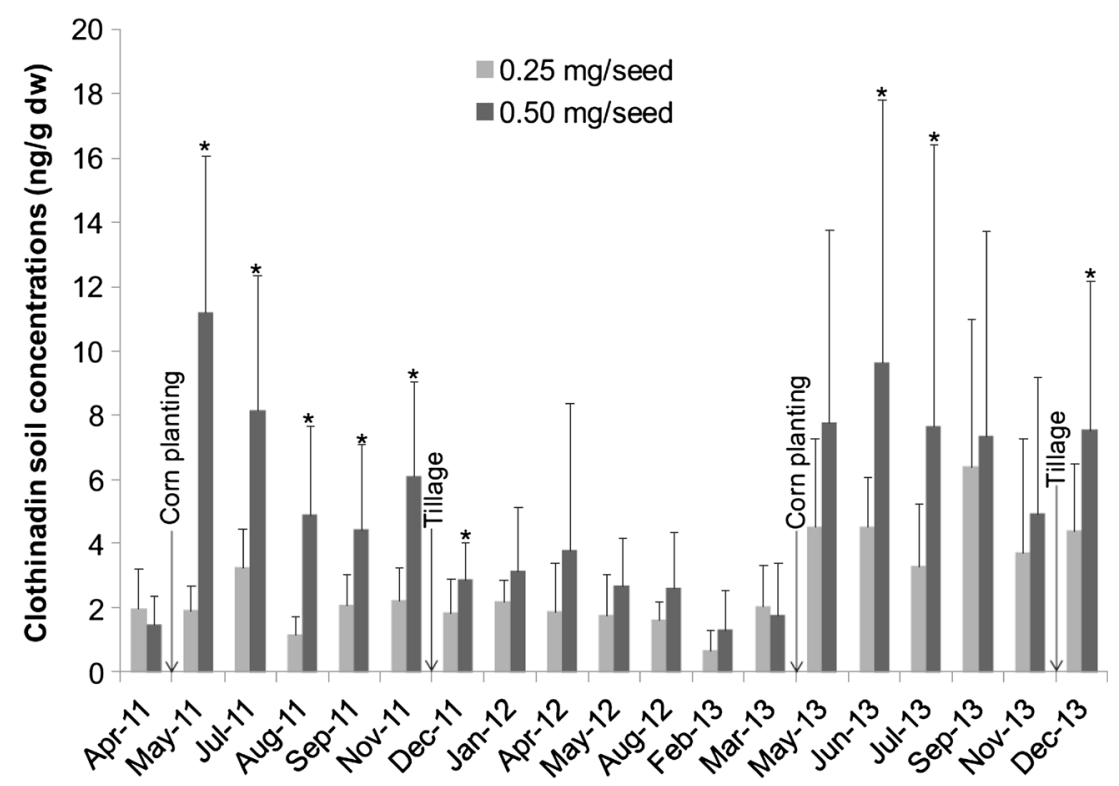

Fig. 4 Mean clothianidin soil concentrations from 2011 to 2013 for each maize seed-coating rate $(0.25 \mathrm{vs} 0.50 \mathrm{mg}$ of clothianidin/seed). Maize planting is presented because it represents the introduction of clothianidin in the field, and tillage events are also presented. Asterisks represent significantly different concentrations between seed-coating treatments

$5.6 \mathrm{ng} / \mathrm{g}$ in 2014. Using the observed residues and the recharge rate applied at planting via treated maize seeds, fields studied in 2013 had an estimated $\mathrm{DT}_{50}$ of 0.64 years (234 days) and fields studied in 2014 had an estimated $\mathrm{DT}_{50}$ of 0.57 years (208 days). For fields studied in both years, $\mathrm{DT}_{50}$ was calculated at 0.41 years ( 150 days). Schaafsma et al. conclude that, at current rates of neonicotinoid application in Canadian maize cultivation, soil residues of neonicotinoids will plateau at under $6 \mathrm{ng} / \mathrm{g}$.

Using the same method, Schaafsma et al. also calculated imidacloprid $\mathrm{DT}_{50}$ using the data from Placke (1998a, b); Table 4), producing a very similar $\mathrm{DT}_{50}$ of 0.57 years (208 days). Schaafsma et al. argue that the Placke studies show neonicotinoid concentrations plateauing after repeated use of neonicotinoid seed treatments. However, observed levels were high, so even if plateauing occurred after 6 years the average concentration of neonicotinoids in the soil would be around $30 \mathrm{ng} / \mathrm{g}$ (Table 4).

$\mathrm{Xu}$ et al. (2016) analysed soil samples from 50 maizeproducing sites in the Midwestern USA across 2012 and 2013 and soil samples from 27 oilseed rape-producing sites in western Canada across 2012, 2013 and 2014. Samples were collected after planting, but it is not clear exactly how long after. Average clothianidin soil concentration at Midwestern maizeproducing sites with a range of 2-11 years of planting clothianidin-treated seeds was $7.0 \mathrm{ng} / \mathrm{g}$ with a 90th percentile concentration of $13.5 \mathrm{ng} / \mathrm{g}$. Xu et al. argue that this average is similar to the theoretical soil concentrations $(6.3 \mathrm{ng} / \mathrm{g})$ expected from a single application of $0.25 \mathrm{mg}$ clothianidin-treated maize seed. Clothianidin levels in soil appear to plateau after 4 years, but the sample size for sites with a history of more than 4 years is for one sampling event ( $t$ test, $p \leq 0.05, n=13$ and $n=17$ for 0.25 and $0.50 \mathrm{mg} / \mathrm{seed}$, respectively, from April 2011 to March 2013; $n=15$ for both seed treatment rates since May 2013). Reproduced from de Perre et al. (2015). Note - untreated soybeans were sown in 2012

much smaller than the number of sites with a history of under 4 years of use. At the oilseed rape-producing sites, average clothianidin concentrations were $5.7 \mathrm{ng} / \mathrm{g}$ with the 90 th percentile concentration of $10.2 \mathrm{ng} / \mathrm{g}$. This is also similar to the theoretical soil concentration $(6.7 \mathrm{ng} / \mathrm{g})$ from a single application of oilseed rape seed treated at $4 \mathrm{~g}$ clothianidin per kilogram of seed. The oilseed rape sites do not have the same history of clothianidin use, but levels appear to be fairly stable over the 4 years of applications. For reference, $10 \mathrm{~g}$ clothianidin per kilogram of oilseed rape seed is the most common dosage rate in recent field trials (the Elado seed dressing, the "Impact on colony growth and reproductive success" section).

Table 4 Observed concentrations of imidacloprid and estimated dissipation rates (half-life) in orchard soil in Germany and in winter barley fields in the UK

\begin{tabular}{lll}
\hline Field & $\begin{array}{l}\text { Observed imidacloprid } \\
\text { concentration (ng/g) }\end{array}$ & $\begin{array}{l}\text { Half-life } \\
\text { (years) }\end{array}$ \\
\hline Barley_66_1 & 31.4 & 0.74 \\
Barley_133_1 & 49.4 & 0.63 \\
Barley_66_2 & 17.8 & 0.53 \\
Barley_133_2 & 36.3 & 0.54 \\
Orchard_1 & 23.3 & 0.48 \\
Orchard_2 & 34.5 & 0.59 \\
Orchard_3 & 23.1 & 0.47 \\
Mean \pm standard error & 30.8 & $0.57 \pm 0.04$ \\
\hline
\end{tabular}

Data taken from Placke (1998a, b). Half-life calculated iteratively by varying the half-life incrementally until the predicted and measured values are equal. Reproduced from Schaafsma et al. (2016) 
The current body of evidence shows that detectable levels of neonicotinoids are found in agricultural soils over a year after treated seeds were planted, clearly demonstrating a level of neonicotinoid persistence greater than the annual agricultural cycle. Moreover, neonicotinoids known not to have been recently used can still be present in soils several years after the last application date. The available data suggest that, whilst a proportion of the total neonicotinoids applied can and do persist in the soil from year to year, there appears to be sufficient degradation that means they do not continue to accumulate indefinitely but instead plateau after 2-6 years of repeated application. However, these studies also show that overall, the annual sowing of neonicotinoid-treated seed results in chronic levels of neonicotinoid soil contamination in the range of $3.5-13.3 \mathrm{ng} / \mathrm{g}$ for clothianidin and $0.4-4.0 \mathrm{ng} / \mathrm{g}$ for thiamethoxam which will act as a constant source of exposure for soil-dwelling organisms, and for neonicotinoid transport into the wider environment.

\section{Persistence of neonicotinoids in water and transport mechanisms for contamination of aquatic systems}

Neonicotinoids are soluble in water, a property that is necessary for them to function effectively as systemic pesticides which can be taken up by crops. The solubility of neonicotinoids depends on local conditions such as ambient temperature, water $\mathrm{pH}$ and the form that the neonicotinoids are applied in, such as granules, as a seed dressing or as dust drift from seed drilling (Bonmatin et al. 2015). Under standard conditions $\left(20^{\circ} \mathrm{C}, \mathrm{pH} 7\right)$, neonicotinoid solubility varies between $184 \mathrm{mg} / \mathrm{L}$ (moderate) to $590,000 \mathrm{mg} / \mathrm{L}$ (high) for thiacloprid and nitenpyram respectively (PPDB 2012). The values for clothianidin, imidacloprid and thiamethoxam are $340 \mathrm{mg} / \mathrm{L}$ (moderate), $610 \mathrm{mg} / \mathrm{L}$ (high) and $4100 \mathrm{mg} / \mathrm{L}$ (high) respectively. In contrast, Fipronil has a solubility two to three orders of magnitude lower at $3.78 \mathrm{mg} / \mathrm{L}$ under the same conditions.

Because of the high solubility of neonicotinoids in water, concerns were raised that neonicotinoids might be passing into waterbodies in the wider environment and that this may pose a risk for aquatic organisms. Available evidence to 2015 was reviewed by Bonmatin et al. 2015 and Morrissey et al. 2015. In general, under simulated environmental conditions, neonicotinoids readily leach into water (Gupta et al. 2008; Tišler et al. 2009). Neonicotinoids have been identified passing into waterways through several different routes. These include direct leaching into groundwater and subsequent discharge into surface water, decay of treated plant material in waterways and direct contact from dust from the drilling of treated seed, treated seeds or spray drift into waterbodies (Krupke et al. 2012; Nuyttens et al. 2013). The majority of this contamination is thought to occur from run-off after acute rainfall (Hladik et al.
2014; Sánchez-Bayo and Hyne 2014; Main et al. 2016). Run-off will be particularly severe where soil organic content is low and on steep slopes (Goulson 2013).

Whilst rainfall during or shortly after the planting season appears to be the main mechanism for neonicotinoid transport into waterbodies, detectable levels of neonicotinoids can be found in prairie wetlands in Canada during early spring before the planting season (Main et al. 2014). Main et al. (2016) analysed snow, spring meltwater, particulate matter and wetland water from 16 wetland sites adjacent to agricultural fields that had been used to grow either oilseed rape (canola, treated with neonicotinoids) or oats (not treated). They found that all meltwater samples were contaminated with clothianidin and thiamethoxam in the range of $0.014-0.633 \mu \mathrm{g} / \mathrm{L}(1 \mu \mathrm{g} /$ $1=1 \mathrm{ppb}$ ). Levels of contamination in meltwater were higher adjacent to fields planted with neonicotinoid-treated oilseed rape in the previous year (mean $0.267 \mu \mathrm{g} / \mathrm{l}$ ). However, fields planted with non-neonicotinoid-treated oats in the previous year still showed similar levels of contamination (mean $0.181 \mu \mathrm{g} / \mathrm{l})$. Treated oilseed rape and untreated oats are frequently rotated from year to year (Main et al. 2014), and the small difference in neonicotinoid concentration in meltwater from fields previously planted with treated and untreated crops suggests the persistence of neonicotinoids in the soil over multiple years (see the "Persistence of neonicotinoids in water and transport mechanisms for contamination of aquatic systems" section). The findings of this study suggest that neonicotinoid active ingredients previously bound to soil particles are eroded during spring freeze-thaw cycles. The demonstration of this route of transport in addition to general rainfall suggests a more chronic transport of neonicotinoids into waterbodies outside the main period of crop planting.

The effect of neonicotinoids on aquatic habitats will depend on their persistence therein. Field and laboratory studies investigating the breakdown of imidacloprid, thiamethoxam and clothianidin in water report half-lives of minutes to several weeks depending on the conditions, several of which are not field-realistic (see Anderson et al. 2015; Lu et al. 2015). There has been no formal review of the degradation of neonicotinoids in water, and existing literature consists of published peer review studies and grey literature government studies, all using different methodologies. However, a number of studies have attempted to measure neonicotinoid degradation under field-realistic conditions. Peña et al. (2011) measured degradation of thiamethoxam in wastewaters and sewage in Spain finding maximum absorption at 250-255 nm, suggesting high susceptibility to direct photolysis from natural light. In control waters, thiamethoxam half-life was found to be $18.7 \mathrm{~h}$ (Peña et al. 2011). Under natural light in rice paddies in Japan, imidacloprid had a half-life of $24.2 \mathrm{~h}$ (Thuyet et al. 2011). Under natural light in Switzerland, von Gunten (2012) reported a half-life of $2 \mathrm{~h}$ for imidacloprid and $254 \mathrm{~h}$ for acetamiprid. Under laboratory conditions, Lu et al. (2015) 
measured half-lives for five neonicotinoids under differing conditions to mimic the seasonal change found in Canada (Table 5). They found 7-8-fold variation in the rate of neonicotinoid photolysis due to the variation in light levels across the season. The results are broadly similar to previously published studies with nitro-substituted neonicotinoid halflives in the region of $<1-3$ days depending on light levels.

In addition to these peer-reviewed studies, $\mathrm{Lu}$ et al. drew comparison with European Commission regulatory studies on neonicotinoid compounds (European Commission (EC) 2004a, b, 2005, 2006). The European Commission studies found half-lives in water of $3.3 \mathrm{~h}$ for clothianidin, 2.3-3.1 days for thiamethoxam, 34 days for acetamiprid and 80 days for thiacloprid. The exact methodology used in these studies is unclear and inconsistent (see Lu et al. 2015 discussion). Nevertheless, the overall trend is consistent with the cyanosubstituted neonicotinoids (acetamiprid and thiacloprid) taking one to two orders of magnitude longer to degrade than the nitro-substituted neonicotinoids (thiamethoxam, clothianidin and imidacloprid). The short half-lives of these three, most widely used neonicotinoids suggests that, under field conditions, free neonicotinoids in surface waters should be broken down by natural light in a matter of hours or days. However, local environmental conditions can affect this, with increasing turbidity increasing neonicotinoid persistence. Moreover, in mesocosm experiments, photolysis of thiamethoxam was found to be negligible at depths of greater than $8 \mathrm{~cm}(\mathrm{Lu}$ et al. 2015). This significant light attenuation through the water column suggests that neonicotinoids may be shielded from photolysis even in shallow waterbodies. In waterbodies such as groundwater that are not exposed to light, there will be no photolysis. In these circumstances, clothianidin is persistent and has the potential to accumulate over time (Anderson et al. 2015), though empirical data demonstrating this is lacking.

\section{Levels of neonicotinoid contamination found in waterbodies}

The most comprehensive review of levels of neonicotinoid contamination in global surface waters was conducted by Morrissey et al. (2015), though see also Anderson et al.

Table 5 Estimated photolysis and half-lives $\left(t_{1 / 2 E}\right)$ (days) for neonicotinoid pesticides in surface water at $50^{\circ} \mathrm{N}$ latitude for spring, summer, autumn and winter by sunlight on clear days. Reproduced from Lu et al. (2015)

\begin{tabular}{lllll}
\hline Compound & Spring & Summer & Autumn & Winter \\
\hline Thiamethoxam & 0.32 & 0.20 & 0.63 & 1.49 \\
Clothianidin & 0.53 & 0.35 & 1.23 & 3.31 \\
Imidacloprid & 0.36 & 0.24 & 0.83 & 2.22 \\
Acetamiprid & 16.5 & 9.67 & 29.7 & 67.9 \\
Thiacloprid & 14.3 & 8.75 & 26.6 & 60.3 \\
\hline
\end{tabular}

(2015). Morrissey reviewed reported average and peak levels of neonicotinoid contamination from 29 studies from nine countries between 1998 and 2013. The waterbodies studied included streams, rivers, drainage, ditches, groundwater, wetlands, ponds, lakes, puddled surface waters and run-off waters. Study systems were adjacent to or receiving run-off water from agricultural land. From this dataset (Fig. 5), the geometric mean for average surface water neonicotinoid concentration was $0.13 \mu \mathrm{g} / \mathrm{l}(=0.13 \mathrm{ppb}, n=19$ studies $)$ and the geometric mean for peak surface water concentration was $0.63 \mu \mathrm{g} / 1(=0.63 \mathrm{ppb}$, $n=27$ studies). Because most monitoring schemes use spot sampling, they are likely to underreport the true maximum concentrations that occur immediately after maximum periods of neonicotinoid influx (Xing et al. 2013). As peak concentrations are often found after acute events such as heavy rainfall, this limits our understanding of the true average and maximum concentrations that are found in waterbodies.

Since Morrissey et al. (2015) was published, a number of studies have become available documenting broadly similar neonicotinoid contamination levels in a wide range of aquatic environments. At a small scale in agricultural regions, Schaafsma et al. (2015) measured concentrations in surface water (puddles and ditches) in and around 18 maize fields in Ontario, Canada. They found arithmetic mean residues of $0.002 \mu \mathrm{g} / \mathrm{L}$ of clothianidin $($ maximum $=0.043 \mu \mathrm{g} / \mathrm{L}$ ) and $0.001 \mu \mathrm{g} / \mathrm{L}$ of thiamethoxam $($ maximum $=0.017 \mu \mathrm{g} / \mathrm{L}$ ). In Iowa, USA, Smalling et al. (2015) assessed six wetlands surrounded by agricultural land and found arithmetic mean neonicotinoid concentrations of $0.007 \mu \mathrm{g} / \mathrm{L}$ (maximum $0.070 \mu \mathrm{g} / \mathrm{L}$ ). Away from agricultural land, Benton et al. (2016) measured concentrations in mountain streams in the southern Appalachians, USA, where eastern hemlock forests are treated with imidacloprid to control pests. Average concentrations of $0.067 \mu \mathrm{g} / \mathrm{L}$ of imidacloprid (maximum $=0.379 \mu \mathrm{g} / \mathrm{L}$ ) were found in seven of the 10 streams investigated. de Perre et al. (2015) measured concentrations of clothianidin in groundwater below fields of treated maize. Data on average concentrations are not available, but concentrations peaked at $0.060 \mu \mathrm{g} / \mathrm{L}$ shortly after crop planting.

At a wider scale, Qi et al. (2015) and Sadaria et al. (2016) measured concentrations in wastewater treatment plants. Qi et al. (2015) recorded imidacloprid at concentrations between 0.045 and $0.100 \mu \mathrm{g} / \mathrm{L}$ in influent and 0.045 and $0.106 \mu \mathrm{g} / \mathrm{L}$ in effluent at five wastewater treatment plants in Beijing, China, with no data available on arithmetic mean concentrations. Sadaria et al. (2016) assessed influent and effluent wastewater at 13 conventional wastewater treatment plants around the USA. For influent, imidacloprid was found at arithmetic mean concentrations of $0.061 \mu \mathrm{g} / \mathrm{L}$, acetamiprid at $0.003 \mu \mathrm{g} / \mathrm{L}$ and clothianidin at $0.149 \mu \mathrm{g} / \mathrm{L}$. For effluent, imidacloprid was found at concentrations of $0.059 \mu \mathrm{g} / \mathrm{L}$, acetamiprid at $0.002 \mu \mathrm{g} / \mathrm{L}$ and clothianidin at $0.070 \mu \mathrm{g} / \mathrm{L}$.

Two nationwide surveys for neonicotinoids were also published. Hladik and Kolpin (2016) measured neonicotinoid 


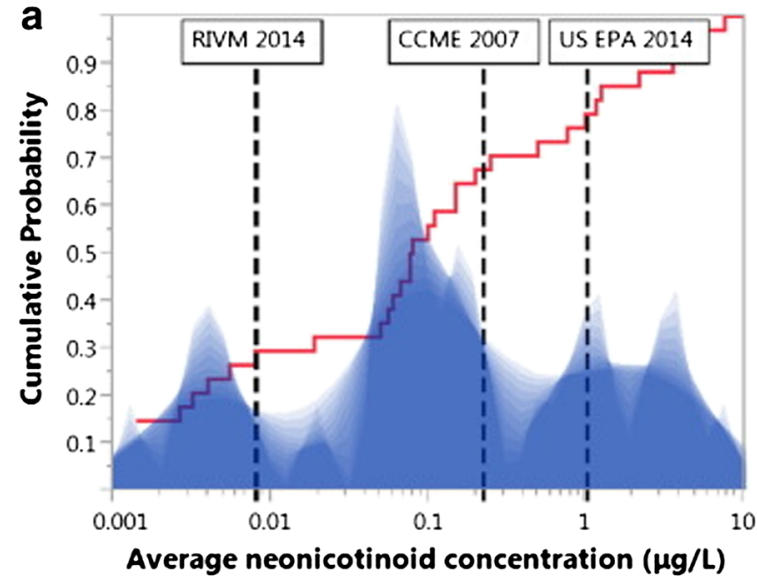

Fig. 5 Shadow histogram of $\mathbf{a}$ average and $\mathbf{b}$ maximum individual neonicotinoid concentrations ( $\log$ scale, $\mu \mathrm{g} / \mathrm{L}$ ) reported from water monitoring studies. Overlaid is the cumulative distribution probability (red ascending line) using all available surface water monitoring data showing proportion of data below any given neonicotinoid

concentrations in 38 streams from 24 US states plus Puerto Rico. Five neonicotinoids (acetamiprid, clothianidin, dinotefuran, imidacloprid, thiamethoxam) were recorded with at least one compound found in $53 \%$ of sampled streams, with an arithmetic mean contamination of $0.030 \mu \mathrm{g} / \mathrm{L}$ and median contamination of $0.031 \mu \mathrm{g} / \mathrm{L}$. Thiacloprid was not recorded. Székács et al. (2015) conducted a nationwide survey of Hungarian watercourses, finding clothianidin at concentrations of $0.017-0.040 \mu \mathrm{g} / \mathrm{L}$ and thiamethoxam at concentrations of $0.004-0.030 \mu \mathrm{g} / \mathrm{L}$.

Across all studies, the highest levels of neonicotinoid contamination were found in agricultural areas. In the most comprehensive nationwide survey of streams across the USA conducted between 2012 and 2014, levels of clothianidin and thiamethoxam contamination (the now dominant agricultural neonicotinoids) were significantly positively correlated with the proportion of the surrounding landscape used for crop cultivation (Hladik and Kolpin 2016). The most acute levels of neonicotinoid contamination in agricultural areas are reported from surface water in the immediate vicinity of cultivated crops. Puddles adjacent to fields planted with neonicotinoid-treated maize seeds were found to contain maximum concentrations of $55.7 \mu \mathrm{g} / \mathrm{L}$ clothianidin and $63.4 \mu \mathrm{g} / \mathrm{L}$ thiamethoxam in Quebec, Canada (Samson-Robert et al. 2014). Surface water in the Netherlands had imidacloprid concentrations up to $320 \mu \mathrm{g} / \mathrm{L}$ (van Dijk et al. 2013), and transient wetlands found in intensively farmed areas of Texas had thiamethoxam and acetamiprid concentrations of up to $225 \mu \mathrm{g} / \mathrm{L}$ (Anderson et al. 2013). In Hungary, the highest neonicotinoid concentrations of $10-41 \mu \mathrm{g} / \mathrm{L}$ were found in temporary shallow waterbodies after rain events in early summer (Székács et al. 2015). More generally, watercourses draining agricultural fields had high levels of neonicotinoids after rainfall in Canada, the USA and Australia (Hladik et al. 2014, Sánchez-Bayo and Hyne 2014). Where

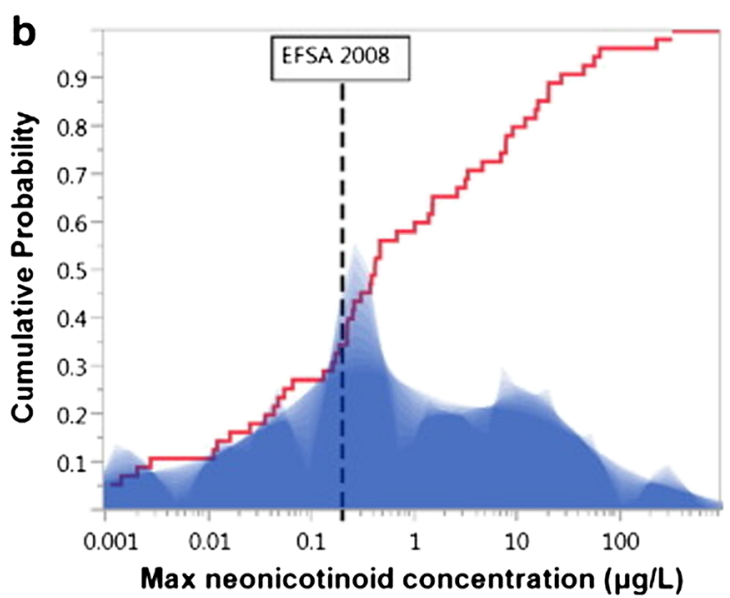

concentration. Vertical dashed lines illustrate multiple ecological quality reference values set for average imidacloprid water concentrations (RIVM 2014, $0.0083 \mu \mathrm{g} / \mathrm{L}$; CCME 2007, $0.23 \mu \mathrm{g} / \mathrm{L}$ and US EPA $2014 \mathrm{a}, 1.05 \mu \mathrm{g} / \mathrm{L}$ ) or for maximum imidacloprid water concentrations (EFSA 2008, $0.2 \mu \mathrm{g} / \mathrm{L}$ ). Reproduced from Morrissey et al. 2015

repeated sampling of the same site has been carried out, the highest neonicotinoid concentrations have been found in early summer and are associated with rainfall during the planting season (Main et al. 2014; Hladik et al. 2014). Hladik and Kolpin (2016) measured neonicotinoid concentrations in three agriculturally affected streams in Maryland and Pennsylvania and found peak levels after rain events during the crop planting season in May, though this could not be formally statistically analysed due to low sample size (Fig. 6).

In addition to agricultural run-off, urban areas also contribute towards neonicotinoid contamination of waterbodies. Whilst the use of imidacloprid as an agricultural pesticide has declined, it is still found in a wide range of domestic products and veterinary treatments for pets (Goulson 2013). Hladik and Kolpin (2016) continuously monitored neonicotinoid levels in Slope Creek, a stream surrounded by a largely urban catchment (39\% urban), and the Chattahoochee River which includes the drainage of Slope Creek and overall has a lower proportion of urbanisation (9\%). Imidacloprid was the dominant neonicotinoid found, present in $87 \%$ of the 67 collected samples (Fig. 7). Dinotefuran and acetamiprid were less frequently encountered. Unlike in the studied watercourses draining agricultural land, no significant relationship was seen with stream flow in either Slope Creek or the Chattahoochee River. Hladik and Kolpin suggest that this may be because, unlike for the planting period of arable crops, there is no distinct period of use for domestic imidacloprid in an urbanised catchment. No clothianidin or thiamethoxam was detected, probably because neither catchment contained cultivated crops.

\section{Risk of exposure from and uptake of neonicotinoids in non-crop plants}

Since neonicotinoids are water soluble and can persist in soils and waterbodies, there is the possibility that they may be taken up by 
(a)

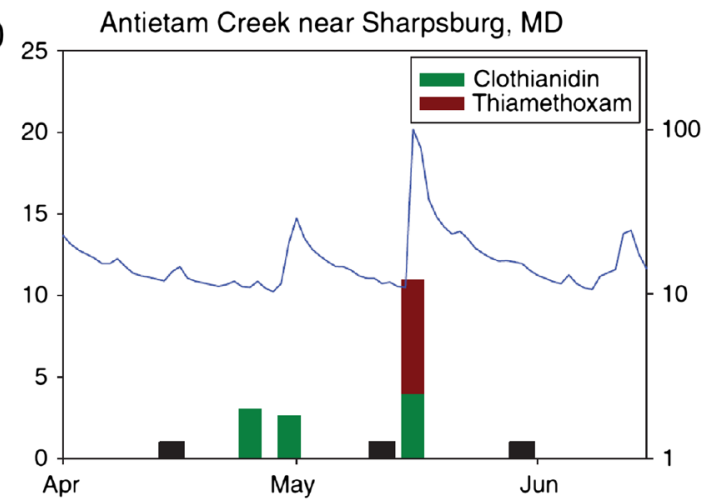

(b)

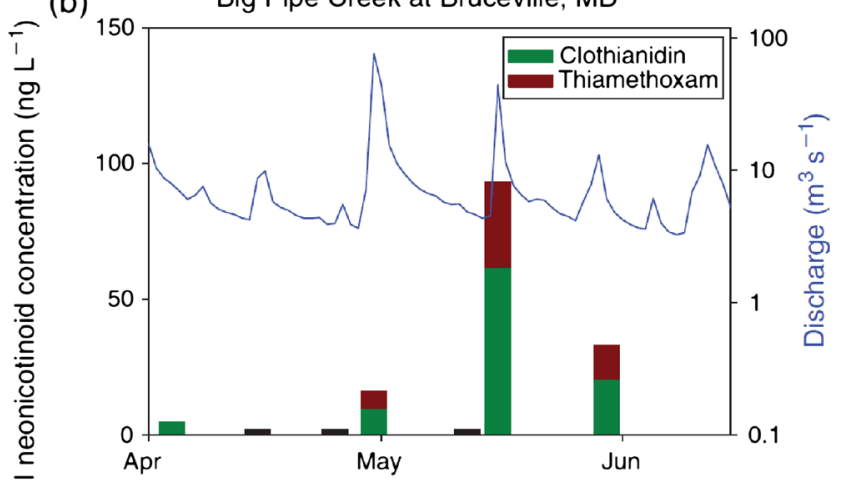

(c) Chillisquaque Creek at Chillisquaque, PA

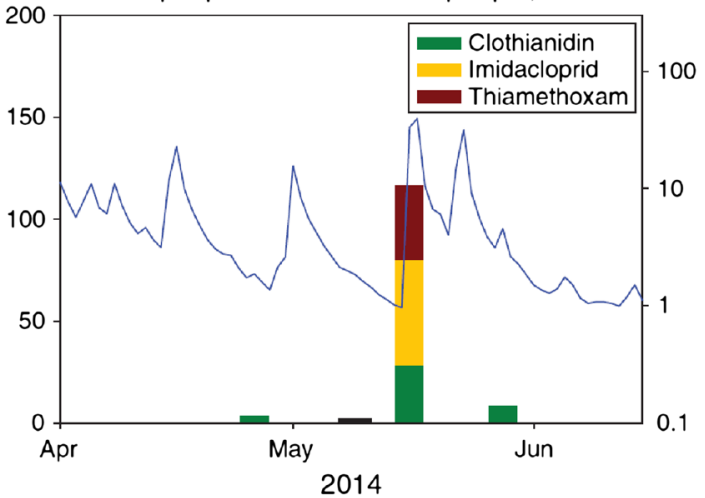

Fig. 6 Concentrations of clothianidin, imidacloprid and thiamethoxam and the corresponding stream discharge at three sites in the Chesapeake Bay area sampled in 2014. Black bars represent samples where no neonicotinoids were detected. Reproduced from Hladik and Kolpin (2016)

any wild plants present nearby. In April 2013, little empirical data was available documenting neonicotinoid contamination of wild plants. The EFSA reports considered that uptake of neonicotinoids by wild weed plants and subsequent exposure would be negligible, as weeds will not be present in the field when the crop is sown and considerable uptake via the roots would be unlikely as the substance is concentrated around the treated seed. No comment was made on the potential uptake of neonicotinoids by other wild plants in the agricultural environments. In the single study available in 2013, Krupke et al. (2012) found that dandelions Taraxacum agg. growing near to fields planted with neonicotinoid-treated maize contained between 1.1 and $9.4 \mathrm{ng} / \mathrm{g}$ clothianidin and between $<1.0$ (LOD) and $2.9 \mathrm{ng} / \mathrm{g}$ thiamethoxam. They did not assess whether the pesticides were found in the pollen or nectar. It was not clear whether the contamination came from neonicotinoid dust settling on the external surface of the plants or if the neonicotinoids had been directly taken up through the roots, in which case we would expect them to be present inside all plant tissues, pollen and nectar. Since April 2013, a number of studies have been published which demonstrate that neonicotinoids are frequently taken up in wild plants surrounding agricultural fields (Table 6).

Botías et al. (2015) collected pollen and nectar from wildflowers growing in field margins adjacent to agricultural fields planted with neonicotinoid-treated oilseed rape and wheat. Pollen samples from 54 wild flower species were collected. Thiamethoxam, imidacloprid and thiacloprid were all detected. Thiamethoxam was the most frequently encountered neonicotinoid, and levels were highly variable with the highest concentrations found in Heracleum sphondylium at $86 \mathrm{ng} / \mathrm{g}$ and Papaver rhoeas at $64 \mathrm{ng} / \mathrm{g}$. There was substantial variation in the levels of contamination in the same wildflower species found in different field margins. Average levels of total neonicotinoid contamination in wildflower pollen were significantly higher in margins adjacent to treated oilseed rape (c. $15 \mathrm{ng} / \mathrm{g}$ ) than for margins adjacent to treated wheat (c. $0.3 \mathrm{ng} / \mathrm{g}$ ). Levels of neonicotinoids were much lower in wild plant nectar. Only thiamethoxam was detected at average levels of $0.1 \mathrm{ng} / \mathrm{g}$ in wild flowers adjacent to oilseed rape fields and $<0.1 \mathrm{ng} / \mathrm{g}$ adjacent to wheat fields.

Botías et al. (2015) is the only available study which has specifically measured neonicotinoid concentrations in pollen and nectar directly taken from wild plants growing in close proximity to neonicotinoid-treated crops. Mogren and Lundgren (2016) assessed neonicotinoid concentrations in the nectar of five wild flower species sown as part of pollinator conservation measures which were located adjacent to neonicotinoid-treated maize. This was achieved by collecting honeybees seen to visit these flowers for nectar and extracting the contents of their crop for neonicotinoid residue analysis. Honeybees generally have a very high fidelity to visiting the same flower species on a single forage flight so the authors assumed that the nectar was representative of that particular species. Average clothianidin concentrations found in this nectar ranged between 0.2 and $1.5 \mathrm{ng} / \mathrm{g}$, with significant differences found between wild plant species. Mogren and Lundgren (2016) also tested the foliage of seven wildflower species for neonicotinoid residues directly. There was high variability in clothianidin uptake between and within plant species. Sunflowers Helianthus annuus accumulated the highest levels with concentrations of $0-81 \mathrm{ng} / \mathrm{g}$, with buckwheat Fagopyrum esculentum and phacelia Phacelia tanacetifolia accumulating lower levels at $0-52$ and 0 $33 \mathrm{ng} / \mathrm{g}$ respectively. Similarly, high levels of variation were 
Fig. 7 a Concentrations of imidacloprid and the corresponding stream discharge from October 2011 to October 2013 for Sope Creek (a largely urban catchment). b Concentrations of imidacloprid, dinotefuran and acetamiprid along with the corresponding stream discharge from September 2011 to September 2012 for Chattahoochee River. Black bars represent samples where no neonicotinoids were detected. Reproduced from Hladik and Kolpin (2016)

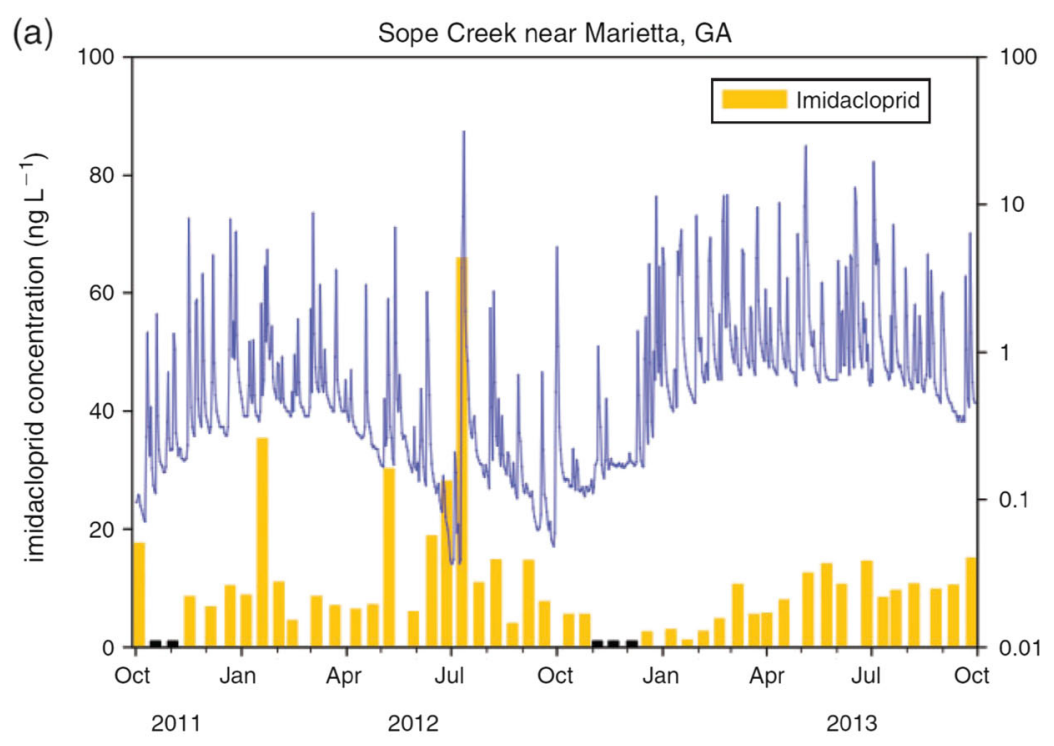

(b)

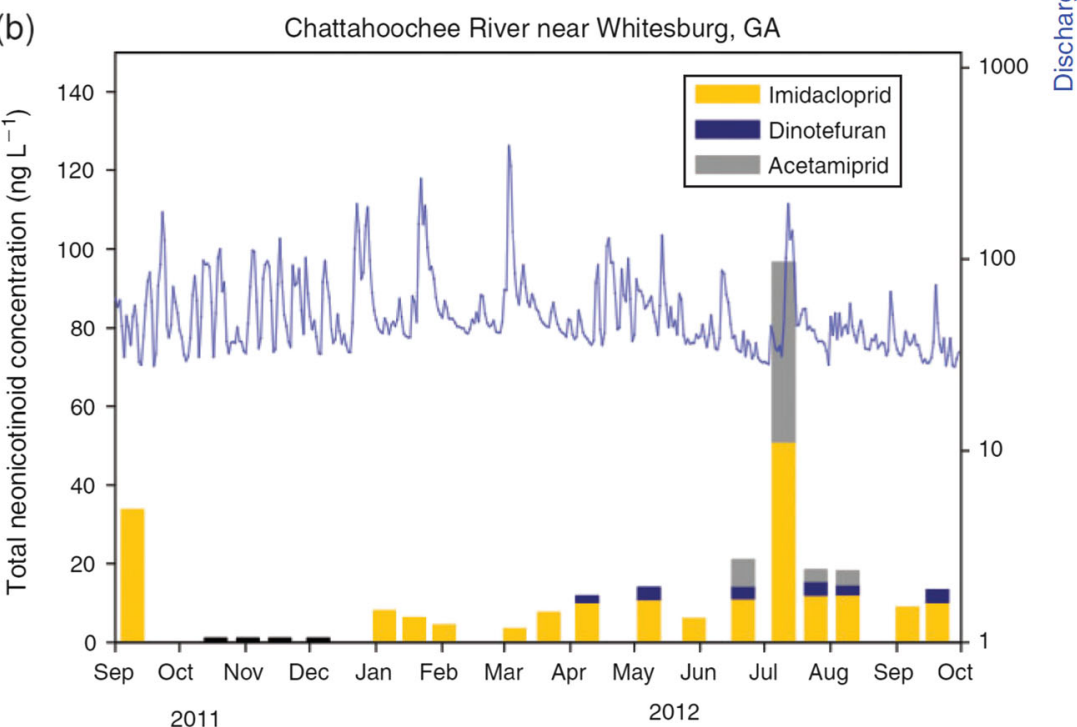

found by Botías et al. (2016) who sampled the foliage of 45 species of wild plant in field margins adjacent to treated oilseed rape crops. Average total neonicotinoid contamination was $10 \mathrm{ng} / \mathrm{g}$, with the highest levels seen in creeping thistle Cirsium arvense of $106 \mathrm{ng} / \mathrm{g}$ of thiamethoxam. Pecenka and Lundgren (2015) looked specifically at clothianidin concentrations in milkweed Asclepias syriaca in field margins adjacent to clothianidin-treated maize. Levels were lower than the previous two studies, with mean levels of $0.58 \mathrm{ng} / \mathrm{g}$ with a maximum concentration of $4.02 \mathrm{ng} / \mathrm{g}$.

Whilst not looking at specific concentrations in pollen, nectar or foliage, Stewart et al. (2014) and Rundlöf et al. (2015) found total mean neonicotinoid concentrations of 10 and $1 \mathrm{ng} / \mathrm{g}$ respectively in whole wild flower samples collected around neonicotinoid-treated fields. As discussed in the "Risk of exposure from the drilling of treated seed and subsequent dust drift" section, these levels may have been a direct result of neonicotinoid-contaminated dust drift onto surrounding vegetation and do not in and of themselves demonstrate uptake of neonicotinoids from contaminated soil and/or water.

Across all studies published since 2013, average levels of neonicotinoids in wild plants range from 1.0 to $7.2 \mathrm{ng} / \mathrm{g}$ in whole flower samples, 0.4 to $13.5 \mathrm{ng} / \mathrm{g}$ in foliage samples, $<0.1$ to $1.5 \mathrm{ng} / \mathrm{g}$ in nectar samples and $<0.04$ to $14.8 \mathrm{ng} / \mathrm{g}$ in pollen samples. Due to the limited number of studies available, it is difficult to make a comparison with levels in directly treated crop plants. However, they are broadly comparable to the levels found in the treated crop itself (see the "Risk of exposure from pollen and nectar of treated flowering crops" section).

In 2013, it was known that honeybees collected neonicotinoid contaminated pollen from crop plants, but the extent to which this was diluted by uncontaminated pollen from wild plants was unknown. Krupke et al. (2012) found levels of clothianidin and thiamethoxam in honeybee- 


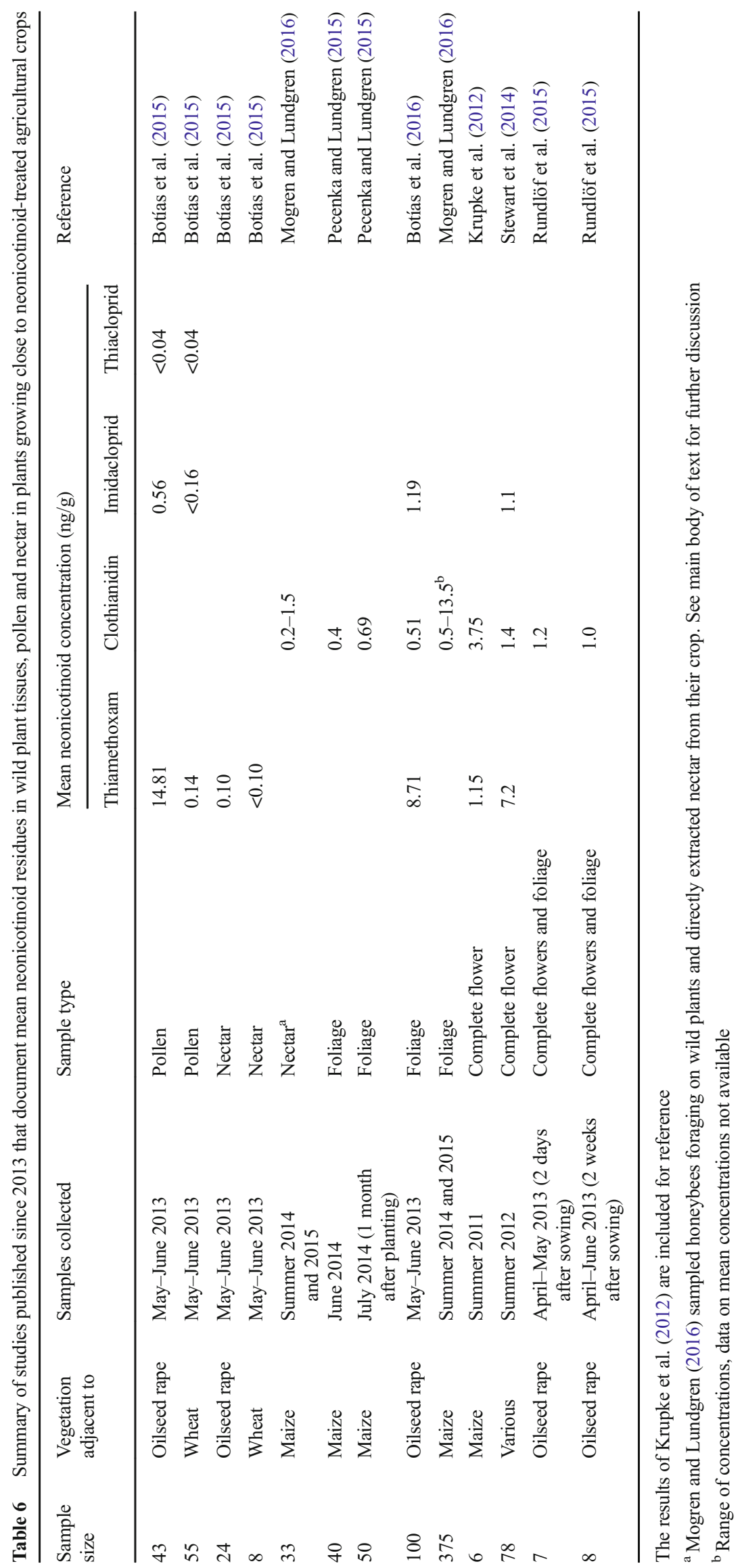


collected pollen that ranged between 0 and $88 \mathrm{ng} / \mathrm{g}$, with the proportion of pollen collected from maize (the main treated crop in their study area) also varying substantially between 2.6 and $82.7 \%$. There was no correlation between the proportion of maize pollen collected and the total neonicotinoid concentration. Given the uncertainty over the contamination of wild plants, it was not clear what long-term chronic neonicotinoid exposure was from pollen or nectar over a whole season. A number of studies have attempted to quantify the levels of neonicotinoids in bee-collected pollen and, through microscopic identification of the constituent pollen grains, to identify the major source of neonicotinoid contamination throughout the season. Most of these studies have used honeybeecollected pollen as the model, as pollen traps are easy to fit to apiaries that can be moved into targeted locations and because individual honeybees display floral constancy the origin of collected pollen pellets can be quickly identified.

Studies are summarised in Table 7. Most of these studies used honeybees, placing apiaries out next to neonicotinoidtreated and untreated crops. As summarised in the "Risk of exposure from pollen and nectar of treated flowering crops" section, bees placed near treated crops collected pollen with higher concentrations of neonicotinoids (Cutler et al. 2014; Rundlöf et al. 2015; Long and Krupke 2016; Rolke et al. 2016). The highest levels of acute contamination are found when a large proportion of crop pollen is collected. Pohorecka et al. (2013) found average clothianidin concentrations of $27.0 \mathrm{ng} / \mathrm{g}$ in pollen samples $(73.7 \%$ wildflower pollen) collected from apiaries adjacent to treated maize fields. Rundlöf et al. (2015) found average clothianidin concentrations of $13.9 \mathrm{ng} / \mathrm{g}$ in pollen samples $(37.9 \%$ wildflower pollen) collected from apiaries adjacent to treated oilseed rape fields. Apiaries adjacent to untreated oilseed rape fields collected pollen consisting of $47.4 \%$ wildflower pollen with no detectable levels of neonicotinoids $(<0.5 \mathrm{ng} / \mathrm{g})$.

Where bees collect a greater proportion of wildflower pollen, neonicotinoid concentrations are lower. Botías et al. (2015) measured neonicotinoid concentrations in pollen during the peak flowering period of oilseed rape and 2 months after this period. During peak flowering, honeybees collected $91.1 \%$ of their pollen from wildflowers and $8.9 \%$ from oilseed rape, with a total neonicotinoid concentration of $3.09 \mathrm{ng} / \mathrm{g}$. In the later period, $100 \%$ of their pollen was collected from wildflowers, with a total neonicotinoid concentration of $0.20 \mathrm{ng} / \mathrm{g}$. Cutler et al. (2014) also sampled honeybee pollen from apiaries adjacent to treated and untreated oilseed rape for a 2-week period in July during peak flowering. Honeybees collected low levels of crop pollen, and higher levels of neonicotinoid contamination were found adjacent to treated fields $(9.0 \%$ wildflower pollen week 1 to $45.2 \%$ week $2,0.84 \mathrm{ng} / \mathrm{g}$ ) than untreated fields ( $15.1 \%$ wildflower pollen week 1 to $62.5 \%$ week 2, $0.24 \mathrm{ng} / \mathrm{g}$ ). Long and Krupke (2016) collected data over a longer period of time, from May to September, covering the flowering period of maize, the flowering crop at their study sites. At all sites, a high proportion of pollen was collected from wildflowers. Average neonicotinoid concentrations were lowest at non-agricultural sites (93.9\% wildflower pollen, $0.047 \mathrm{ng} / \mathrm{g}$ ), higher at untreated agricultural sites $(95.8 \%$ wildflower pollen, $0.078 \mathrm{ng} / \mathrm{g})$ and highest at treated agricultural sites (95.3\% wildflower pollen, $0.176 \mathrm{ng}$ / g). Alburaki et al. $(2015,2016)$ found low levels of neonicotinoids when honeybees collected predominantly wildflower pollen, with none detected in loads of $99 \%$ wildflower pollen and average neonicotinoid concentrations of $0.04 \mathrm{ng} / \mathrm{g}$ in loads of $93.5 \%$ wildflower pollen.

Only two studies are available which measured neonicotinoid concentrations in bumblebee-collected pollen and quantified the proportion of pollen collected from wildflowers. Cutler and Scott-Dupreee (2014) placed out Bombus impatiens nests next to neonicotinoid-treated and untreated maize fields. Bumblebees collected a very low proportion of their pollen from maize, less than $1 \%$, in contrast to honeybees which can collect large quantities of maize pollen during its flowering period (Krupke et al. 2012; Pohorecka et al. 2013, though see Alburaki et al. 2015, 2016; Long and Krupke 2016). Levels of neonicotinoid residues were low, at $<0.1 \mathrm{ng} / \mathrm{g}$ by untreated fields and $0.4 \mathrm{ng} / \mathrm{g}$ by treated fields. In contrast, David et al. (2016) placed out five B. terrestris nests adjacent to treated oilseed rape fields, a crop with pollen attractive to bumblebees. Pollen was sampled from nest stores at the end of June. Bumblebees collected an average of $68.1 \%$ wildflower pollen and $31.9 \%$ oilseed rape pollen.

Thiamethoxam was found in this pollen at an average concentration of $18 \mathrm{ng} / \mathrm{g}$ and thiacloprid at an average concentration of $2.9 \mathrm{ng} / \mathrm{g}$. These levels are much higher than the levels found in honeybee-collected pollen from the same study area in the same year of $3.09 \mathrm{ng} / \mathrm{g}$ total neonicotinoids, though a much higher proportion (91.9\%) of pollen was collected from wildflowers (Botías et al. 2015). Comparisons are difficult because few other studies have assessed neonicotinoid concentrations in bumblebee-collected pollen with reference to pollen origin. Rolke et al. (2016) placed B. terrestris colonies out next to treated oilseed rape fields and found much lower concentrations of $0.88 \mathrm{ng} / \mathrm{g}$ of clothianidin in pollen taken directly from returning bumblebees, but the origin of this pollen is unknown. The concentrations found by David et al. are however lower than the levels reported by Pohorecka et al. (2013) and within a factor of 2 of the levels reported by Rundlöf et al. (2015) who found neonicotinoid concentrations of 27.0 and $13.9 \mathrm{ng} / \mathrm{g}$ in honeybee-collected pollen respectively, samples which also contained a high proportion of crop pollen.

Overall, these studies show that the highest acute exposure (0.84-27.0 ng/g) comes during the flowering period of insectattractive neonicotinoid-treated flowering crops in situations where over a quarter of total pollen intake comes from crop 


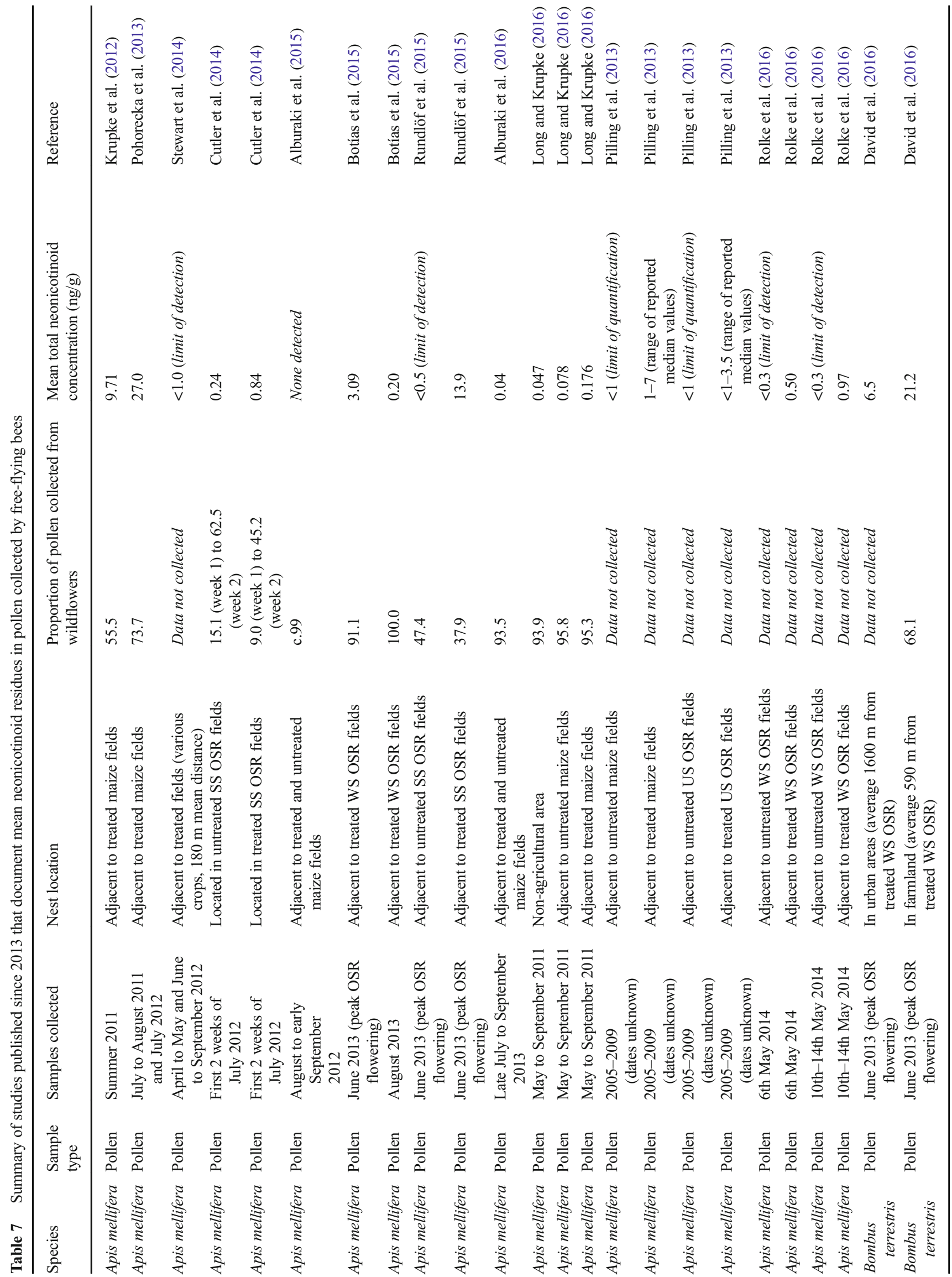


plants. Reported values vary by up to two orders of magnitude depending on crop type, date of sample collection, initial strength of neonicotinoid seed coating and the proportion of wildflower pollen collected. Because only one study has explicitly measured neonicotinoid concentrations in wildflower pollen, it is difficult to judge whether wildflower pollen consistently contains higher or lower concentrations of neonicotinoids than crop pollen. However, when looking at honeybee pollen diets in neonicotinoid-treated agricultural areas outside of the main flowering period of attractive crops, or where flowering crops are unattractive to a specific bee species, neonicotinoid concentrations are generally low, in the region of 0.04- $0.40 \mathrm{ng} / \mathrm{g}$ from pollen diets composed of 95.3-100\% wildflower pollen (Cutler and Scott-Dupreee 2014; Botías et al. 2015; Long and Krupke 2016; Alburaki et al. 2016). Whilst the highest levels of acute exposure come from pollen diets containing a proportion of crop pollen, because honeybees collect pollen over the whole season, total exposure to neonicotinoids may primarily be determined by concentrations in wildflowers. Botías et al. (2015) calculated, based on pollen collected in June and August, that $97 \%$ of the total neonicotinoids present in pollen were of wildflower origin. Non-crop plants surrounding agricultural areas represent an additional and chronic source of neonicotinoid exposure.

\section{Risk of exposure from succeeding crops}

The risk of neonicotinoid exposure from succeeding crops was identified as a key knowledge gap by the EFSA reports. The available studies suggested that residues in succeeding crops are below LOQ, but the data set was limited. Since 2013, few studies have explicitly looked at neonicotinoid levels in untreated crops grown in soil that had previously been used to grow neonicotinoid-treated crops, as most crops will be sown with a new dose of neonicotinoids each year. However, where specific neonicotinoid formulations are changed, this analysis is possible. Botías et al. $(2015,2016)$ analysed neonicotinoid concentrations in oilseed rape treated with thiamethoxam. The fields had been used to grow clothianidin-treated cereals over at least the previous 2 years. Imidacloprid had not been used for the previous 3 years. Oilseed rape pollen and foliage were found to contain 3.15 and $1.04 \mathrm{ng} / \mathrm{g}$ of thiamethoxam, 1.90 and $2.91 \mathrm{ng} / \mathrm{g}$ of clothianidin and 0 and $0.23 \mathrm{ng} / \mathrm{g}$ of imidacloprid respectively. As clothianidin can be produced as a metabolite of thiamethoxam, it is not possible to comment on the origin of these detected residues. Imidacloprid was absent from the pollen samples, reflecting the time since the last known agricultural use. Given that these compounds can persist in soil for multiple years, the level of exposure from succeeding crops will broadly depend on the date since the last application, as well as the other factors determining neonicotinoid persistence in soil ("Persistence of neonicotinoids in soil" section). 
However, as demonstrated by the presence of imidacloprid in foliage samples, succeeding crops can take up residues of neonicotinoids remaining from applications made at least 2 years previously. Given the presence of neonicotinoids in annual, perennial and woody vegetation surrounding agricultural land ("Risk of exposure from and uptake of neonicotinoids in non-crop plants" section), and the medium-term persistence of neonicotinoids in soil and water ("Persistence of neonicotinoids in water and transport mechanisms for contamination of aquatic systems" and "Levels of neonicotinoid contamination found in waterbodies" sections), the risk of exposure from succeeding crops is likely to be in line with levels reported from general vegetation in agricultural environments. However, more explicit investigation in this area is required.

\section{Evidence for impact of neonicotinoids on animal health}

\section{Sensitivity of bumblebees and solitary bees to neonicotinoids}

\section{Direct lethality of neonicotinoids to adult wild bees}

Almost all of the studies conducted on the toxicity of neonicotinoids to bees have been conducted on honeybees, Apis mellifera. Fourteen studies conducted up to 2010 were reviewed in a meta-analysis by Cresswell (2011) who concluded that for acute oral toxicity imidacloprid has a $48-\mathrm{h}$ $\mathrm{LD}_{50}=4.5 \mathrm{ng} / \mathrm{bee}$. The EFSA studies $(2013 \mathrm{a}, \mathrm{b}, \mathrm{c})$ reviewed existing studies for acute oral toxicity up to 2013, including both peer-reviewed studies and also private studies that are not in the public domain (summarised in Godfray et al. 2014). These analyses produced $\mathrm{LD}_{50} \mathrm{~s}$ of $3.7 \mathrm{ng} / \mathrm{bee}$ for imidacloprid, $3.8 \mathrm{ng} /$ bee for clothianidin and $5.0 \mathrm{ng} /$ bee for thiamethoxam. Equivalent $\mathrm{LD}_{50} \mathrm{~s}$ for acute contact have also been calculated by EFSA (2013a, b, c) for honeybees to be $81 \mathrm{ng} /$ bee for imidacloprid, $44 \mathrm{ng} / \mathrm{bee}$ for clothianidin and $24 \mathrm{ng} / \mathrm{bee}$ for thiamethoxam.

However, the EFSA reports highlighted a knowledge gap for the effects of neonicotinoids on bees other than honeybees. Arena and Sgolastra (2014) conducted a meta-analysis comparing the sensitivity of bees to pesticides relative to the sensitivity of honeybees. This analysis combined data from 47 studies covering 53 pesticides from six chemical families with a total of 150 case studies covering 18 bee species (plus A. mellifera). Arena and Sgolastra calculated a sensitivity ratio $\mathrm{R}$ between the lethal dose for species $a$ (A. mellifera) and for species $s$ (other than $A$. mellifera), $\mathrm{R}=\mathrm{LD}_{50} a / \mathrm{LD}_{50} s$. A ratio of over 1 indicates that the other bee species is more sensitive to the selected pesticides than A. mellifera and vice versa. There was high variability in relative sensitivity ranging from
0.001 to 2085.7 , but across all pesticides a median sensitivity of 0.57 was calculated, suggesting that $A$. mellifera was generally more sensitive to pesticides than other bee species. In the vast majority of cases $(95 \%)$, the sensitivity ratio was below 10 .

Combining data for all neonicotinoids (acetamiprid, imidacloprid, thiacloprid and thiamethoxam) and for both acute contact and acute oral toxicity, nine studies covering nine bee species (plus A. mellifera) were found. These studies showed a median sensitivity ratio of 1.045 which is the highest median value of all the analysed pesticide chemical families. The most relatively toxic neonicotinoids to other bees were the cyano-substituted neonicotinoids acetamiprid and thiacloprid as these exhibit lower toxicity to honeybees than the nitro-substituted neonicotinoids imidacloprid and thiamethoxam.

Selecting pesticides covered by the moratorium (excluding acetamiprid and thiacloprid and including fipronil) and including both acute contact and acute oral toxicity, 12 studies covering 10 bee species (plus A. mellifera) were found. These studies showed a median sensitivity ratio of 0.957 which is close to the calculated sensitivity ratio for all neonicotinoids. The greatest discrepancy between honeybees and other bees was found for stingless bees (Apidae: Meliponini). The effect of acute contact of fipronil on Scaptotrigona postica (24-fold greater), of acute contact of fipronil on Melipona scutellaris (14-fold greater) and of acute contact of Thiacloprid on Nannotrigona perilampoides (2086-fold) were the only three cases with a sensitivity ratio of over 10 . Stingless bees are predominantly equatorial with the greatest diversity found in the neotropics. No species are found in Europe (Nieto et al. 2014). In contrast, studies on $B$. terrestris consistently report a lower sensitivity ratio between 0.005 and 0.914 , median 0.264. B. terrestris is widespread in Europe and is the most commonly used non-Apis model system for assessing the effects of neonicotinoids on wild bees (see the "Sublethal effects of neonicotinoids on wild bees" section). Differences in bee body weight have been proposed to explain these differences, with sensitivity to pesticides inversely correlated with body size (Devillers et al. 2003). However, this has not been consistently demonstrated and other mechanisms have been suggested such as species level adaptation to feeding on alkaloidrich nectar (Cresswell et al. 2012) and differential abilities to clear neonicotinoid residues from their bodies (Cresswell et al. 2014). With the limited data available, Arena and Sgolastra could not comment on the strength of these claims.

Spurgeon et al. (2016) calculated various toxicity measures of clothianidin on honeybees, the bumblebee species $B$. terrestris and the solitary bee species $O$. bicornis. Acute oral toxicity 48-, 96- and $240-\mathrm{h} \mathrm{LD}_{50}$ s for honeybees were 14.6, 15.4 and $11.7 \mathrm{ng} /$ bee respectively. For $B$. terrestris, the corresponding values were $26.6,35$ and $57.4 \mathrm{ng} / \mathrm{bee}$ respectively. For $O$. bicornis, the corresponding values were 
8.4, 12.4 and $28.0 \mathrm{ng} / \mathrm{bee}$ respectively. These findings are generally in line with the findings of Arena and Sgolastra, with $B$. terrestris less sensitive than A. mellifera at all time points and $O$. bicornis less sensitive at $240 \mathrm{~h}$.

Sgolastra et al. (2016) calculated relative sensitivity to clothianidin to these same three species over a range of time periods from 24 to $96 \mathrm{~h}$. The highest $\mathrm{LD}_{50}$ values were obtained after $24 \mathrm{~h}$ for A. mellifera and B. terrestris and after $72 \mathrm{~h}$ for O. bicornis. At these time points, $O$. bicornis was the most sensitive of the three species, with $\mathrm{LD}_{50}$ measurements of $1.17 \mathrm{ng} /$ bee and $9.47 \mathrm{ng} / \mathrm{g}$, compared to $1.68 \mathrm{ng} / \mathrm{bee}$ and $19.08 \mathrm{ng} / \mathrm{g}$ for A. mellifera and $3.12 \mathrm{ng} / \mathrm{bee}$ and $11.90 \mathrm{ng} / \mathrm{g}$ for $B$. terrestris. These results are in line with the values calculated by Spurgeon et al. (except for the 240 -h values), with decreasing sensitivity in the order of $O$. bicornis $>A$. mellifera $>B$. terrestris. Together, these studies support the position that small-bodied species show greater sensitivity to neonicotinoids.

Around 2000 bee species are known from Europe. The biology, behaviour and ecology of each of these species differ from those of honeybees. Consequently, extrapolating from the limited toxicological data available for 19 bee species to the effects of neonicotinoids on the wider European fauna is fraught with difficulties given the wide variation in relative sensitivity. Current data suggests that wild bees are equally to slightly less sensitive to neonicotinoids compared to honeybees when considering direct mortality. However, care must be taken when considering individual bee species, genera and families, as different taxonomic groups may show consistently different individual-level sensitivity. Most European wild bees are smaller than honeybees, and there is the potential for them to be more sensitive on a nanogram per bee basis. In general, continuing to use honeybee neonicotinoid sensitivity metrics is likely to be a reasonable proxy measure for the direct sensitivity of the wild bee community to neonicotinoids (Arena and Sgolastra 2014).

\section{Sublethal effects of neonicotinoids on wild bees}

In 2013, a number of studies looking at sublethal effects of neonicotinoids were available, predominantly using honeybees as a model organism in laboratory conditions. Blacquière et al. (2012) reviewed studies on neonicotinoid side effects on bees published between 1995 and 2011 with a specific focus on sublethal effects. The authors found that whilst many laboratory studies described lethal and sublethal effects of neonicotinoids on the foraging behaviour and learning and memory abilities of bees, no effects were observed in field studies at field-realistic dosages. Two major studies that substantially contributed towards the initiation and subsequent implementation of the EU neonicotinoid moratorium were published after this review in 2012.

Henry et al. (2012) gave honeybee workers an acute dose of $1.34 \mathrm{ng}$ of thiamethoxam in a $20 \mu \mathrm{L}$ sucrose solution, equivalent to $27 \%$ of the $\mathrm{LD}_{50}$ (see the "Direct lethality of neonicotinoids to adult wild bees" section), then released them $1 \mathrm{~km}$ away from their nests and measured their return rate. Dosed bees were significantly less likely to return to the nest than control bees. Whitehorn et al. (2012) exposed $B$. terrestris colonies to two levels of neonicotinoid-treated pollen ( 6 and $12 \mathrm{ng} / \mathrm{g}$ plus control) and nectar ( 0.7 and $1.4 \mathrm{ng} / \mathrm{g}$ plus control) in the laboratory for 2 weeks before moving them outdoors to forage independently for 6 weeks, aiming to mimic a pulse exposure that would be expected for bees foraging on neonicotinoid-treated oilseed rape. Bees in the two neonicotinoid treatments grew significantly more slowly and had an $85 \%$ reduction in the number of new queens produced when compared to control colonies.

Both of these studies have been criticised for using neonicotinoid concentrations greater than those wild bees are likely to be exposed to in the field (see Godfray et al. 2014; Carreck and Ratnieks 2014). The $1.34 \mathrm{ng}$ of thiamethoxam in a $20 \mu \mathrm{L}$ sucrose solution used by Henry et al. is a concentration of $67 \mathrm{ng} / \mathrm{g}$. Taking maximum estimated concentrations of thiamethoxam in oilseed rape nectar of $2.72 \mathrm{ng} / \mathrm{g}$ (see the "Risk of exposure from pollen and nectar of treated flowering crops" section), a honeybee would have to consume $0.49 \mathrm{~g}$ of nectar to receive this dose. Honeybees typically carry 25 $40 \mathrm{mg}$ of nectar per foraging trip, equivalent to 0.025 $0.040 \mathrm{~g}$, some $10 \%$ of the volume necessary to receive a dose as high as the one used by Henry et al. Moreover, as honeybee workers regurgitate this nectar at the hive, the total dose consumed is likely to be a fraction of the total amount carried. Consequently, it is extremely unlikely that the findings of Henry et al. are representative of a real-world situation.

The pollen and nectar concentrations used by Whitehorn et al. are much closer to field-realistic levels with the lower treatment within maximum estimated concentrations of imidacloprid in oilseed rape pollen and nectar (see the "Risk of exposure from pollen and nectar of treated flowering crops" section). However, the experimental setup, where bumblebees had no choice but to consume treated pollen and nectar, has been criticised as unrealistic, as in the real-world alternative, uncontaminated forage sources would be available. Studies that have measured residues in both crop and wildflower pollen and have assessed the origin of bee-collected pollen (see "Risk of exposure from and uptake of neonicotinoids in noncrop plants" section) have recorded neonicotinoid concentrations of between 0.84 and $27.0 \mathrm{ng} / \mathrm{g}$ in wild bee-collected pollen where a substantial proportion of this pollen is collected from crop plants during their period of peak flowering. Pollen extracted from bumblebee nests contained neonicotinoid concentrations of $6.5 \mathrm{ng} / \mathrm{g}$ in urban areas and $21.2 \mathrm{ng} / \mathrm{g}$ in rural areas during the peak flowering period of oilseed rape, though the number of nests sampled (three and five) were low. However, other studies measuring levels in pollen taken directly from bumblebees found concentrations of $<1 \mathrm{ng} / \mathrm{g}$, so 
there is still a lack of clarity surrounding true levels of neonicotinoid exposure for wild bumblebees. On the basis of these described concentrations, the results of Whitehorn et al. are likely to be closer to real-world conditions than the findings of Henry et al.

Post April 2013, much work on sublethal effects of neonicotinoids on bees has been carried out on individual honeybees and honeybee colony fitness metrics, such as colony growth, overwintering success and the production of sexuals. This work is beyond the scope of this review, but important recent publications include Pilling et al. (2013), Cutler et al. (2014), Rundlöf et al. (2015) and Divley et al. (2015) who all found limited to negligible impacts of neonicotinoids at the colony level. See also Cresswell (2011) for a metaanalysis of 13 laboratory and semi-field studies conducted before 2011. Various authors note that interpreting the findings of studies on honeybees to wild bees is fraught with difficulty, given the differing size of individual bees and the social behaviour of honeybees that gives rise to colonies containing many thousands of workers.

\section{Impact on colony growth and reproductive success Several} authors have investigated the effects of neonicotinoids on bumblebees using micro-colonies. These are small groups of worker bumblebees that are taken from a queenright colony and isolated in a new nest box. These workers, lacking a queen, will begin to rear their own male offspring. As such, micro-colonies are useful for generating a large sample size for investigating pesticide impacts on bee mortality and larval rearing behaviour and reproductive success.

Elston et al. (2013) fed micro-colonies of three B. terrestris workers a 'field-realistic' dose of $1 \mathrm{ng} / \mathrm{g}$ thiamethoxam and a 'field-maximum' dose of $10 \mathrm{ng} / \mathrm{g}$ in both pollen paste and sugar solution for a 28-day period. Micro-colonies from both thiamethoxam treatments consumed significantly less sugar solution than control colonies. There was no impact on worker mortality, but colonies fed $10 \mathrm{ng} / \mathrm{g}$ thiamethoxam had reduced nest-building activity and produced significantly fewer eggs and larvae, with the $10 \mathrm{ng} / \mathrm{g}$ thiamethoxam treatment the only one to produce no larvae over the 28-day experimental period.

Laycock et al. (2014) fed micro-colonies of four $B$. terrestris workers thiamethoxam-treated sugar solution at a range of concentrations up to $98 \mathrm{ng} / \mathrm{g}$. Pollen was not treated with thiamethoxam. Sugar solution consumption was significantly reduced at the 39 and $98 \mathrm{ng} / \mathrm{g}$ treatments. Worker mortality was only increased at the highest dose of $98 \mathrm{ng} / \mathrm{g}$. Worker oviposition failure was only significantly higher at the 39 and $98 \mathrm{ng} / \mathrm{g}$ treatments, with no significant differences seen between the lower-concentration treatments between 0 and $16 \mathrm{ng} / \mathrm{g}$.

The findings of these two studies are generally in line with pre-2013 knowledge. Mommaerts et al. (2010) exposed $B$. terrestris micro-colonies to sugar solution treated with thiamethoxam concentrations of up to $100 \mathrm{ng} / \mathrm{g}$. Whilst the $100 \mathrm{ng} / \mathrm{g}$ level reduced brood production, the $10 \mathrm{ng} / \mathrm{g}$ treatment had no detectable effect. The difference between the findings of Elston et al. and Laycock et al. may partially be explained by the fact that Elston et al. treated pollen with thiamethoxam as well as sugar solution. Laycock et al. confirm that concentrations of $98 \mathrm{ng} / \mathrm{g}$ increase worker mortality, but as such concentrations are not usually encountered in the field, this is of limited relevance.

Scholer and Krischik (2014) exposed greenhouse queenright colonies of $B$. impatiens to imidacloprid- and clothianidin-treated sugar syrup at concentrations of 0,10 , 20,50 and $100 \mathrm{ng} / \mathrm{g}$ for 11 weeks. Queen mortality was significantly increased at 6 weeks for the 50 and $100 \mathrm{ng} / \mathrm{g}$ treatments, and at 11 weeks for the $20 \mathrm{ng} / \mathrm{g}$ treatment for both clothianidin and imidacloprid. Surprisingly, no significant impact was found on numbers of workers or new queens produced, though this was in part because very low numbers of new queens were produced across all treatments (average of four per colony). Colonies in treatments above $10 \mathrm{ng} / \mathrm{g}$ imidacloprid and $20 \mathrm{ng} / \mathrm{g}$ of clothianidin gained significantly less weight over the course of the study. Neonicotinoid concentrations of $20 \mathrm{ng} / \mathrm{g}$ and above are very high and are unlikely to be consistently encountered by bees for prolonged periods of times under real-world conditions. As a result, queen mortality in the real world is unlikely to be significantly affected by currently observed neonicotinoid concentrations.

Several field studies have also been published since 2013 that investigate the impact of neonicotinoid-treated mass flowering crops on wild bee colony growth and reproductive success. Cutler and Scott-Dupreee (2014) placed B. impatiens colonies adjacent to maize fields during pollen shed in Ontario, Canada. Four neonicotinoid-treated conventional and four untreated organic fields were used. Colonies were placed out adjacent to each field on the first day of major pollen shed. Colonies were left for 5-6 days and then transported to an area of semi-natural habitat for 30-35 days, after which they were frozen. Colonies placed next to treated maize produced significantly fewer workers than those placed next to organic farms. All other metrics (colony weight, honey and pollen pots, brood cells, worker weight, male and queen numbers and weights) were not significantly different. Bumblebees collected less than $1 \%$ of their pollen from maize ("Risk of exposure from and uptake of neonicotinoids in noncrop plants" section) and neonicotinoid residues in collected pollen were low, at $0.4 \mathrm{ng} / \mathrm{g}$ from bees foraging adjacent to treated fields and below the LOD for bees adjacent to organic fields. Given that it is well known that bumblebees collect very low volumes of maize pollen, the relevance of this study is unclear.

Rundlöf et al. (2015) conducted an extensive field trial of the effects of clothianidin-treated oilseed rape on wild bees. Sixteen oilseed rape fields separated by at least $4 \mathrm{~km}$ were 
selected across southern Sweden and were paired on the basis of similar landscape composition. In each pair, one of the fields was randomly selected to be sown with oilseed rape treated with $10 \mathrm{~g}$ clothianidin $/ \mathrm{kg}$ of seed and the other field was sown without a neonicotinoid seed treatment. Twentyseven cocoons of the solitary bee $O$. bicornis (15 male, 12 female) were placed out alongside each field a week before the oilseed rape began to flower, and six colonies of $B$. terrestris were placed alongside each field on the day the oilseed rape began to flower. The $O$. bicornis placed adjacent to treated oilseed rape showed no nesting behaviour and did not initiate brood cell construction. O. bicornis adjacent to untreated fields showed nesting behaviour in six of the eight fields studied. The reasons for these differences in nest initiation are unclear, and it is difficult to draw firm conclusions with a small sample size. Bumblebees placed next to treated oilseed rape showed reduced colony growth and reproductive output. Bumblebee colonies were collected and frozen when new queens began to emerge, with this happening between the 7 th of July and 5th of August depending on each colony. The number of queen and worker/male cocoons present was counted. At the point of freezing, colonies placed next to treated oilseed rape fields had significantly fewer queen and worker/male cocoons present.

Sterk et al. (2016) performed a similar field experiment to Rundlöf et al. Two $65 \mathrm{~km}^{2}$ areas in northern Germany were selected in which the only flowering crops comprised wintersown oilseed rape. In one area, the oilseed rape was treated with the same seed coating used by Rundlöf et al. of $10 \mathrm{~g}$ clothianidin $/ \mathrm{kg}$ seed. The other area was an untreated control. In each area, $10 \mathrm{~B}$. terrestris colonies were placed at each of six localities. Colonies were left adjacent to oilseed rape between April and June, covering its main flowering period. After this, the colonies were moved to a nature reserve. No differences were found in colony weight growth, number of workers produced or reproductive output as measured by the production of new queens.

That these two field studies using the same neonicotinoid seed dressing found markedly different results is interesting. The major difference is that whilst Rundlöf et al. used springsown oilseed rape, Sterk et al. used winter-sown oilseed rape. The length of time between sowing and peak flowering is much greater for winter-sown oilseed rape (mid-August to May) than for spring-sown oilseed rape (April/May to midJune). As such, there is more time for neonicotinoids to leach into soil and water for winter-sown oilseed rape, reducing the amount of active ingredient available to be taken up by the crop. This may explain some of the order of magnitude differences in neonicotinoid concentrations in pollen collected from the two crops ("Risk of exposure from and uptake of neonicotinoids in non-crop plants" section) and the difference in reported colony growth and number of reproductives produced. An additional difference is that in the Sterk et al. study, colonies were moved to a nature reserve consisting of forests, lakes and heaths after the flowering period of oilseed rape ended. The quality of available forage at this nature reserve is likely to have been of both a higher quality and a higher quantity than what was available in a conventional agricultural landscape and is not typical of the experience of a bumblebee colony located in such a landscape that will have to continue foraging there after crops such as oilseed rape cease flowering. In addition, Sterk et al. had only one treated and one control area, so there is no true site level replication, as opposed to Rundlöf et al. who used eight treated and eight control fields. These differences in experimental design should be taken into account when considering why the studies produced such different results.

One of the studies conducted in response to the results of Henry et al. (2012) and Whitehorn et al. (2012) was produced by FERA (2013). It consisted of a field trial with bumblebee colonies placed out adjacent to oilseed rape treated with either clothianidin, imidacloprid or an untreated control. Colonies were allowed to forage freely for 6-7 weeks whilst the oilseed rape flowered and then were moved to a non-agricultural area to continue developing. The study was ultimately not published in a peer-reviewed journal, but it came to the conclusion that there was no clear relationship between bumblebee colony success and neonicotinoid concentrations. Goulson (2015) reanalysed the FERA data using linear models and retaining two colonies excluded in the original study as outliers, but which do not meet the statistical definition of this term. This reanalysis found that the concentration of clothianidin in nectar and the concentration of thiamethoxam in pollen significantly negatively predicted both colony weight gain and production of new queens.

Only one study is available that looked at the impact of neonicotinoids on the reproductive success of a solitary bee in controlled conditions. Sandrock et al. (2014) established laboratory populations of $O$. bicornis, a solitary stem nesting bee. Bees were fed on sugar solution treated with $2.87 \mathrm{ng} / \mathrm{g}$ thiamethoxam and $0.45 \mathrm{ng} / \mathrm{g}$ clothianidin along with untreated pollen. There was no impact of neonicotinoids on adult female longevity or body weight. However, treated bees completed $22 \%$ fewer nests over the course of the experiment. Nests completed by treated bees contained $43.7 \%$ fewer total cells, and relative offspring mortality was significantly higher, with mortality rates of 15 and $8.5 \%$ in the treated and untreated groups respectively. Overall, chronic neonicotinoid exposure resulted in a significant reduction in offspring emergence per nest, with treated bees producing $47.7 \%$ fewer offspring. These results suggest that exposure to these low-level, fieldrealistic doses of neonicotinoids $(<3.5 \mathrm{ng} / \mathrm{g})$ did not increase adult mortality but did have sublethal impacts on their ability to successfully build nests and provision offspring. However, it is important to note that this study had no true replication, 
and thus, the results should be interpreted with considerable caution.

Overall, the studies produced since 2013 are generally in line with existing knowledge at this point but have advanced our knowledge in several key areas. Laboratory studies have continued to demonstrate negative effects of neonicotinoids on bumblebee reproductive output at generally high concentrations, with the lowest sublethal effects on reproductive output detected at $10 \mathrm{ng} / \mathrm{g}$. Field studies using bumblebees demonstrate that exposure to neonicotinoid-treated flowering crops can have significant impacts on colony growth and reproductive output depending on the levels exposed to, with crop flowering date relative to sowing and availability of uncontaminated forage plants likely to explain variation in the detected residues between the available studies. Our understanding of the impact on solitary bees is much improved with the findings of Sandrock et al. (2014) suggesting substantial impacts on solitary bee reproductive output at field-realistic concentrations of $3.5 \mathrm{ng} / \mathrm{g}$. Field studies demonstrating this under real-world conditions are limited with the work of Rundlöf et al. (2015) suffering from no nest-building activity at the neonicotinoid treatment sites.

Impact on foraging efficiency In 2013, a limited amount was known about how neonicotinoids affected the foraging behaviour of individual bees, and whether this affected colony level fitness. Gill et al. (2012) exposed B. terrestris colonies to $10 \mathrm{ng} / \mathrm{g}$ imidacloprid in sugar solution in the nest for a period of 4 weeks. Colonies were housed indoors, but access tubes allowed them to forage freely outdoors. Imidacloprid-exposed colonies grew more slowly, but there were substantial effects on worker foraging behaviour. Compared to controls, imidacloprid-treated colonies had more workers initiating foraging trips, workers brought back smaller volumes of pollen on each successful trip and successful pollen foraging trips were of a significantly longer duration. Treated workers also collected pollen less frequently, with $59 \%$ of foraging bouts collecting pollen versus $82 \%$ for control workers, a decline of $28 \%$. The authors conclude that exposure to imidacloprid at these concentrations significantly reduced the ability of bumblebee workers to collect pollen in the field. The reduced ability to collect pollen resulted in imidacloprid-treated colonies collecting less pollen than control colonies, subsequently resulting in reduced growth through pollen limitation. Since the publication of this paper, several new studies assessing neonicotinoid impacts on the foraging behaviour of bumblebees have been published.

Feltham et al. (2014) exposed B. terrestris colonies to sugar solution treated with $0.7 \mathrm{ng} / \mathrm{g}$ and pollen treated with $6 \mathrm{ng} / \mathrm{g}$ of imidacloprid for 2 weeks. These sugar solution concentrations were an order of magnitude lower than the $10 \mathrm{ng} / \mathrm{g}$ used by Gill et al. (2012). Colonies were then placed out in an urban area in Scotland. The foraging workers from each nest were then monitored for a further 4 weeks. There was no difference in the length of time spent collecting nectar or the volume of nectar collected between workers from treated and control colonies. However, treated workers collected significantly less pollen, bringing back $31 \%$ less pollen per time unit to their colonies. Treated workers also collected pollen less frequently, with $41 \%$ of foraging bouts collecting pollen versus $65 \%$ for control workers, a decline of $23 \%$.

Gill and Raine (2014) performed a similar experiment to Gill et al. (2012) where B. terrestris colonies were exposed to sugar solution treated with $10 \mathrm{ng} / \mathrm{g}$ of imidacloprid whilst also having access to forage freely outside. Colonies and individual worker bumblebees were studied over a 4 -week period. In common with their previous findings (Gill et al. 2012), imidacloprid-treated workers initiated significantly more foraging trips across all 4 weeks of the experiment. The authors note that this is likely driven by an acute individual-level response in the first weeks (neonicotinoids acting as a neural partial agonist, increasing desire to forage) and by a chronic colony-level response in the latter part of the experiment, with treated colonies allocating a higher proportion of workers to pollen collection. Pollen foraging efficiency of treated workers decreased as the experiment progressed with the smallest collected pollen loads recorded in week 4 , suggesting a chronic effect of imidacloprid on pollen foraging ability. It is not clear whether this is as a result of individual performance deteriorating, or new emerging workers having been exposed for a greater period of time.

Stanley et al. (2015) exposed B. terrestris colonies to 2.4 or $10 \mathrm{ng} / \mathrm{g}$ thiamethoxam-treated sugar solution for 13 days. Colonies were then moved to pollinator exclusion cages where they were allowed to forage freely on two varieties of apple blossom. Bees from colonies exposed to $10 \mathrm{ng} / \mathrm{g}$ spent longer foraging, visited fewer flowers and brought back pollen on a lower proportion of foraging trips compared to bees from control colonies. Stanley and Raine (2016) also exposed B. terrestris colonies to $10 \mathrm{ng} / \mathrm{g}$ thiamethoxam sugar solution for a 9- to 10-day period. At this point, colonies were moved to a flight arena provisioned with two common bird's-foot trefoil Lotus corniculatus plants and one white clover Trifolium repens plant. Worker bees were individually released, and their interaction with the flowers was recorded. Significantly more treated workers displayed pollen-foraging behaviour compared to control workers. However, control workers learnt to handle flowers efficiently after fewer learning visits.

Arce et al. (2016) placed B. terrestris nests out in an area of parkland for a 5 -week period whilst also supplying them with sugar solution treated with $5 \mathrm{ng} / \mathrm{g}$ of clothianidin. The volume of sugar solution provided was estimated to be half that which colonies typically consume over the course of the experiment. No pollen was provided, so workers had to forage for this and to make up the shortfall in nectar resources. In contrast to the 
previous papers, only subtle changes to patterns of foraging activity and pollen collection were detected. There was no clear difference in colony weight gain between treatments or number of brood individuals. However, by the end of the experiment, treated colonies contained fewer workers, drones and gynes when compared with control colonies.

Switzer and Combes (2016) studied the impact of acute imidacloprid ingestion on sonicating behaviour of $B$. impatiens. Sonicating is a behaviour whereby a bumblebee lands on a flower and vibrates loudly to shake pollen loose from anthers. Bumblebee workers were fed a dose of 0 , $0.0515,0.515$ or $5.15 \mathrm{ng}$ of imidacloprid in $10 \mu \mathrm{L}$ of sugar solution. These are equivalent to concentrations of $0,5.15$, 51.5 and $515 \mathrm{ng} / \mathrm{g}$, with the highest volume consumed equivalent to $139 \%$ of the honeybee $\mathrm{LD}_{50}$, a moderate proxy for bumblebees (see "Direct lethality of neonicotinoids to adult wild bees" section). Bees were then allowed to forage from tomato Solanum lysopersicum plants, and sonicating behaviour was observed. At the lowest dose of $0.0515 \mathrm{ng}$ of imidacloprid, no impact was found on wingbeat frequency, sonication frequency or sonication length. No analysis could be made for higher doses, as bees in these treatments rarely resumed foraging behaviour after ingesting imidacloprid. Given the neonicotinoid concentrations used in this study and the lack of observed sonicating behaviour at higher doses, it is difficult to draw many conclusions other than that high levels of exposure may impair bumblebee pollen foraging behaviour.

Overall, these studies suggest that exposure to neonicotinoids in nectar at concentrations of between 0.7 and $10 \mathrm{ng} / \mathrm{g}$ can have sublethal effects on the ability of bumblebees to collect pollen at both the individual and colony levels. This shortfall in pollen and subsequent resource stress is a plausible mechanism to explain diminished colony growth and production of sexuals in the absence of increased direct worker mortality. Given that concentrations as high as $10 \mathrm{ng} / \mathrm{g}$ are at, but within, the upper limit of what bumblebees are likely to experience in the field ("Risk of exposure from pollen and nectar of treated flowering crops" and "Risk of exposure from and uptake of neonicotinoids in non-crop plants" sections), it is likely that wild bumblebees exposed to neonicotinoids in contemporary agricultural environments suffer from a reduced ability to collect pollen, with a subsequent impact on their reproductive output.

Impact on bee immune systems Bee diseases (including both parasites and pathogens) have been implicated as the major factor affecting managed honeybee colony survival in recent years (vanEngelsdorp et al. 2010). Whilst most evidence for the negative effects of diseases comes from studies of honeybees, most diseases can affect a wide range of bee species. For example, the microsporidian parasite Nosema ceranae, originates in Asia but has spread around the world during the last
20 years, probably as a result of the international trade in honeybees (Klee et al. 2007). N. ceranae has now been detected in four different genera of wild bees (Bombus, Osmia, Andrena, Heriades) across Europe and the Americas (see Goulson et al. 2015). The spread of diseases between wild and managed bees can occur at shared flowering plants (Graystock et al. 2015).

Sánchez-Bayo et al. (2016) reviewed evidence that linked the use of neonicotinoids to the incidence and severity of bee diseases. Prior to 2013, several studies demonstrated a link between neonicotinoid exposure and increased susceptibility to diseases in honeybees (Vidau et al. 2011; Pettis et al. 2012). Exposure of honeybees infected with $N$. ceranae to imidacloprid reduced their ability to sterilise the brood, increasing the spread of $N$. ceranae within the colonies (Alaux et al. 2010). In addition, exposure to sublethal doses of imidacloprid or fipronil increased honeybee worker mortality due to a suppression of immunity-related genes (Aufauvre et al. 2012). Di Prisco et al. (2013) found that sublethal doses of clothianidin adversely affected honeybee antiviral defences. By enhancing the transcription of the gene encoding a protein that inhibits immune signalling activation, the neonicotinoid pesticides reduce immune defences and promote the replication of deformed wing virus in honeybees bearing covert viral infections. At the field level, a positive correlation is found between neonicotinoid treatment and Varroa mite infestation and viral load of honeybee colonies (Divley et al. 2015; Alburaki et al. 2015). No studies are available that measure the impact of neonicotinoids on the immune systems of wild bees or on the incidence of diseases in wild bees in conjunction with neonicotinoid usage. However, given that wild bees share a very similar nervous and immune system, it is highly likely that neonicotinoids will have similar effects, increasing wild bee susceptibility to parasites and pathogens.

\section{Population-level effects of neonicotinoids on wild bees}

Nothing was known about the population level effects of neonicotinoids on wild bees in 2013. As a managed domesticated species, population trends are available for honeybees, but no such data are available for wild bees. One study has attempted to investigate the impact of neonicotinoids on wild bee population trends. Woodcock et al. (2016) used an incidence dataset of wild bee presence in $10 \times 10 \mathrm{~km}$ grid squares across the UK. The dataset is composed of bee sightings by amateur and professional entomologists and is probably the most complete national bee distribution database currently in existence. Sixty-two wild bee species were selected, and their geographic distance and persistence over an 18-year period between 1994 and 2011 was calculated. Neonicotinoid seedtreated oilseed rape was first used in the UK in 2002, and so the authors calculated spatially and temporally explicit 
information describing the cover of oilseed rape and the area of this crop treated with neonicotinoids. The 62 species were split into two groups - species that foraged on oilseed rape $(n=34)$ and species that did not $(n=28)$. Species persistence across this time period was then compared with expected neonicotinoid exposure. Over the 18 -year period, wild bee species persistence was significantly negatively correlated with neonicotinoid exposure for both the foraging and nonforaging groups, with the effect size three times larger for the oilseed rape foraging group.

The characterisation of bees as foragers or non-foragers has one major problem. Many species of bees are obligately parasitic on other bees and do not forage for their own pollen. Some parasitic bees were included in the oilseed rape forager category $(n=2)$, and some in the non-forager category $(n=12)$ based on observed nectar visits from a previous study. Some of the parasitic bees in the non-forager group are parasitic on bees included in the forager group $(n=10 / 28)$. Given that these species are highly dependent on their host's abundance, this classification does not make ecological sense. A decline due to a decline in their host or because of increased direct mortality cannot be separated, introducing an additional confounding issue into the analysis. In addition, given the presence of neonicotinoids in wild plants adjacent to agricultural areas ("Risk of exposure from and uptake of neonicotinoids in non-crop plants" section), the amount applied to oilseed rape is not necessarily a true measure of actual neonicotinoid exposure for wild bees.

Overall, the study suggests that bee species were more likely to disappear from areas with a high exposure to neonicotinoids as measured by the amounts applied as seed dressings to oilseed rape, and that this trend was more pronounced for species known to forage on oilseed rape.

\section{Sensitivity of butterflies and moths to neonicotinoids}

Pisa et al. (2015) reviewed the existing literature on the impact of neonicotinoids on butterflies and moths (Lepidoptera). In contrast to bees, very few comparative toxicity tests have been conducted for butterflies. Most existing studies have compared butterfly abundance and diversity on organic versus conventional farms. Organic farms host a greater diversity of species, but the specific reasons for this cannot be isolated. For example, the relative importance of herbicide use that reduces the abundance of larval food and adult nectar plants versus direct mortality or sublethal stress from pesticides is unknown.

Most available toxicological studies looking at the sensitivity of Lepidoptera to neonicotinoids and fipronil have been conducted on 32 species of moths from nine families that are pests of crops (Pisa et al. 2015). There is considerable variation in reported sensitivities between species, with the susceptibility to acetamiprid of two cotton pests differing almost 3 -fold $\left(\mathrm{LC}_{50}=11,049\right.$ and $\left.3798 \mathrm{ppm}\right)$. There is also variation between different stages of larval development, with first instar caterpillars more than 100 times as sensitive as fifth instar caterpillars with a $\mathrm{LC}_{50} / \mathrm{LC}_{90}$ of $0.84 / 1.83$ and $114.78 / 462.11 \mathrm{ppm}$ respectively. Botías et al. (2016) listed $\mathrm{LC}_{50}$ values for three moth species that are agricultural crop pests, with $24-\mathrm{h} \mathrm{LC}_{50}$ values between 2400 and $186,000 \mathrm{ppb}$ clothianidin. These levels are generally very high, and there are multiple examples of neonicotinoid resistance in wild populations (see Pisa et al. 2015). Because many of the studied moths species are pests of major crops, they have been exposed to multiple pesticides over many generations in recent decades, and their sensitivity to neonicotinoids may not necessarily be representative of non-pest wild Lepidoptera species.

Since 2013, few studies looking at the sensitivity of wild Lepidoptera to neonicotinoids are available. Pecenka and Lundgren (2015) assessed the lethality of clothianidin to caterpillars of monarch butterflies Danaus plexippus. First instar caterpillars were fed treated leaves for a $36-\mathrm{h}$ period. $\mathrm{A} \mathrm{LC}_{50}$ of $15.63 \mathrm{ng} / \mathrm{g}$ was calculated. In addition, sublethal effects on growth were measured at $0.5 \mathrm{ng} / \mathrm{g}$ with first instar larvae taking longer to develop, having reduced body length and lower weight. These differences did not extend into the second instar. Yu et al. (2015) fed second instar silkworm Bombyx mori caterpillars leaves treated with imidacloprid and thiamethoxam for a 96-h period. They calculated $\mathrm{LC}_{50}$ values of $1270 \mathrm{ng} / \mathrm{g}$ for imidacloprid and $2380 \mathrm{ng} / \mathrm{g}$ for thiamethoxam. This wide range of reported tolerances for a limited number of ecologically different species means that thorough assessment of butterfly and moth sensitivity to neonicotinoids is difficult. Much more research is required in this area.

Whilst there is a paucity of toxicological data on wild butterflies and moths, two recent studies have used long-term butterfly population datasets to assess the relative impact of neonicotinoid usage in agricultural areas. Gilburn et al. (2015) used data from the UK butterfly monitoring scheme. The data consists of butterfly counts from a wide variety of habitats, and the period studied was 1984-2012, a more extensive time period than that used for UK wild bees by Woodcock et al. (2016, Section 3.1.3) in order to include a 10-year period before the introduction of neonicotinoids onto British farmland. Seventeen UK butterfly species were selected that are predominantly generalists and are found in a wide range of habitats including agricultural habitats. The area of the UK treated with neonicotinoids and a range of temperature and weather variables were included in the model, as local climatic conditions are a very important factor impacting butterfly populations. In line with expectations, summer temperature was significantly positively and spring rainfall significantly negatively correlated with the butterfly population indexes. Neonicotinoid usage was also significantly negatively associated with butterfly population indices after controlling for the effects of weather. The pattern of association varied between butterfly species, but most (14 out of 17) had a negative association. In the most recent time period between 2000 and 2009 
when neonicotinoid usage was at its highest, 15 of the 17 studied species showed a negative population trend.

Forister et al. (2016) conducted a similar analysis on Californian lowland butterfly populations. Butterflies have been monitored continuously with biweekly walks at four sites in a region of northern California since 1972, 1975 and 1988 depending on the individual site. These sites are situated across a land gradient that includes arable, semi-natural and urban habitats. The data were used to examine the impact of annual neonicotinoid input and other factors such as summer temperature and land use change.

A substantial decline in butterfly species richness was seen from 1997 onwards, with 1997 being the breakpoint identified by the statistical models. Neonicotinoid usage in the region began in 1995 and has increased since that point. Neonicotinoid use was significantly negatively correlated with butterfly species richness, with smaller-bodied butterflies showing the strongest negative correlation.

Both of these analyses are strictly correlational, and neonicotinoid usage may simply be a proxy measurement for some other factor that is driving declines. Gilburn et al. note that if habitat deterioration and loss of food plants is the main cause of butterfly declines, and agricultural intensification is playing a key role in this habitat deterioration, then levels of neonicotinoid usage might be acting as a proxy for agricultural intensification and therefore habitat deterioration. Thus, neonicotinoid usage could be responsible for driving butterfly declines or alternatively it could provide the first useful quantifiable measure of agricultural intensification that strongly correlates with butterfly population trends. As most of the UK butterfly monitoring scheme survey areas are not directly on agricultural land, Gilburn et al. suspect that it is the transport of neonicotinoids into the wider environment ("Risk of exposure from and uptake of neonicotinoids in non-crop plants" section) and farmed areas acting as population sinks that is driving the declines of butterflies, rather than neonicotinoid use acting as a proxy for agricultural intensification. No data are available to assess this hypothesis.

Overall, recent studies have demonstrated that Lepidoptera show a wide range of tolerances to ingested neonicotinoids in their larval stages. No data are available on sensitivity to neonicotinoids ingested during the adult stage, for example from crop plant nectar. Two correlational studies using long-term datasets show a strong association between neonicotinoid use and declines in butterfly abundance and species richness, though more laboratory and field studies are required to establish the exact mechanism causing this decline.

\section{Sensitivity of other terrestrial invertebrates to neonicotinoids}

Most available studies that have assessed neonicotinoid sensitivity for insect species have focused on pest species of economically important crops. Pisa et al. (2015) reviewed existing literature on the impacts of neonicotinoids on other terrestrial invertebrates, and Botías et al. (2016) presented a summary on reported $\mathrm{LC}_{50}$ s for 24 species of insects across four orders (Hymenoptera, Lepidoptera, Hemiptera and Coleoptera) from studies conducted between 1996 and 2015. Pisa et al. (2015) review found no post-2013 research on the effects of neonicotinoids on Neuroptera, Hemiptera and Syrphidae (hoverflies).

Four studies are available that have looked at the impact of neonicotinoids on ants. Galvanho et al. (2013) treated Acromyrmex subterraneus leafcutter ants with imidacloprid to investigate impacts on grooming, an important behaviour for limiting the spread of fungal pathogens. Workers were treated with 10, 20 or $40 \mathrm{ng}$ /insect imidacloprid. Only workers with a head capsule of $1.6-2.0 \mathrm{~mm}$ in width were selected. This is a large size relative to most species of ants in the world. At this size, individual ants would weigh around $10-20 \mathrm{mg}$, giving a concentration of 10-40 ng active ingredient per $0.015 \mathrm{~g}$ of ant, or $666.7-2666.7 \mathrm{ng} / \mathrm{g}$. The lowest dose was sufficient to significantly decrease grooming behaviour. Mortality was not measured, but a previous study found that another species of leafcutter ant, Atta sexdens, had significantly increased mortality when exposed to a fungal pathogen and imidacloprid at the same concentration $10 \mathrm{ng} /$ insect concentration compared to ants exposed only to the fungal pathogen (Santos et al. 2007).

Barbieri et al. (2013) exposed colonies of the Southern ant Monomorium antarcticum (native to New Zealand where the study was conducted) and the invasive Argentine ant Linepithema humile to imidacloprid in sugar water at a concentration of $1.0 \mu \mathrm{g} / \mathrm{mL}$, equivalent to $1000 \mathrm{ng} / \mathrm{g}$. Relative aggression was affected by neonicotinoid exposure, with native ants lowering their aggression to invasive ants, and conversely exposed invasive ants increasing their aggression, resulting in a lower survival probability. Brood production was not affected in the Southern ant, but exposure to neonicotinoids reduced Argentine ant brood production by $50 \%$ relative to non-exposed colonies. No effect of neonicotinoid exposure on foraging ability was detected.

Wang et al. (2015a) fed colonies of fire ants Solenopsis invicta sugar water at concentrations of $0.01,0.05,0.25$, 0.50 and $1.00 \mu \mathrm{g} / \mathrm{mL}$, equivalent to $10-1000 \mathrm{ng} / \mathrm{g}$. The impacts on feeding, digging and foraging were quantified. Ants exposed to the $10 \mathrm{ng} / \mathrm{g}$ concentration consumed significantly more sugar water and increased digging activity. Concentrations greater than or equal to $250 \mathrm{ng} / \mathrm{g}$ significantly supressed sugar water consumption, digging and foraging behaviour.

Wang et al. (2015b) fed S. invicta newly mated queens water containing imidacloprid concentrations of 10 or $250 \mathrm{ng} / \mathrm{g}$. Neither concentration increased queen mortality, but they did both significantly reduce queens' brood tending 
ability and the length of time taken to respond to light, an indication of disturbance and colony threat. In Solenopsis species, eggs are groomed and coated with an adhesive substance that maintains moisture levels and allows for rapid transport of egg clumps. At the $250 \mathrm{ng} / \mathrm{g}$ concentration, the number of egg clumps was significantly increased (indicating low egg care and an increase in the effort needed to transport brood), suggesting that the queens had a reduced ability to groom eggs. Untended eggs become mouldy, reducing colony growth. Colonies exposed to $10 \mathrm{ng} / \mathrm{g}$ showed no difference in egg clump numbers compared to controls.

Across these ant studies, the neonicotinoid concentrations used are generally very high, in most cases far higher than expected exposure rates under field-realistic conditions ("Risk of exposure for non-target organisms from neonicotinoids applied directly to crops" and "Risk of exposure for non-target organisms from neonicotinoids persisting in the wider environment" sections). Few sublethal effects were detected at concentrations of $10 \mathrm{ng} / \mathrm{g}$, the levels that might be reasonably expected to be encountered under field conditions.

Earthworms have similar neural pathways to insects, and earthworms are highly likely to be exposed to neonicotinoids through direct contact with soil, ingestion of organic material bound to neonicotinoids and consumption of contaminated plant material (Wang et al. 2012, "Persistence of neonicotinoids in soil" section). Reported neonicotinoid $\mathrm{LC}_{50} \mathrm{~s}$ for earthworms from 13 studies range from 1500 to $25,500 \mathrm{ppb}$, with a mean of $5800 \mathrm{ppb}$ and a median of $3700 \mathrm{ppb}$ (see Pisa et al. 2015). Fewer studies are available that measured sublethal effects on reproduction. Negative impacts on cocoon production were measured at between 300 and $7000 \mathrm{ppb}$ depending on earthworm species and neonicotinoid type.

Very little data are available for realistic neonicotinoid exposure to earthworms under field conditions. Neonicotinoid concentrations in soils can range from 2 to $50 \mathrm{ng} / \mathrm{g}$ depending on organic matter composition, application rate and other factors, although they may be much higher in immediate proximity to dressed seeds ("Persistence of neonicotinoids in soil" section). Douglas et al. (2015) detected neonicotinoids in earthworms present in thiamethoxam-treated soybean fields. Two earthworms were casually collected during soil sample collection. The two samples were found to contain total neonicotinoid concentrations of 54 and 279 ppb corresponding to $\sim 16$ and $\sim 126 \mathrm{ng}$ per worm. In addition to thiamethoxam and its degradates, the two earthworm samples contained imidacloprid at 25 and $23 \mathrm{ppb}$. The fields from which they were taken had not been treated with imidacloprid for at least 1 year previously, adding further to the evidence that neonicotinoids can persist in soils for over 1 year ("Persistence of neonicotinoids in soil" section). Because only live earthworms were collected and because of the small sample size, it is not clear if these are representative of typical concentrations or are an underestimate. For example, if earthworms are exposed to higher levels that cause mortality, they cannot be subsequently sampled for residue analysis.

Overall, these studies continue to increase our understanding of the negative effects of neonicotinoids on non-target organisms. In contrast to bees, most studied groups had lower sensitivity to neonicotinoids, in some cases by several orders of magnitude.

\section{Sensitivity of aquatic invertebrates to neonicotinoids}

The most comprehensive review of the acute and chronic effects of neonicotinoids on aquatic invertebrates was conducted by Morrissey et al. (2015). This followed on from and updated the reviews of Goulson (2013), Mineau and Palmer (2013) and Vijver and van den Brink (2014). Morrissey's analysis covered 214 toxicity tests for acute and chronic exposure to imidacloprid, acetamiprid, clothianidin, dinotefuran, thiacloprid and thiamethoxam for 48 species of aquatic invertebrate species from 12 orders (Crustacea: Amphipoda (11.7\% of tests), Cladocera (21.0\%), Decapoda (1.9\%), Isopoda (4.2\%), Mysida (7.9\%), Podocopida (12.6\%), Insecta: Diptera (22.9\%), Ephemeroptera (6.5\%), Hemiptera (3.7\%), Megaloptera (1.9\%), Odonata (1.9\%), Trichoptera (3.3\%)) from peer-reviewed and government studies. Both $\mathrm{LC}_{50}$ and $\mathrm{ED}_{50}$ values were included. Acute and chronic toxicity of neonicotinoids vary greatly across aquatic invertebrates with differences of six orders of magnitude observed (Fig. 8). In general, insects were more sensitive than crustaceans; in particular, the Ephemeroptera (mayflies), Trichoptera (caddisflies) and Diptera (flies, most specifically the midges, Chironomidae) were highly sensitive.

The Cladoceran water flea D. magna was the most commonly used model organism, represented in 34 of the 214 toxicity tests $(16 \%)$. Its widespread use is because of its position as a global industry standard for the majority (82\%) of commercial chemicals tested (Sánchez-Bayo 2006). It shows a wide variation in sensitivity to neonicotinoids, but the mean short-term $\mathrm{L}[\mathrm{E}] \mathrm{C}_{50}$ is at least two to three orders of magnitude greater than for all other tested invertebrate groups (Fig. 8). This has been highlighted by several authors (e.g. Beketov and Liess 2008) who argue that given the low sensitivity of D. magna to neonicotinoids, a different model organism such as a Dipteran should be selected when conducting tests on this class of pesticide. This is illustrated by the most recent study to calculate $\mathrm{LC}_{50}$ s for a range of aquatic invertebrates that was not included in Morrissey's review. de Perre et al. (2015) found no sublethal or lethal effects of clothianidin on D. magna at concentrations of over $500 \mu \mathrm{g} / \mathrm{L}$. In contrast, C. dilutus showed $\mathrm{EC}_{50}$ effects at $1.85 \mu \mathrm{g} / \mathrm{L}$ and $\mathrm{LC}_{50}$ effects at $2.32 \mu \mathrm{g} / \mathrm{L}$, in line with previous findings (Fig. 8). 


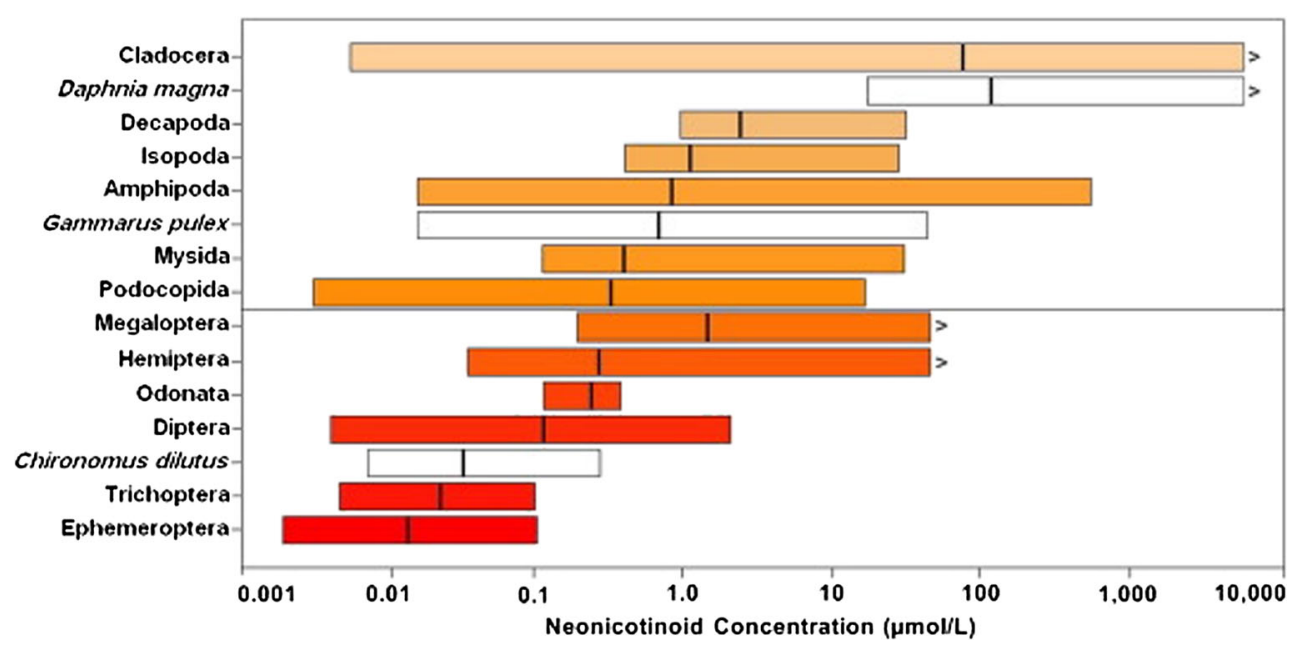

Fig. 8 Range of neonicotinoid toxicity $\left(\mathrm{L}[\mathrm{E}] \mathrm{C}_{50}, 24-96 \mathrm{~h}\right.$ in $\mu \mathrm{mol} / \mathrm{L}$, both lethal and sublethal values included) among all tested aquatic invertebrate orders. For context, three of the most common test species (white bars) for the orders Cladocera (Daphnia magna), Amphipoda (Gammarus pulex) and Diptera (Chironomus dilutus) are shown to illustrate differences in sensitivity by species. Vertical lines within bars represent geometric means of test values. Concentrations are given as molar equivalents micromoles per litre to standardise for the variable molecular weights of the different neonicotinoids. Back conversions to concentrations in micrograms per litre ( $\mathrm{ppb}$ ) can be obtained by multiplying the molar concentration by the molar weight of the neonicotinoid compound. Reproduced from Morrissey et al. 2015
Kunce et al. (2015) also investigated the impacts of neonicotinoids on the similar $C$. riparius. First instar midge larvae were exposed to thiacloprid and imidacloprid at $50 \%$ of the 96-h LC $\mathrm{L}_{50} \mathrm{~s}$ reported in the literature, corresponding to $2.3 \mu \mathrm{g} / \mathrm{L}$ for thiacloprid and $2.7 \mu \mathrm{g} / \mathrm{L}$ for imidacloprid. Three-day-old larvae were pulse exposed to these concentrations for $1 \mathrm{~h}$ then transferred to clean water and allowed to develop normally. The 1-h exposure to thiacloprid significantly decreased the proportion of larvae surviving to adulthood from $94 \%$ in the control to $68 \%$. However, imidacloprid alone and thiacloprid and imidacloprid combined had no observable effect. No difference on adult egg production levels was detected.

These recent studies in conjunction with the review of Morrissey et al. strongly support the position that insect larvae are most sensitive to neonicotinoids in aquatic environments. Morrissey et al. conclude that chronic neonicotinoid concentrations of over $0.035 \mu \mathrm{g} / \mathrm{L}$ or acute concentrations of over $0.200 \mu \mathrm{g} / \mathrm{L}$ can affect the most sensitive aquatic invertebrate species. This finding is consistent with the value suggested by Vijver and van den Brink (2014) of 0.013-0.067 $\mu \mathrm{g} / \mathrm{L}$ for imidacloprid. A number of water quality reference values have been published by governmental regulatory bodies and independent researchers in Europe and North America (Table 8). Most of these studies are based on assessments for imidacloprid only. Values for acceptable long-term concentrations vary by three orders of magnitude from $0.0083 \mu \mathrm{g} / \mathrm{L}$ in the Netherlands (RIVM 2014; Smit et al. 2014) to $1.05 \mu \mathrm{g} / \mathrm{L}$ in the USA (US EPA 2014a). There is considerable difference in the methodologies used to calculate these reference values, with the US EPA value likely to have been strongly based on results from D. magna, a species known to have relatively low sensitivity to neonicotinoids (Morrissey et al. 2015).
Current levels of neonicotinoids in aquatic habitats regularly exceed this threshold, as discussed in "Levels of neonicotinoid contamination found in waterbodies" section. Combining the review of Morrissey et al. (2015) with recent publications, a total of $65.3 \%$ of studies (17/26) report average neonicotinoid concentrations over the $0.035 \mu \mathrm{g} / \mathrm{L}$ chronic threshold and $73.5 \%$ of studies (25/34) report peak concentrations over the $0.200 \mu \mathrm{g} / \mathrm{L}$ acute threshold. The number of countries that have been studied and their widespread distribution (Australia, Brazil, Canada, China, Hungary, Japan, the Netherlands, Sweden, Switzerland, the USA and Vietnam) indicates the widespread contamination of watercourses of all kinds with levels of neonicotinoids known to be harmful to sensitive aquatic invertebrates. This is now a chronic global problem, likely to be impacting significantly on aquatic insect abundance and on food availability for their predators, including fish, birds and amphibians.

\section{Sensitivity of birds and bats to neonicotinoids}

Gibbons et al. (2015) reviewed the direct and indirect effects of neonicotinoids and fipronil on vertebrate wildlife including mammals, fish, birds, amphibians and reptiles. $\mathrm{LD}_{50}$ values for imidacloprid, clothianidin and fipronil are available for 11 species of bird (Table 9). There is considerable variation in the lethality of these compounds to birds, both between bird species and pesticide type. Using US EPA (2012) classifications for toxicity (see legend for Table 9), imidacloprid ranged from moderately toxic to highly toxic, clothianidin from practically non-toxic to moderately toxic and fipronil from practically non-toxic to highly toxic. Many of these studied bird species are granivorous and can be expected to feed on sown seeds shortly after the sowing period. Theoretical levels of 
Table 8 Summary of published ecological quality reference values for neonicotinoids (imidacloprid except this review) in freshwater environments against which average (chronic or long-term) or maximum (acute or peak) exposure concentrations are to be compared

\begin{tabular}{|c|c|c|c|}
\hline Source & $\begin{array}{l}\text { Average } \\
\text { concentration } \\
(\mu \mathrm{g} / \mathrm{L})\end{array}$ & $\begin{array}{l}\text { Maximum } \\
\text { concentration } \\
(\mu \mathrm{g} / \mathrm{L})\end{array}$ & Justification \\
\hline US EPA (2014a) USA & 1.05 & 35.0 & Aquatic life benchmark - methodology uncertain \\
\hline CCME (2007) Canada & 0.23 & & $\begin{array}{l}\mathrm{EC}_{15} \text { for the most sensitive of two freshwater species tested with } \\
\text { assessment factor of } 10 \text { applied }\end{array}$ \\
\hline $\begin{array}{l}\text { EFSA (2008) European } \\
\text { Union }\end{array}$ & & 0.2 & $\begin{array}{l}\text { No Observable Effect Concentration (NOEC) }(0.6 \mu \mathrm{g} / \mathrm{L}) \text { from a } 21 \text {-day } \\
\text { German microcosm study to which an assessment factor of } 1-3 \text { has } \\
\text { been applied based on expert deliberations }\end{array}$ \\
\hline RIVM (2008) Netherlands & 0.067 & & $\begin{array}{l}\text { Maximum permissible concentration (MPC) for long-term exposure derived } \\
\text { from the lowest NOEC value for chronic toxicity studies with assessment } \\
\text { factor of } 10 \text { applied }\end{array}$ \\
\hline Morrissey et al. (2015) & 0.035 & 0.2 & $\begin{array}{l}\text { Lower confidence interval of } \mathrm{HC}_{5} \text { from SSDs generated using } 137 \text { acute } \\
\left(\mathrm{LC}_{50}\right) \text { and } 36 \text { chronic }\left(\mathrm{L}[\mathrm{E}] \mathrm{C}_{50}\right) \text { toxicity tests considering all neonicotinoid } \\
\text { compounds weighted and standardised to imidacloprid and all available } \\
\text { test species }\end{array}$ \\
\hline $\begin{array}{l}\text { RIVM (2014) Netherlands } \\
\quad \text { (see Smit et al. 2014) }\end{array}$ & 0.0083 & & $\begin{array}{l}\text { Updated MPC for long-term exposure derived from chronic studies } \\
\text { using species sensitivity distribution }(\mathrm{SSD}) \text { approach and Hazard } \\
\text { Concentration }\left(\mathrm{HC}_{5}\right) \text { applied to } \mathrm{NOEC} / \mathrm{LC}_{10} / \mathrm{EC}_{10} \text { values with } \\
\text { assessment factor of } 3 \text { applied }\end{array}$ \\
\hline Mineau and Palmer (2013) & 0.0086 or 0.029 & & $\begin{array}{l}\text { The higher of two empirically-determined acute-chronic ratios applied to } \\
\text { the most sensitive of } 8 \text { aquatic species tested to date; or } \mathrm{HC}_{5} \text { from } \\
\text { SSD applied using NOECs from chronic studies of } 7 \text { single species a } \\
\text { nd } 1 \text { species assemblage }\end{array}$ \\
\hline
\end{tabular}

Reference values are placed in descending order. Reproduced from Morrissey et al. (2015)

seed consumption necessary to cause mortality were calculated by Goulson (2013); see "Risk from non-flowering crops and cropping stages prior to flowering" section.

In addition to lethal effects, several studies have identified sublethal effects of neonicotinoid ingestion on birds (Table 10). House sparrows can become uncoordinated and unable to fly, and studies of Japanese quail and red-legged partridges have reported DNA breakages and a reduced immune response, respectively. Many of these sublethal effects occur at lower concentrations than the lethal dose. A single oral dose of $41,000,000 \mathrm{ng} / \mathrm{g}$ of imidacloprid will cause mortality in house sparrows; a substantially lower dose $(6000,000 \mathrm{ng} / \mathrm{g})$ can induce uncoordinated behaviour and an inability to fly (Cox 2001). Whilst imidacloprid is highly toxic to Japanese quail, with an $\mathrm{LD}_{50}$ of $31,000,000 \mathrm{ng} / \mathrm{g}$, chronic daily doses of $1000,000 \mathrm{ng} / \mathrm{g} /$ day can lead to testicular anomalies, DNA damage in males and reductions in embryo size when those males are mated with control females (Tokumoto et al. 2013).

In addition to the studies reviewed by Gibbons et al., one additional study is available that assessed the impact of neonicotinoid ingestion on birds. Lopez-Anita et al. (2015) fed red-legged partridge Alectoris rufa imidacloprid-treated wheat seeds for a period of 25 days in the autumn and an additional period of 10 days in the spring, matching the pattern of cereal cropping in Spain. One treatment contained seeds treated at the recommended dosage rate and the second at $20 \%$ of the recommended rate, to mimic a diet composed of $20 \%$ of treated seeds. Treated seeds contained concentrations of imidacloprid of $140,000-700,000 \mathrm{ng} / \mathrm{g}$ at the two dose rates. As the $400 \mathrm{~g}$ partridges used in this study consume around $25 \mathrm{~g}$ of seeds a day, a daily ingestion of 8800 and 44,000 ng/g/day was expected.

Imidacloprid at the highest dose killed all adult partridges in 21 days, with first deaths occurring on day 3. Mortality in the low dose and control groups was significantly lower at 18.7 and $15.6 \%$ respectively. As all partridges in the high dose died, effects on reproductive output were only measured in the low dose treatment. Compared to controls, low dose females laid significantly smaller clutches, and the time to first egg laying was also significantly increased. There was no difference in egg size, shell thickness, fertile egg rate and hatching rate. There was no detectable impact on chick survival, chick growth or sex ratio between these two groups. These results are in line with previous findings for lethal (Table 9) and sublethal (Table 10) effects of neonicotinoid consumption by birds. Whilst $\mathrm{LD}_{50} \mathrm{~S}$ vary across two orders of magnitude from 11,300 to $>2000,000 \mathrm{ng} / \mathrm{g}$, sublethal effects are seen across a more consistent range of doses over one order of magnitude between 1000 and 53,000 ng/g. The greatest outstanding issue is that no data exist that quantify the actual exposure rate to granivorous birds from neonicotinoidtreated seeds. As such, it is difficult to judge whether these clearly demonstrated lethal and sublethal effects are manifested in wild bird populations in the field. 
Table 9 Single (acute) dose $\mathrm{LD}_{50}$ for bird species $(\mathrm{ng} / \mathrm{g})$ for imidacloprid, clothianidin and fipronil

\begin{tabular}{|c|c|c|c|}
\hline Species & Pesticide & $\mathrm{LD}_{50}$ & Reference \\
\hline Mallard, Anas platyrhynchos & Imidacloprid & $283,000(\mathrm{MT})$ & Fossen (2006) \\
\hline Grey partridge, Perdix perdix & Imidacloprid & $13,900(\mathrm{HT})$ & Anon (2012) \\
\hline $\begin{array}{l}\text { Northern bobwhite quail, Colinus } \\
\text { virginianus }\end{array}$ & Imidacloprid & $152,000(\mathrm{MT})$ & SERA (2005) \\
\hline Japanese quail, Coturnix japonica & Imidacloprid & $31,000(\mathrm{HT})$ & SERA (2005) \\
\hline Feral pigeon, Columba livia & Imidacloprid & $25,000-50,000(\mathrm{HT})$ & SERA (2005) \\
\hline House sparrow, Passer domesticus & Imidacloprid & $41,000(\mathrm{HT})$ & SERA (2005) \\
\hline Canary, Serinus canaria & Imidacloprid & $25,000-50,000(\mathrm{HT})$ & SERA (2005) \\
\hline Mallard, Anas platyrhynchos & Clothianidin & $>752,000(\mathrm{ST})$ & $\begin{array}{l}\text { European Commission } \\
\quad(2005)\end{array}$ \\
\hline $\begin{array}{l}\text { Northern bobwhite quail, Colinus } \\
\text { virginianus }\end{array}$ & Clothianidin & $>2000,000(\mathrm{PNT})$ & $\begin{array}{l}\text { Mineau and Palmer } \\
\text { (2013) }\end{array}$ \\
\hline Japanese quail, Coturnix japonica & Clothianidin & $423,000(\mathrm{MT})$ & $\begin{array}{l}\text { Mineau and Palmer } \\
\text { (2013) }\end{array}$ \\
\hline Mallard, Anas platyrhynchos & Fipronil & $2,150,000(\mathrm{PNT})$ & Tingle et al. (2003) \\
\hline $\begin{array}{l}\text { Ring-necked pheasant, Phasianus } \\
\text { colchicus }\end{array}$ & Fipronil & $31,000(\mathrm{HT})$ & Tingle et al. (2003) \\
\hline Red-legged partridge, Alectoris rufa & Fipronil & $34,000(\mathrm{HT})$ & Tingle et al. (2003) \\
\hline $\begin{array}{l}\text { Northern bobwhite quail, Colinus } \\
\text { virginianus }\end{array}$ & Fipronil & $11,300(\mathrm{HT})$ & Tingle et al. (2003) \\
\hline Feral pigeon, Columba livia & Fipronil & $>2000,000(\mathrm{PNT})$ & Tingle et al. (2003) \\
\hline Field sparrow, Spizella pusilla & Fipronil & $1,120,000(\mathrm{ST})$ & Tingle et al. (2003) \\
\hline Zebra finch, Taeniopygia guttata & Fipronil & $310,000(\mathrm{MT})$ & Kitulagodage et al. (2008) \\
\hline
\end{tabular}

Toxicity classification follows US EPA (2012): PNT practically non-toxic, $S T$ slightly toxic, $M T$ moderately toxic, $H T$ highly toxic, VHT very highly toxic. For birds: PNT $>2000$, ST 501-2000, MT 51-500, HT 10-50, VHT<10. Reproduced from Gibbons et al. (2015)
In addition to sublethal and lethal effects potentially caused by the ingestion of neonicotinoids from treated seeds, bird populations may also be affected by a reduction in invertebrate prey. Hallmann et al. (2014) used bird population data from the Dutch Common Breeding Bird Monitoring Scheme, a standardised recording scheme that has been running in the Netherlands since 1984. Surface water quality measurements are also regularly collected across the Netherlands, including data on imidacloprid levels. Hallmann et al. compared surface water imidacloprid levels between 2003 and 2009 with bird population trends for 15 farmland bird species that are insectivorous at least during the breeding season to assess the hypothesis that neonicotinoids may cause bird population declines through a reduction in invertebrate food availability. The average intrinsic rate of increase in local farmland bird populations was significantly negatively affected by the concentration of imidacloprid. At the individual level, 14 of the 15 bird species showed a negative response to imidacloprid concentrations, with 6 out of 15 showing a significant negative response. As previously discussed in "Sensitivity of butterflies and moths to neonicotinoids" section, it is difficult to disentangle the effects of neonicotinoids from the effects of general agricultural intensification. Hallmann et al. attempt to control for proxy measures of intensification including changes in land use area, areas of cropped land and fertiliser input, but imidacloprid levels remained a significant negative predictor.

The only available study that has quantified changes in invertebrate prey availability after neonicotinoid treatment and concurrent changes in the bird community was conducted in the USA. Falcone and DeWald (2010) measured invertebrates in eastern hemlock Tsuga canadensis forests in Tennessee after trees have been treated with imidacloprid to control hemlock woolly adelgid Adelges tsugae. The imidacloprid treatment had a significantly negative effect on non-target Hemiptera and larval Lepidoptera. However, there was no corresponding decline in insectivorous bird density between treatments. Direct comparison between this study and the findings of Hallmann et al. 2014 are difficult due to the very different ecological conditions. It is likely sufficient untreated areas existed in hemlock forests for insectivorous birds to find sufficient forage. In the Netherlands, one of the most agriculturally intensified regions in the world, unaffected semi-natural habitat is scarce and a reduction in prey availability caused by neonicotinoid application would have a more severe impact.

No studies are available that measure the effect of neonicotinoids on bats and bat populations. A link between neonicotinoid use and declining farmland butterfly 


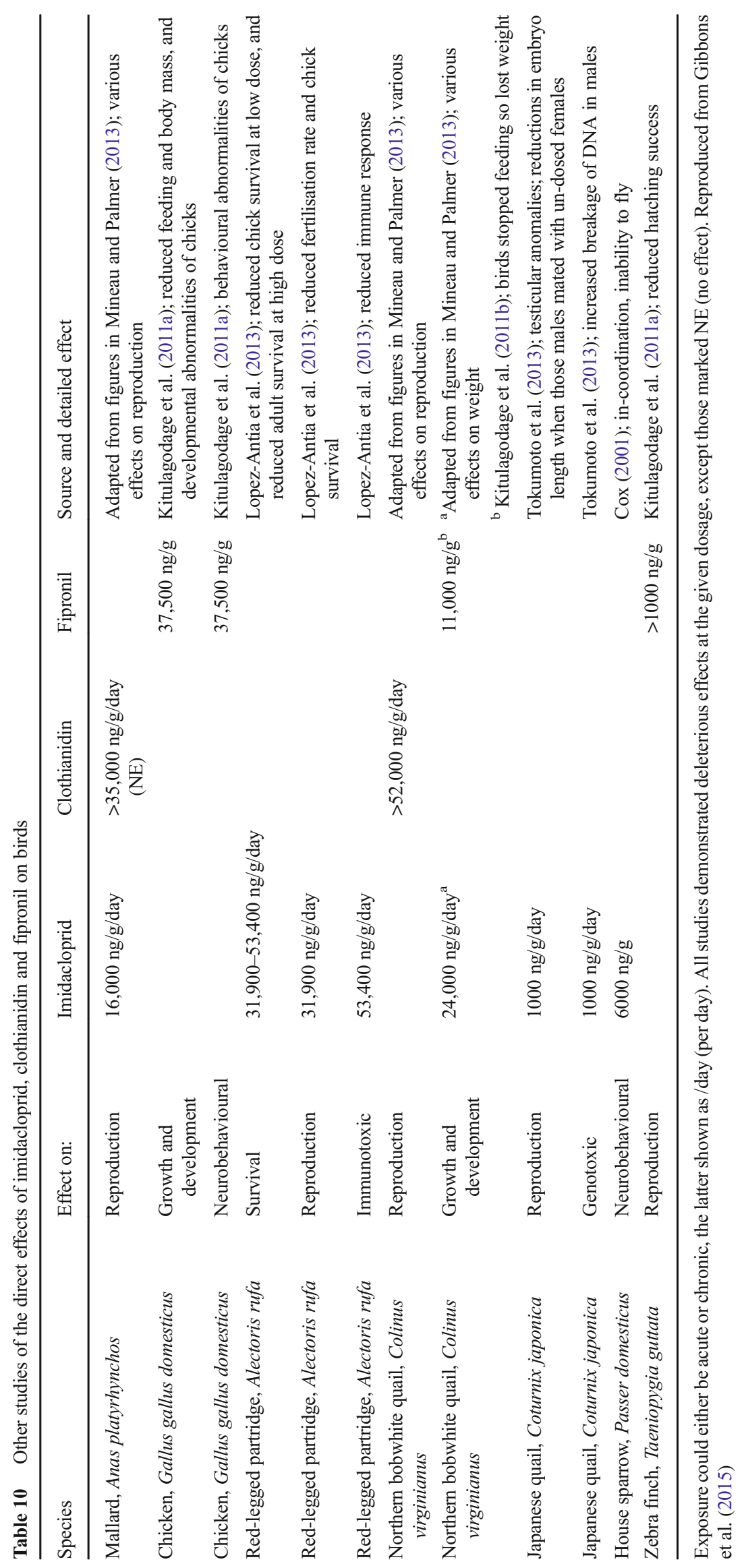


populations has been suggested (Gilburn et al. 2015; Forister et al. 2016), and given the ecological similarity between butterflies and moths, a similar trend may be ongoing, though this has not yet been investigated. Many bat species feed on moths, so a reduction in the moth population is likely to impact bat populations through a reduction in food availability. Mason et al. (2014) link neonicotinoid use with an increase in the frequency of bat diseases such as White Nose Syndrome (caused by the fungus Geomyces destructans) in both the USA and Europe. They hypothesise that consumption of neonicotinoid residues in insect prey weakens the immune system of bats. However, no evidence is presented demonstrating the presence of neonicotinoid residues in moths or bats or a passage across these trophic levels or that exposure to neonicotinoids weaken the immune system of bats, resulting in increased rates of fungal infection. The position of Mason et al. must currently be considered unsupported.

\section{Synergistic effects of additional pesticides with neonicotinoids}

The EFSA (2013a, b, c) risk assessments for clothianidin, imidacloprid and thiamethoxam considered these pesticides and their impacts on honeybees individually. In the field, multiple neonicotinoids, other insecticides and other pesticides such as herbicides and fungicides are commonly applied to a single crop. Bees are frequently exposed to complex mixtures of pesticides, with 19 detected in trap-caught bees from an agricultural region of Colorado (Hladik et al. 2016). It is possible that combinations of neonicotinoids and other pesticides may have antagonistic (become less effective), additive (equivalent to adding together existing effectiveness) or synergistic (multiplicative) effects. Morrissey et al. (2015) briefly listed known examples of synergistic effects between neonicotinoids and other pesticides. Several examples have been demonstrated by pesticide companies themselves. For example, Bayer demonstrated that the combination of clothianidin and the fungicide trifloxystrobin resulted in a 150-fold increase in kill rate to Phaedon leaf beetle larvae over clothianidin alone (Wachendorff-Neumann et al. 2012). Bayer scientists also demonstrated that treatments of $8000 \mathrm{ppb}$ of thiacloprid and $8000 \mathrm{ppb}$ of clothianidin resulted in aphid population kill rates of 25 and $0 \%$ after 6 days. Combining the two increased the kill rate to $98 \%$ (Andersch et al. 2010). Specifically for honeybees, Iwasa et al. (2004) demonstrated that the combination of thiacloprid with the fungicide propiconazole increased the toxicity of the mixture several hundred fold. Whilst synergies have been demonstrated, few environmental risk assessments have been made for neonicotinoids in combination with other pesticides.

Since 2013, a number of studies have investigated possible synergistic effects in neonicotinoids. Several have focused on the interaction between neonicotinoids and ergosterol biosynthesis inhibitor (EBI) fungicides (which include propiconazole) and their impact on bees. Biddinger et al. (2013) studied the interaction between the contact toxicity of acetamiprid, imidacloprid and the fungicide fenbuconazole, a substance virtually non-toxic to bees (except at extremely high concentrations), using A. mellifera and Japanese orchard bees Osmia cornifrons. These pesticides are commonly found together in tank mixes used in orchards. The doses ranged from 1.38 to $60 \mu \mathrm{g} /$ bee $1: 1$ acetamiprid plus fenbuconazole mixture and 0.86 to $983 \mu \mathrm{g} /$ bee $2: 1$ imidacloprid plus fenbuconazole mixture. At $\mathrm{LD}_{50}$, the acetamiprid and fenbuconazole mixture was $\sim 5$ times more toxic than acetamiprid alone for A. mellifera and $\sim 2$ times more toxic than acetamiprid for $O$. cornifrons. However, these doses are exceptionally high, for example the $0.86 \mu \mathrm{g} / \mathrm{bee}$ imidacloprid/fenbuconazole mixture is equivalent to $567.6 \mathrm{ng} / \mathrm{bee}$, with the A. mellifera contact toxicity to imidacloprid $\mathrm{LD}_{50}$ calculated as $81 \mathrm{ng} / \mathrm{bee}$ ("Sensitivity of bumblebees and solitary bees to neonicotinoids" section). Unsurprisingly, this dose killed $85 \%$ of honeybees in this treatment. At unrealistically high concentrations, it is not clear how informative these results are.

Thompson et al. (2014) investigated synergies between several EBI fungicides (flusilazole, propiconazole, myclobutanil and tebuconazole) and a range of neonicotinoids (clothianidin, thiacloprid, imidacloprid and thiamethoxam) on A. mellifera. Individual pesticides and mixtures of one neonicotinoid and one fungicide were administered through both contact and ingestion at a range of concentrations sufficient to increase mortality, and bees were observed for a 96-h period. $\mathrm{LD}_{50} \mathrm{~s}$ were calculated after $48 \mathrm{~h}$ as mortality did not significantly increase after this point. Single neonicotinoid and fungicide doses showed similar toxicity to previous published results, with no individual fungicide causing toxic effects even at concentrations of $22.4 \mu \mathrm{g} / \mathrm{bee}$.

For neonicotinoid/fungicide mixtures, neonicotinoids were applied at calculated $\mathrm{LD}_{50} \mathrm{~s}$, in the region of $0.035-0.124 \mu \mathrm{g} /$ bee for clothianidin, imidacloprid and thiamethoxam and $122.4 \mu \mathrm{g} / \mathrm{b}$ ee for thiacloprid (cyano-substituted neonicotinoids having lower toxicity to bees, "Direct lethality of neonicotinoids to adult wild bees" section). Fungicides were applied at doses of between 0.161 and $0.447 \mu \mathrm{g} / \mathrm{bee}$ depending on the particular compound. These values were calculated as realistic worst-case exposures based on approved application rates for UK crops. For these mixtures, a synergy ratio was calculated where the $\mathrm{LD}_{50}$ of the neonicotinoid was divided by the $\mathrm{LD}_{50}$ of the neonicotinoid plus fungicide mixture. Consequently, a value of over 1 indicates that the mixture was more toxic and a value under 1 indicates that the mixture was less toxic. Combinations of fungicides with thiacloprid and clothianidin showed negligible synergy for contact toxicity, with an average synergism ratio of 0.30 and 1.07 
respectively. Imidacloprid and thiamethoxam were higher at 1.53 and 2.02. For oral toxicity, thiacloprid and imidacloprid showed low synergy at 0.60 and 0.48 whereas clothianidin and thiamethoxam were higher at 1.52 and 1.31 respectively. Only two combinations showed significant synergy, for a contact dose of tebuconazole and thiamethoxam with a synergy of 2.59 and for an oral dose of clothianidin and tebuconazole at a synergy of 1.90 .

Sgolastra et al. (2016) investigated the interaction between clothianidin and the fungicide propiconazole in three bee species, A. mellifera, B. terrestris and O. bicornis. Each species was administered a $\mathrm{LD}_{10}$ dose of clothianidin $(0.86,1.87$ and $0.66 \mathrm{ng} /$ bee respectively; see "Direct lethality of neonicotinoids to adult wild bees" section for more details), a non-lethal dose of propiconazole ( $7 \mu \mathrm{g} / \mathrm{bee})$ and a combination of the two treatments. Bees were then observed for a $96-\mathrm{h}$ period and mortality quantified. Some synergistic effects were seen. In A. mellifera, mortality was significantly higher for the combined dose in the first two time periods (4 and $24 \mathrm{~h}$ ). Mortality in $B$. terrestris for the combined dose was only significantly higher in the first time period, after $4 \mathrm{~h}$. However, in O. bicornis, exposure to the combination of clothianidin and propiconazole resulted in significantly higher mortality at all time points.

Spurgeon et al. (2016) conducted similar experiments to Sgolastra et al., investigating the effect of a combination of clothianidin and propiconazole on A. mellifera, B. terrestris and $O$. bicornis. In order to calculate an $\mathrm{LD}_{50}$, clothianidin concentrations were varied and propiconazole concentrations were held at zero, a low dose and a high dose. The low dose was taken from the EFSA Panel on Plant Protection Products (2012) reported environmental concentrations, and the high dose was 10 times the low dose to represent a plausible worst case scenario, but it is not clear what these values actually are. Mortality was quantified over 48, 96 and $240 \mathrm{~h}$. For A. mellifera, clothianidin $\mathrm{LC}_{50} \mathrm{~s}$ with and without propiconazole were always within a factor of 2 , with no clear negative trend at higher propiconazole concentrations. For B. terrestris, clothianidin $\mathrm{LC}_{50} \mathrm{~s}$ with propiconazole were between 1.5 to 2 fold lower. For $O$. bicornis, clothianidin $\mathrm{LC}_{50} \mathrm{~S}$ with propiconazole was up to 2-fold lower with a negative trend as propiconazole concentrations increased. Spurgeon et al. concluded that the clothianidin and propiconazole combination had no to slight synergy for $A$. mellifera and slight to moderate synergy for $B$. terrestris and $O$. bicornis.

In an additional trial, Thompson et al. (2014) demonstrated that the dose of fungicide applied is a key factor determining neonicotinoid toxicity using propiconazole and thiamethoxam mixtures (Table 11). The authors argue that their low rates of significant synergies between neonicotinoids and fungicides was because of their lower, more field-realistic fungicide doses of $0.161-0.447 \mu \mathrm{g} / \mathrm{bee}$ compared to $10 \mu \mathrm{g} /$ bee used by Iwasa et al. (2004), an early study demonstrating this interaction. The values of $0.161-0.447 \mu \mathrm{g} / \mathrm{bee}$ were calculated as realistic worst-case exposures based on approved application rates for UK crops. However, data are lacking that demonstrate true field-realistic exposure rates to fungicides for free flying bees. Whilst studies such as Sgolastra et al. (2016) show a clear synergistic effect between fungicides and neonicotinoids on $O$. bicornis, the dose of fungicide used is more than an order of magnitude greater than that used by Thompson et al. Bees are consistently exposed to fungicides with 40 types found in honeybee pollen, wax and nectar (Sánchex-Bayo and Goka 2014). Pollen collected by bumblebees and stored in their nests has also been found to contain fungicides at average concentrations between 0.15 and $25 \mathrm{ppb}$ (EBI fungicides 0.15-17 ppb; David et al. 2016). However, almost nothing is known about how concentrations present in bee-collected material translate into acute or chronic exposure to bees. It is currently not known what fungicide doses represent a realistic situation that bees are likely to encounter in the wild, though models such as Bee-REX are attempting to bridge this gap (US EPA Agency 2014b).

In addition to work on bees, Kunce et al. (2015) investigated the impact of 1-h pulse exposure of imidacloprid and thiamethoxam and two pyrethroids, deltamethrin and esfenvalerate, in single, pairwise and combined doses on the

Table 11 Comparison of the ratio of propiconazole to the doses of thiamethoxam and the resultant $\mathrm{LD}_{50}$ in the contact and oral studies

\begin{tabular}{|c|c|c|c|c|c|c|}
\hline $\begin{array}{l}\text { Contact dose } \\
\text { propiconazole } \mu \mathrm{g} / \mathrm{bee}\end{array}$ & $\begin{array}{l}\text { Ratio fungicide/ } \\
\text { thiamethoxam contact } \mathrm{LD}_{50}\end{array}$ & $\begin{array}{l}\text { Contact } \mathrm{LD}_{50} \\
\text { thiamethoxam } \mu \mathrm{g} / \mathrm{bee}\end{array}$ & $\begin{array}{l}\text { Synergy } \\
\text { ratio }\end{array}$ & $\begin{array}{l}\text { Ratio fungicide/ } \\
\text { thiamethoxam oral } \mathrm{LD}_{50}\end{array}$ & $\begin{array}{l}\text { Oral } \mathrm{LD}_{50} \\
\text { thiamethoxam } \mu \mathrm{g} / \\
\text { bee }\end{array}$ & $\begin{array}{l}\text { Synergy } \\
\text { ratio }\end{array}$ \\
\hline 0 & - & 0.0373 & - & - & 0.0641 & - \\
\hline 0.0224 & 0.6 & 0.0288 & 1.3 & 0.349 & 0.0268 & 2.4 \\
\hline 0.224 & 6 & 0.0247 & 1.5 & 3.49 & 0.0277 & 2.3 \\
\hline 2.24 & 60 & 0.0134 & $2.8^{\mathrm{a}}$ & 34.9 & 0.0265 & 2.4 \\
\hline 22.4 & 600 & 0.0104 & $3.6^{\mathrm{a}}$ & 349 & 0.00776 & $8.3^{\mathrm{a}}$ \\
\hline
\end{tabular}

Reproduced from Thompson et al. (2014)

${ }^{a}$ Synergy ratios were significantly different 
development of the aquatic midge $C$. riparius (see "Sensitivity of aquatic invertebrates to neonicotinoids" section for more methodological and concentration details). Most pesticide treatments reduced the survival of the larvae, but the deleterious effects did not appear to be synergistically amplified by a combination of pesticides. Kunce et al. conclude that at the low doses and period of exposure used, the risk of synergistic or additive effects is very low.

Overall, these studies support the position that neonicotinoids can act synergistically with fungicides, increasing their lethality to bees. However, the dose rate of both neonicotinoids and fungicides, time of exposure, neonicotinoid and fungicide chemical class and length of time after exposure are all important explanatory factors affecting this relationship. The concentration of fungicide used in laboratory studies appears to be the most important factor determining synergistic lethality. Fungicides are regularly sprayed during the period when flowering crops are in bloom under the assumption that these compounds are safe for bees, but this work demonstrates that their toxicity is contingent on other chemical management choices at a site. Studies to date have only examined pairwise interactions between pesticides. It is clear that bees and other non-target organisms inhabiting farmland are routinely exposed to far more complex mixtures of pesticides than any experimental protocol has yet attempted to examine. For example, honeybee and bumblebee food stores commonly contain 10 or more pesticides (e.g. David et al. 2016). A major challenge for scientists and regulators is to attempt to understand how chronic exposure to complex mixtures of neonicotinoids and other chemicals affects wildlife.

\section{Concluding remarks}

\section{Advances in scientific understanding and comparison with the 2013 knowledge base}

The EFSA reports into clothianidin, imidacloprid and thiamethoxam are naturally narrow in scope, focusing specifically on the risks that these neonicotinoids pose to bees, with almost all data consisting of and referring to the honeybee Apis mellifera. Because the scope of this review is much wider, focusing on neonicotinoid persistence in the wider environment and possible impacts on many non-target organisms, a simple comparison with the EFSA reports is not possible as there is no well-defined baseline of existing knowledge prior to 2013 for most topic areas. However, it is possible to comment on the change in the scientific evidence since 2013 compared to the EFSA reports. This process is not meant to be a formal assessment of the risk posed by neonicotinoids in the manner of that conducted by EFSA. Instead, it aims to summarise how the new evidence has changed our understanding of the likely risks to bees; is it lower, similar or greater than the risk perceived in 2013? With reference to the EFSA risk assessments baseline, advances in each considered area and their impact on the original assessment can be briefly summarised thus:

- Risk of exposure from pollen and nectar of treated flowering crops. The EFSA reports calculated typical exposure from flowering crops treated with neonicotinoids as seed dressings. Considerably more data are now available in this area, with new studies broadly supporting the calculated exposure values. For bees, flowering crops pose a Risk Unchanged to that reported by EFSA (2013a, b, c).

- Risk from non-flowering crops and cropping stages prior to flowering. Non-flowering crops were considered to pose no risk to bees. No new studies have demonstrated that these non-flowering crops pose a direct risk to bees. They remain a Risk Unchanged.

- Risk of exposure from the drilling of treated seed and subsequent dust drift. Despite modification in seed drilling technology, available studies suggest that dust drift continues to occur, and that dust drift still represents a source of acute exposure and so is best considered a Risk Unchanged.

- Risk of exposure from guttation fluid. Based on available evidence, this was considered a low-risk exposure path by EFSA (2013a, b, c). New data have not changed this position, and so it remains a Risk Unchanged.

- Risk of exposure from and uptake of neonicotinoids in non-crop plants. Uptake of neonicotinoids by non-target plants was considered likely to be negligible, though a data gap was identified. Many studies have since been published demonstrating extensive uptake of neonicotinoids and their presence in the pollen, nectar and foliage of wild plants, and this source of exposure may be much more prolonged than the flowering period of the crop. Bees collecting pollen from neonicotinoidtreated crops can generally be expected to be exposed to the highest neonicotinoid concentrations, but non-trivial quantities of neonicotinoids are also present in pollen and nectar collected from wild plants. Exposure from non-target plants clearly represents a Greater Risk.

- Risk of exposure from succeeding crops. A data gap was identified for this issue. Few studies have explicitly investigated this, but this area does represent some level of risk as neonicotinoids and now known to have the potential to persist for years in the soil, and can be detected in crops multiple years after the last known application. However, as few data exist this is currently considered a Risk Unchanged.

- Direct lethality of neonicotinoids to adult bees. Additional studies on toxicity to honeybees have supported the values calculated by EFSA. More data have been produced on 
neonicotinoid toxicity for wild bee species, and metaanalyses suggest a broadly similar response. Reference to individual species is important, but neonicotinoid lethality should be broadly considered a Risk Unchanged.

- Sublethal effects of neonicotinoids on wild bees. Consideration of sublethal effects by EFSA was limited as there is no agreed testing methodology for the assessment of such effects. A data gap was identified. Exposure to neonicotinoid-treated flowering crops has been shown to have significant negative effects on free flying wild bees under field conditions, and some laboratory studies continue to demonstrate negative effects on bee foraging ability and fitness using field-realistic neonicotinoid concentrations. Greater Risk.

Within this context, research produced since 2013 suggest that neonicotinoids pose a similar to greater risk to wild and managed bees, compared to the state of play in 2013. Given that the initial 2013 risk assessment was sufficient to impose a moratorium on the use of neonicotinoids on flowering crops, and given that new evidence either confirms or enhances evidence of risk to bees, it is logical to conclude that the current scientific evidence supports the extension of the moratorium.

In addition to the use of neonicotinoids on flowering crops, research since 2013 has demonstrated neonicotinoid migration into and persistence in agricultural soils, waterways and constituent parts of non-crop vegetation. Where assessments have been made of concentrations likely to significantly negatively affect non-target organisms, levels have been demonstrated to be above these thresholds in numerous non-crop agricultural habitats.

The strongest evidence for this is found in waterbodies surrounding agricultural areas, both temporary and permanent. The impact of neonicotinoids on aquatic organisms appears to be the easiest to quantify, as field-realistic concentrations can be easily obtained through sample collection and once neonicotinoids are present in waterbodies, aquatic organisms cannot limit their exposure to them. In contrast, assessing the field-realistic exposure of bees to neonicotinoids is much harder, as it will depend on numerous factors including but not limited to the type of flowering crop, its relative attractiveness compared to existing available forage, the crop type and levels of neonicotinoid loss into the wider environment through seed dust and leaching, soil type and organic content and consequent retention of neonicotinoid active ingredient, uptake of neonicotinoids by surrounding vegetation and relative collection of pollen and nectar from various wild plants containing variable levels of neonicotinoids at different parts of the year. In addition, wild and managed bees have traits such as flight period, floral choice preferences and social structure that vary radically between different bee species, as can be clearly seen in the three most commonly used bee model organisms A. mellifera, B. terrestris and O. bicornis. As such, it is much more difficult to gain a completely accurate and consistent measure of neonicotinoid exposure for taxa such as these.

However, whilst these aforementioned factors are all important, it is still possible to comment on likely outcomes based on average exposure levels across a range of studies. This is as true for other taxa as it is for bees. Given these caveats, it is clear that since 2013, new research has substantially advanced our understanding of the effect of neonicotinoids on non-target organisms in the following areas:

- Non-flowering crops treated with neonicotinoids can pose a risk to non-target organisms through increasing mortality in beneficial predator populations.

- Neonicotinoids can persist in agricultural soils for several years, leading to chronic contamination and, in some instances, accumulation over time.

- Neonicotinoids continue to be found in a wide range of different waterways including ditches, puddles, ponds, mountain streams, rivers, temporary wetlands, snowmelt and groundwater and in outflow from water processing plants.

- Reviews of the sensitivity of aquatic organisms to neonicotinoids show that many aquatic insect species are several orders of magnitude more sensitive to these compounds than the traditional model organisms used in regulatory assessments for pesticide use.

- Neonicotinoids have been shown to be present in the pollen, nectar and foliage of non-crop plants adjacent to agricultural fields. This ranges from herbaceous annual weeds to perennial woody vegetation. We would thus expect non-target herbivorous insects and non-bee pollinators inhabiting field margins and hedgerows to be exposed to neonicotinoids. Of particular concern, this includes some plants sown adjacent to agricultural fields specifically for the purposes of pollinator conservation.

- Correlational studies have suggested a link between neonicotinoid usage in agricultural areas and population metrics for butterflies, bees and insectivorous birds in three different countries.

\section{Existing knowledge gaps and future research}

Whilst much research has been conducted on neonicotinoid pesticides and their impact on non-target organisms since 2013, a number of key knowledge gaps exist. As stated by Godfray et al. (2015) in their update on the existing scientific literature concerning neonicotinoids and insect pollinators, it is important to remember that major gaps in our understanding occur and different policy conclusions can be drawn depending on the weight given to important (but not definitive) scientific findings and the economic and other interests of 
different stakeholders. This review is not intended as a risk assessment, simply as a review of advances in our scientific understanding of the environmental risks that neonicotinoids pose.

From the perspective of better understanding the impacts of neonicotinoids on non-target organisms, further research is needed in the following areas:

- Whilst the impacts of neonicotinoids on bees have been relatively well studied, few data exist for most taxa. The sensitivity of non-pest herbivorous taxa and important natural enemies of crop pests to neonicotinoids are particularly poorly understood.

- Continue to improve our understanding of realistic neonicotinoid and other pesticide exposure in agricultural and non-agricultural areas for understudied taxa. The implications of laboratory studies assessing the lethal and sublethal impacts of neonicotinoids are unclear without a realistic baseline for comparison with real-world conditions. Data are most lacking for herbivorous, soil-dwelling, parasitic and predatory invertebrates and granivorous and insectivorous terrestrial vertebrates.

- In addition to sensitivity and exposure, the movement of neonicotinoids through trophic levels is poorly understood with the exception of a few field studies which demonstrate the principle. Some authors have linked direct neonicotinoid exposure with declines in higher trophic level organisms, but little to no data exist regarding these claims.

- Long-term datasets exist that have demonstrated recent population declines across various taxa, with the most pronounced declines correlating with neonicotinoid use. Whilst these studies are suggestive in their own right, the effects of general agricultural intensification relative to the effects of neonicotinoid pesticides must be teased apart if long-term declines in taxa are to be better understood and reversed.

- Possible synergistic and additive effects of neonicotinoids with other pesticides are still poorly understood for bees, and almost nothing is known about their effects on other non-target taxa. This problem is compounded by a lack of understanding of field-realistic exposures to the various constituent active ingredients, with different taxa likely to be receiving different doses depending on their interaction with agricultural environments.

\section{Closing statement}

Recent work on neonicotinoids continues to improve our understanding of how these compounds move through and persist in the wider environment. These water-soluble compounds are not restricted to agricultural crops, instead permeating most parts of the agricultural environments in which they are used and in some cases reaching further afield via waterways and run-off water. Field-realistic laboratory experiments and field trials continue to demonstrate that residual neonicotinoid traces can have a mixture of lethal and sublethal effects on a wide range of taxa. Relative to the risk assessments produced in 2013 for clothianidin, imidacloprid and thiamethoxam which focused on their effects on bees, new research strengthens arguments for the imposition of a moratorium on their use, in particular because it has become evident that they pose significant risks to many non-target organisms, not just bees. Given the improvement in scientific knowledge of how neonicotinoids move into the wider environment from all crop types, a discussion on the risks posed by their use on non-flowering crops and in non-agricultural areas is needed.

Open Access This article is distributed under the terms of the Creative Commons Attribution 4.0 International License (http:// creativecommons.org/licenses/by/4.0/), which permits unrestricted use, distribution, and reproduction in any medium, provided you give appropriate credit to the original author(s) and the source, provide a link to the Creative Commons license, and indicate if changes were made.

\section{References}

Alaux C, Brunet J-L, Dussaubat C, Mondet F, Tchamitchan S, Cousin M, Brillard J, Baldy A, Belzunces LP, Le Conte Y (2010) Interactions between Nosema microspores and a neonicotinoid weaken honeybees (Apis mellifera). Environ Microbiol 12:774-782

Alburaki M, Boutin S, Mercier P-L, Loubier Y, Chagnon M, Derome N (2015) Neonicotinoid-treated Zea mays seeds indirectly affect honeybee performance and pathogen susceptibility in field trials. PLoS One 10:e125790

Alburaki M, Cheaib B, Quesnel L, Mercier P-L, Chagnon M, Derome N (2016) Performance of honeybee colonies located in neonicotinoidtreated and untreated cornfields in Quebec. J Appl Entomol 141: $112-121$

Andersch W, Jeschke P, Thielert W (2010) Combination of methiocarb and one or more compounds selected from thiacloprid, thiamethoxam, acetamiprid, nitenpyram, and dinotefuran; effective animal pests control and for plant seed dressing. Google Patents. United States: Bayer CropScience AG

Anderson TA, Salice CJ, Erickson RA, McMurray ST, Cox SB, Smith LM (2013) Effects of landuse and precipitation on pesticides and water quality in playa lakes of the southern high plains. Chemosphere 92:84-90

Anderson JC, Dubetz C, Palace VP (2015) Neonicotinoids in the Canadian aquatic environment: a literature review on current use products with a focus on fate, exposure, and biological effects. Sci Total Environ 505:409-422

Anon (2012) Addendum 7 to the draft assessment report; confirmatory data; imidacloprid. European Food Safety Authority, Parma

Arce AN, David TI, Randall EL, Rodrigues AR, Colgan TJ, Wurm Y, Gill RJ (2016) Impact of controlled neonicotinoid exposure on bumblebees in a realistic field setting. J Appl Ecol. doi:10.1111/1365-2664. 12792 
Arena M, Sgolastra F (2014) A meta-analysis comparing the sensitivity of bees to pesticides. Ecotoxicology 23:324-334

Aufauvre J, Biron DG, Vidau C, Fontbonne R, Roudel M, Diogon M, Vigues B, Belzunces LP, Delbac F, Blot N (2012) Parasiteinsecticide interactions: a case study of Nosema ceranae and fipronil synergy on honeybee. Sci Rep 2:326

Barbieri RF, Lester PJ, Miller AS, Ryan KG (2013) A neurotoxic pesticide changes the outcome of aggressive interactions between native and invasive ants. Proc R Soc B 280:20132157

Beketov MA, Liess M (2008) Acute and delayed effects of the neonicotinoid insecticide thiacloprid on seven freshwater arthropods. Environ Toxicol Chem 27:461-470

Benton EP, Grant JF, Mueller TC, Webster RJ, Nicholls RJ (2016) Consequences of imidacloprid treatments for hemlock woolly adelgid on stream water quality in the southern Appalachians. For Ecol Manag 360:152-158

Biddinger DJ, Robertson JL, Mullin C, Frazier J, Ashcraft SA, Rajotte EG, Joshi NK, Vaughn M (2013) Comparative toxicities and synergism of apple orchard pesticides to Apis mellifera (L.) and Osmia cornifrons (Radoszkowski). PLoS One 8:e72587

Blacquière T, Smagghe G, van Gestel CAM, Mommaerts V (2012) Neonicotinoids in bees: a review on concentrations, side-effects and risk assessment. Ecotoxicology 21:973-992

Bonmatin J-M, Moineau I, Charvet R, Colin ME, Fleche C, Bengsch ER (2005) Behaviour of imidacloprid in fields. Toxicity for honey bees. In: Lichtfouse E, Schwarzbauer J, Robert D (eds) Environmental chemistry. Springer, Berlin, pp 483-494

Bonmatin J-M, Marchand PA, Cotte JF, Aajoud A, Casabianca H, Goutailler G, Courtiade M (2007) Bees and systemic insecticides (imidacloprid, fipronil) in pollen: subnano uantification by HPLC/MS/MS and GC/MS. In: Del Re AAM, Capri E, Fragoulis TM (eds) Environmental fate and ecological effects of pesticide. La Goliardica Pavese, Pavia, pp 827-824

Bonmatin J-M, Giorio C, Girolami V et al (2015) Environmental fate and exposure; neonicotinoids and fipronil. Environ Sci Pollut Res 22: $35-67$

Bortolotti, L., Sabatini, A.G., Mutinelli, F., Astuti, M., Lavazza, A., Piro, R., Tesoriero, D., Medrzycki, P., Sgolastra, F. and Porrini, C. (2009) Spring honeybee losses in Italy. Julius-Kühn Archiv. In: Proceedings 10th international symposium ICP-BR bee protection group "Hazards of pesticides to bees", Bucharest, Romania, 8-10 Oct 2008, vol 423, pp 148-152

Botías C, David A, Horwood J, Abdul-Sada A, Nicholls E, Hill E, Goulson D (2015) Neonicotinoid residues in wildflowers, a potential route of chronic exposure for bees. Environ Sci Technol 49: $12731-12740$

Botías C, David A, Hill E, Goulson D (2016) Contamination of wild plants near neonicotinoid seed-treated crops, and implications for non-target insects. Sci Total Environ 566-567:269-278

Canadian Council of Ministers of the Environment (CCME) (2007) Canadian water quality guidelines: Imidacloprid. Scientific Supporting Document. Canadian Council of Ministers of the Environment, Winnipeg

Carreck NL, Ratnieks FW (2014) The dose makes the poison: have "field realistic" rates of exposure of bees to neonicotinoid insecticides been overestimated in laboratory studies? J Apic Res 53:607-614

Casida JE, Durkin KA (2013) Neuroactive insecticides: targets, selectivity, resistance and secondary effects. Annu Rev Entomol 58:99-117

Cox C (2001) Insecticide factsheet: imidacloprid. J Pest Reform 21:1521

Cresswell JE (2011) A meta-analysis of experiments testing the effects of a neonicotinoid insecticide (imidacloprid) on honey bees. Ecotoxicology 20:149-157

Cresswell JE, Page C, Uygun M et al (2012) Differential sensitivity of honey bees and bumble bees to a dietary insecticide (imidacloprid). Zoology 115:365-371
Cresswell JE, Robert F-XL, Florance H, Smirnoff N (2014) Clearance of ingested neonicotinoid pesticide (imidacloprid) in honey bees (Apis mellifera) and bumblebees (Bombus terrestris). Pest Manag Sci 70: 332-337

Cutler GC, Scott-Dupreee CD (2014) A field study examining the effects of exposure to neonicotinoid seed-treated corn on commercial bumble bee colonies. Ecotoxicology 23:1755-1763

Cutler GC, Scott-Dupree CD, Sultan M, McFarlane AD, Brewer L (2014) A large-scale field study examining effects of exposure to clothianidin seed-treated canola on honey bee colony health, development, and overwintering success. PeerJ 2:e652

David A, Botías C, Abdul-Sada A, Nicholls E, Rotheray EL, Hill EM, Goulson D (2016) Widespread contamination of wildflower and bee-collected pollen with complex mixtures of neonicotinoids and fungicides commonly applied to crops. Environ Int 88:169-178

de Perre C, Murphy TM, Lydy MJ (2015) Fate and effects of clothianidin in fields using conservation practices. Environ Toxicol Chem 34: $258-265$

Devillers J, Decourtye A, Budzinski H, Pham-Delegue MH, Cluzeau S, Maurin G (2003) Comparative toxicity and hazards of pesticides to APIS and non-APIS bees. A chemometrical study. SAR QSAR Environ Res 14:389-403

Di Prisco G, Cavaliere V, Annoscia D, Varricchio P, Caprio E, Nazzi F, Gargiulo G, Pennacchio F (2013) Neonicotinoid clothianidin adversely affects insect immunity and promotes replication of a viral pathogen in honey bees. Proc Natl Acad Sci 110:18466-18471

Divley GP, Embrey MS, Kamel A, Hawthorne DJ, Pettis JS (2015) Assessment of chronic sublethal effects of imidacloprid on honey bee colony health. PLoS One 10:e118748

Douglas MR, Tooker JF (2015) Large-scale deployment of seed treatments has driven rapid increase in use of neonicotinoid insecticides and preemptive pest management in U.S. field crops. Environ Sci Technol 49:5088-5097

Douglas MR, Rohr JR, Tooker JF (2015) Neonicotinoid insecticide travels through a soil food chain, disrupting biological control of non-target pests and decreasing soya bean yield. J Appl Ecol 52: $250-260$

Elston C, Thompson HM, Walters KM (2013) Sublethal effects of thiamethoxam, a neonicotinoid pesticide, and propiconazole, a DMI fungicide, on colony initiation in bumblebee (Bombus terrestris) micro-colonies. Apidologie 44:563

European Commission (EC) (2004a) Review report for the active substance acetamiprid

European Commission (EC) (2004b) Review report for the active substance thiacloprid

European Commission (EC) (2005) Review report for the active substance clothianidin

European Commission (EC) (2006) Review report for the active substance thiamethoxam

European Food Safety Authority (EFSA) (2008) Conclusion regarding the peer review of the pesticide risk assessment of the active substance imidacloprid. European Food Safety Authority Scientific Report, European Food Safety Authority, Parma

European Food Safety Authority (EFSA) (2013a) Conclusion on the peer review of the pesticide risk assessment for bees for the active substance clothianidin. Eur Food Saf Authority J 11:3066

European Food Safety Authority (EFSA) (2013b) Conclusion on the peer review of the pesticide risk assessment for bees for the active substance thiamethoxam. Eur Food Saf Authority J 11:3067

European Food Safety Authority (EFSA) (2013c) Conclusion on the peer review of the pesticide risk assessment for bees for the active substance imidacloprid. Eur Food Saf Authority J 11:3068

Falcone JF, DeWald LE (2010) Comparisons of arthropod and avian assemblages in insecticide-treated and untreated eastern hemlock (Tsuga canadensis [L.] Carr) stands in great Smoky Mountains National Park, USA. For Ecol Manag 260:856-863 
Feltham H, Park K, Goulson D (2014) Field realistic doses of pesticide imidacloprid reduce bumblebee pollen foraging efficiency. Ecotoxicology 23:317-323

Food and Environment Research Agency (FERA) (2013) Effects of neonicotinoid seed treatments on bumble bee colonies under field conditions. Sand Hutton, York YO41 1LZ http://FERA.co.uk/ccss/ documents/defraBumbleBeeReportPS2371V4a.pdf

Forister ML, Cousens B, Harrison JG et al (2016) Increasing neonicotinoid use and the declining butterfly fauna of lowland California. Biol Lett 12:20160475

Fossen M (2006) Environmental fate of imidacloprid. Department of Pesticide Regulation, Sacramento, USA

Frewin AJ, Schaafsma AW, Hallett RH (2014) Susceptibility of Aphelinus certus (Hymenoptera: Aphelinidae) to neonicotinoid seed treatments used for soybean pest management. J Econ Entomol 107: $1450-1457$

Galvanho JP, Carrera MP, Moreira DDO, Erthal M, Silva CP, Samuels RI (2013) Imidacloprid inhibits behavioral defences of the leaf-cutting ant Acromyrmex subterraneus subterraneus (Hymenoptera: Formicidae). J Insect Behav 26:1-13

Gibbons D, Morrissey C, Mineau P (2015) A review of the direct and indirect effects of neonicotinoids and fipronil on vertebrate wildlife. Environ Sci Pollut Res 22:103-118

Gilburn AS, Bunnefeld N, Wilson JM, Botham MS, Brereton TM, Fox R, Goulson D (2015) Are neonicotinoid insecticides driving declines of widespread butterflies? PeerJ 3:e1402

Gill RJ, Raine NE (2014) Chronic impairment of bumblebee natural foraging behaviour induced by sublethal pesticide exposure. Funct Ecol 28:1459-1471

Gill RJ, Ramos-Rodriguez O, Raine NE (2012) Combined pesticide exposure severely affects individual- and colony-level traits in bees. Nature 491:105-108

Girolami V, Marzaro M, Vivan L, Mazzon L, Giorio C, Marton D, Tapparo A (2013) Aerial powdering of bees inside mobile cages and the extent of neonicotinoid cloud surrounding corn drillers. J Appl Entomol 1-2:35-44

Godfray HCJ, Blacquière T, Field LM et al (2014) A restatement of the natural science evidence base concerning neonicotinoid insecticides and insect pollinators. Proc R Soc B 281:20140558

Godfray HCJ, Blacquière T, Field LM et al (2015) A restatement of the natural science evidence base concerning neonicotinoid insecticides and insect pollinators. Proc R Soc B 282:20151821

Goulson D (2013) An overview of the environmental risks posed by neonicotinoid insecticides. J Appl Ecol 50:977-987

Goulson D (2014) Pesticides linked to bee declines. Nature 511:295-296

Goulson D (2015) Neonicotinoids impact bumblebee colony fitness in the field; a reanalysis of the UK's Food \& Environment Research Agency 2012 experiment. Peer J 3:e854

Goulson D, Nicholls E, Botías C, Rotheray EL (2015) Bee declines driven by combined stress from parasites, pesticides and lack of flowers. Science 347:1255957

Graystock P, Goulson D, Hughes WOH (2015) Parasites in bloom: flowers aid dispersal and transmission of pollinator parasites within and between bee species. Proc R Soc B 282:20151371

Gupta S, Gajbhiye VT, Gupta RK (2008) Soil dissipation and leaching behavior of a neonicotinoid insecticide thiamethoxam. Bull Environ Contam Toxicol 80:431-437

Hallmann CA, Foppen RPB, van Turnhout CAM, de Krooon H, Jongejans E (2014) Declines in insectivorous birds are associated with high neonicotinoid concentrations. Nature 511:341-344

Heimbach F, Russ A, Schimmer M, Born K (2016) Large-scale monitoring of effects of clothianidin dressed oilseed rape seeds on pollinating insects in Northern Germany: implementation of the monitoring project and its representativeness. Ecotoxicology 25:1630-1647. doi:10.1007/s10646-016-1724-9
Henry M, Beguin M, Requier F et al (2012) A common pesticide decreases foraging success and survival in honey bees. Science 336: 348-350

Hilton MJ, Jarvis TD, Ricketts DC (2015) The degradation rate of thiamethoxam in European field studies. Pest Manag Sci 72:388397

Hladik ML, Kolpin DW (2016) First national-scale reconnaissance of neonicotinoid insecticides in streams across the USA. Environ Chem 13:12-20

Hladik ML, Kolpin DW, Kuivila KM (2014) Widespread occurrence of neonicotinoid insecticides in streams in a high corn and soybean producing region, USA. Environ Pollut 193:189-196

Hladik ML, Vandever M, Smalling KL (2016) Exposure of native bees foraging in an agricultural landscape to current-use pesticides. Sci Total Environ 542:469-477

Iwasa T, Motoyama N, Ambrose JT, Roe RM (2004) Mechanism for the differential toxicity of neonicotinoid insecticides in the honey bee, Apis mellifera. Crop Prot 23:371-378

Jeschke P, Nauen R, Schindler M, Elbert A (2011) Overview of the status and global strategy for neonicotinoids. J Agric Food Chem 59: 2897-2908

Jones A, Harrington P, Turnbull G (2014) Neonicotinoid concentrations in arable soils after seed treatment applications in preceding years. Pest Manag Sci 70:1780-1784

Kitulagodage M, Astheimer LB, Buttemer WA (2008) Diacetone alcohol, a dispersant solvent, contributes to acute toxicity of a fipronil-based insecticide in a passerine bird. Ecotoxicol Environ Saf 71:597-600

Kitulagodage M, Buttemer WA, Astheimer LB (2011a) Adverse effects of fipronil on avian reproduction and development: maternal transfer of fipronil to eggs in zebra finch Taeniopygia guttata and in ovoexposure in chickens Gallus domesticus. Ecotoxicology 20: 653-660

Kitulagodage M, Isanhart J, Buttemer WA, Hooper MJ, Astheimer LB (2011b) Fipronil toxicity in northern bobwhite quail Colinus virginianus: reduced feeding behaviour and sulfone metabolite formation. Chemosphere 83:524-530

Klee J, Besana AM, Genersch E et al (2007) Widespread dispersal of the microsporidian Nosema ceranae, an emergent pathogen of the western honey bee, Apis mellifera. J Insect Pathol 96:1-10

Krupke CH, Hunt GJ, Eitzer BD, Andino G, Given K (2012) Multiple route of pesticide exposure for honeybees living near agricultural fields. PLoS One 7:e299268

Kunce W, Josefsson S, Örberg J, Johansson F (2015) Combination effects of pyrethroids and neonicotinoids on development and survival of Chironomus riparius. Ecotoxicol Environ Saf 122:426-431

Laycock I, Cotterell K, O’Shea-Wheller TA, Cresswell JE (2014) Effects of the neonicotinoid pesticide thiamethoxam at field-realistic levels on microcolonies of Bombus terrestris worker bumblebees. Ecotoxicol Environ Saf 100:153-158

Limay-Rios V, Forero G, Xue Y, Smith J, Baute T, Schaafsma A (2015) Neonicotinoid insecticide residues in soil dust and associated parent soil in fields with a history of seed treatment use on crops in southwestern Ontario. Environ Toxicol Chem 35:303-310

Long EY, Krupke CH (2015) Intersections between neonicotinoid seed treatments and honey bees. Curr Opin Insect Sci 10:8-13

Long EY, Krupke CH (2016) Non-cultivated plants present a season-long route of pesticide exposure for honey bees. Nat Commun 7:11629

Lopez-Anita A, Ortiz-Santaliestra ME, Mougeot F, Mateo R (2015) Imidacloprid-treated seed ingestion has lethal effect on adult partridges and reduces both breeding investment and offspring immunity. Environ Res 136:97-107

Lopez-Antia A, Ortiz-Santaliestra ME, Mougeot F, Mateo R (2013) Experimental exposure of red-legged partridges (Alectoris rufa) to seeds coated with imidacloprid, thiram and difenoconazole. Ecotoxicology 22:125-138 
Lu Z, Challis JK, Wong CS (2015) Quantum yields for direct photolysis of neonicotinoids insecticides in water: implications for exposure to nontarget aquatic organisms. Environ Sci Technol 2:188-192

Main AR, Headley JV, Peru KM, Michel NL, Cessna AJ, Morrissey CA (2014) Widespread use and frequent detection of neonicotinoid insecticides in wetlands of Canada's prairie pothole region. PLoS One 9:e92821

Main AR, Michel NL, Cavallaro MC, Headley JV, Peru KM, Morrissey CA (2016) Snowmelt transport of neonicotinoid insecticides to Canadian prairie wetlands. Agric Ecosyst Environ 215:76-84

Manzone M, Balsari P, Marucco P, Tamagnone M (2015) Potential external contamination of pneumatic seed drills during sowing of dressed maize seeds. Pest Manag Sci 72:1302-1308

Mason R, Tennekes H, Sánchez-Bayo F, Jepsen PU (2014) Immune suppression by neonicotinoid insecticides at the root of global wildlife declines. J Environ Immunol Toxicol 1:3-12

Mineau P, Palmer C (2013) Neonicotinoid insecticides and birds: the impact of the nation's most widely used insecticides on birds. American Bird Conservancy, USA

Mogren CL, Lundgren JG (2016) Neonicotinoid-contaminated pollinator strips adjacent to cropland reduce honey bee nutritional status. Sci Rep 6:29608

Mommaerts V, Reynders S, Boulet J, Besard L, Sterk G, Smagghe G (2010) Risk assessment for side-effects of neonicotinoids against bumblebees with and without impairing foraging behaviour. Ecotoxicology 19:207-215

Morrissey CA, Mineau P, Devries JH, Sánchex-Bayo F, Liess M, Cavallaro MC, Liber K (2015) Neonicotinoid contamination of global surfacewaters and associated risk to aquatic invertebrates: a review. Environ Int 74:291-303

Mörtl M, Kereki O, Darvas B, Klátyik S, Vehovszky A, Gyóri J, Székács A (2016) Study on soil mobility of two neonicotinoid insecticides. J Chem 2016:4546584

Nieto A, Roberts SPM, Kemp J et al (2014) European red list of bees. Publication Office of the European Union, Luxembourg

Nuyttens D, Devarrewaere W, Verboven P, Foqué P (2013) Pesticideladen dust emission and drift from treated seeds during seed drilling: a review. Pest Manag Sci 69:564-575

Pecenka JR, Lundgren JG (2015) Non-target effects of clothianidin on monarch butterflies. Sc Nat 102:19

Peña A, Rodríguez-Liébana JA, Mingorance MD (2011) Persistence of two neonicotinoid insecticides in wastewater, and in aqueous solutions of surfactants and dissolved organic matter. Chemosphere 84: 464-470

Pesticide properties database (PPDB) (2012) Pesticide properties database. http://sitem.herts.ac.uk/aeru/ppdb/en/index.htm

Pettis J, vanEngelsdorp D, Johnson J, Dively G (2012) Pesticide exposure in honey bees results in increased levels of the gut pathogen Nosema. Naturwissenschaften 99:153-158

Pilling E, Campbell P, Coulson M, Ruddle N, Tornier I (2013) A fouryear field program investigating long-term effects of repeated exposure of honey bee colonies to flowering crops treated with thiamethoxam. PLoS One 8:e77193

Pisa LW, Amaral-Rogers V, Belzunces LP et al (2015) Effects of neonicotinoids and fipronil on non-target invertebrates. Environ Sci Pollut Res 22:68-102

Pistorius J, Bischoff G, Heimbach U, Stähler M (2009) Bee poisoning incidents in Germany in spring 2008 caused by abrasion of active substance from treated seeds during sowing of maize. In: Proceedings "Hazards of pesticides to bees-10th international symposium of the ICP-bee protection group". Julius-Kühn Archiv 423:118-126

Placke FJ (1998a) Long-term soil dissipation study with Confidor 70WG in apple orchards in Germany following spray application. Draft assessment report (DAR) - public version - initial risk assessment provided by the rapporteur member state Germany for the existing active substance imidacloprid. Vol 3, annex B, B8. European Food Safety Authority, Parma, pp 630-637

Placke FJ (1998b) Long-term soil dissipation study with Zelmone 350 FS in great Britain following deed dressing of winter barley. Draft assessment report (DAR) - public version-initial risk assessment provided by the rapporteur member state Germany for the existing active substance imidacloprid. Vol 3, annex B, B8 European Food Safety Authority, Parma, pp 637-642

Pohorecka K, Skubida P, Semkiw P et al (2013) Effects of exposure of honey bee colonies to neonicotinoid seed-treated maize crops. J Agric Sci 57:199-208

Qi W, Singer H, Berg M, Müller B, Pernet-Coudrier B, Liu H, Qu J (2015) Elimination of polar micropollutants and anthropogenic markers by wastewater treatment in Beijing, China. Chemosphere 119:1054-1061

Reetz JE, Schulz W, Seitz W, Spiteller M, Zühlke S, Armbruster W, Wallner K (2015) Uptake of neonicotinoid insecticides by water foraging honey bees (Hymenoptera: Apidae) through guttation fluid of winter oilseed rape. J Econ Entomol 109:31-40

RIVM (2008) In: Posthuma-Doodeman CJAM (ed) Environmental risk limits for imidacloprid. National Institute for Public Health and the Environment Bilthoven, Netherlands

RIVM (2014) Water quality standards for imidacloprid: proposal for an update according to the water framework directive. In: Smit CE (ed) National institute for public health and the environment. Bilthoven, Netherlands

Rolke D, Persigehl M, Peters B, Sterk G, Blenau W (2016) Large-scale monitoring of effects of clothianidin-dressed oilseed rape seeds on pollinating insects in northern Germany: residues of clothianidin in pollen, nectar and honey. Ecotoxicology 25:1691

Rundlöf M, Andersson GKS, Bommarco R et al (2015) Seed coating with a neonicotinoid insecticide negatively affects wild bees. Nature 521: $77-80$

Sadaria AM, Supowit SD, Halden RU (2016) Mass balance assessment for six neonicotinoid insecticides during conventional wastewater and wetland treatment: nationwide reconnaissance in United States wastewater. Sci Total Environ 50:6199-6206

Samson-Robert O, Labrie G, Chagnon M, Fournier V (2014) Neonicotinoid-contaminated puddles of water represent a risk of intoxication for honeybees. PLoS One 9:e108443

Sánchex-Bayo F, Goka K (2014) Pesticide residues and bees - a risk assessment. PLoS One 9:e94482

Sánchez-Bayo F (2006) Comparative acute toxicity of organic pollutants and reference values for crustaceans. I. Branchiopoda, Copepoda and Ostracoda. Environ Pollut 139:385-420

Sánchez-Bayo F, Hyne RV (2014) Detection and analysis of neonicotinoids in river waters - development of a passive sampler for three commonly used insecticides. Chemosphere 99:143-151

Sánchez-Bayo F, Goulson D, Pennacchio F, Nazzi F, Goka K, Desneux N (2016) Are bee diseases linked to pesticides? A brief review. Environ Int 89-90:7-11

Sandrock C, Tanadini LG, Pettis JS, Biesmeijer JC, Potts SG, Neumann P (2014) Sublethal neonicotinoid insecticide exposure reduces solitary bee reproductive success. Agric For Entomol 16:119-128

Santos A, Oliveira BL, Samuels RI (2007) Selection of entomopathogenic fungi for use in combination with sublethal doses of Imidacloprid. Mycopathology 163:233-240

Schaafsma A, Limay-Rios V, Baute T, Smith J, Xue Y (2015) Neonicotinoid insecticide residues in surface water and soil associated with commercial maize (corn) fields in southwestern Ontario. PLoS One 10:e0118139

Schaafsma A, Limay-Rios V, Xue Y, Smith J, Baute T (2016) Field-scale examination of neonicotinoid insecticide persistence in soils as a result of seed treatment use in commercial maize (corn) fields in southerwestern Ontario. Environ Toxicol Chem 35:295-302 
Scholer J, Krischik V (2014) Chronic exposure of imidacloprid and clothianidin reduce queen survival, foraging, and nectar storing in colonies of Bombus impatiens. PLoS One 9:e91573

Selim HM, Jeong CY, Elbana TA (2010) Transport of imidacloprid in soils: miscible displacement experiments. Soil Sci 175:375-381

Sgolastra F, Medrzycki P, Bortolotti L et al (2016) Synergistic mortality between a neonicotinoid insecticide and an ergosterol-biosynthesisinhibiting fungicide in three bee species. Pest Manag Sci 73:12361243

Simon-Delso N, Amaral-Rogers V, Belzunces LP et al (2015) Systemic insecticides (neonicotinoids and fipronil): trends, uses, mode of action and metabolites. Environ Sci Pollut Res 22:5-34

Smalling KL, Reeves R, Muths E, Vandever M, Battaglin WA, Hladik ML, Pierce CL (2015) Pesticide concentrations in frog tissue and wetland habitats in a landscape dominated by agriculture. Sci Total Environ 502:80-90

Smit CE, Posthuma-Doodeman CJAM, Van Vlaardingen PLA, De Jong FMW (2014) Ecotoxicity of imidacloprid to aquatic organisms: derivation of water quality standards for peak and long-term exposure. Hum Ecol Risk Assess. doi:10.1080/10807039.2014.964071

Spurgeon D, Hesketh H, Lahive E et al (2016) Chronic oral lethal and sublethal toxicities of different binary mixtures of pesticides and contaminants in bees (Apis mellifera, Osmia bicornis and Bombus terrestris). EFSA supporting publication 2016:EN-1076. Centre for Ecology and Hydrology, Wallingford

Stanley DA, Raine NE (2016) Chronic exposure to a neonicotinoid pesticide alters the interactions between bumblebees and wild plants. Funct Ecol 30:1132-1139

Stanley DA, Garratt MPD, Wickens JB, Wickens VJ, Potts SG, Raine NE (2015) Neonicotinoid pesticide exposure impairs crop pollination services provided by bumblebees. Nature 528:548-550

Sterk G, Peters B, Gao Z, Zumkier U (2016) Large-scale monitoring of effects of clothianidin-dressed OSR seeds on pollinating insects in northern Germany: effects on large earth bumble bees (Bombus terrestris). Ecotoxicology 25:1666-1678

Stewart SD, Lorenz GM, Catchot AL et al (2014) Potential exposure of pollinators to neonicotinoid insecticides from the use of insecticide seed treatments in the mid-southern United States. Environ Sci Technol 48(9762):9769

Sur R, Stork A (2003) Uptake, translocation and metabolism of imidacloprid in plants. Bull Insectol 56:35-40

Switzer CM, Combes SA (2016) The neonicotinoid pesticide, imidacloprid, affects Bombus impatiens (bumblebee) sonication behavior when consumed at doses below the LD50. Ecotoxicology 25: $1150-1159$

Syracuse Environmental Research Associate (SERA) (2005) Imidacloprid — human health and ecological risk assessment-final report. Report from Syracuse environmental research associates to USDA, Forest Service, Manlius, New York

Szczepaniec A, Creary SF, Laskowski KL, Nyrop JP, Raupp MJ (2011) Neonicotinoid insecticide imidacloprid causes outbreaks of spider mites on elm trees in urban landscapes. PLoS One 6:e20018

Székács A, Mörtl M, Darvas B (2015) Monitoring pesticide residues in surface and ground water in Hungary: surveys in 1990-2015. J Chem 2015:717948

Thompson HM, Fryday SL, Harkin S, Milner S (2014) Potential impacts of synergism in honeybees (Apis mellifera) of exposure to neonicotinoids and sprayed fungicides in crops. Apidologie 45: $545-553$

Thuyet DQ, Watanabe H, Motobayashi T (2011) Effect of formulations and treatment methods of nursery boxes applied with insecticide on the behavior of imidacloprid in rice paddy fields. J Pest Sci 36:9-15
Tingle CCD, Rother JA, Dewhurst CF, Lauer S, King WJ (2003) Fipronil: environmental fate, ecotoxicology and human health concerns. Rev Environ Contam Toxicol 176:1-66

Tišler T, Jemec A, Mozetic B, Trebse P (2009) Hazard identification of imidacloprid to aquatic environment. Chemosphere 76:907-914

Tokumoto J, Danjo M, Kobayashi Y et al (2013) Effects of exposure to clothianidin on the reproductive system of male quails. J Vet Med Sci 75:755-760

U.S. EPA (2012) United States Environmental Protection Agency Ecological Risk Assessment. http://www.epa.gov/oppefed1/ ecorisk ders/toera analysis eco.htm

U.S. EPA (2014a) OPP Pesticide Toxicity Database. http://www.epa.gov/ oppefed1/ecorisk ders/aquatic life benchmark.htm

U.S. EPA (2014b) Guidance for assessing pesticide risks to bees. Washington D.C, USA

Van Dijk TC, Van Staalduinen MA, Van der Sluijs JP (2013) Macroinvertebrate decline in surface water polluted with imidacloprid. PLoS One 8:e62374

vanEngelsdorp D, Speybroeck N, Evans JD et al (2010) Weighing risk factors associated with bee Colony collapse disorder by classification and regression tree analysis. J Econ Entomol 103:1517-1523

Vidau C, Diogon M, Aufauvre J et al (2011) Exposure to sublethal doses of fipronil and thiacloprid highly increases mortality of honeybees previously infected by Nosema ceranae. PLoS One 6:e21550

Vijver MG, van den Brink J (2014) Macro-invertebrate decline in surface water polluted with imidacloprid: a rebuttal and some new analyses. PLoS One 9:e89837

von Gunten K (2012) Photodegradation and sorption to Na-SAz clay, soil and pollen of the neonicotinoids acetamiprid, clothianidin, imidacloprid and thiacloprid. https://www.yumpu.com/en/ document/view/7393414/photodegradation-and-sorption-to-nasazclay-soil-eth-zurich

Wachendorff-Neumann U, Mauler-Machnik A, Erdelen C, Ohtake H (2012) Synergistic mixture of trifloxystrobin and imidacloprid. Google patents. United States: Bayer Cropscience AG

Wang Y, Wu S, Chen L, Wu C, Yu R, Wang Q, Zhao X (2012) Toxicity assessment of 45 pesticides to the epigeic earthworm Eisenia fetida. Chemosphere 88:484-491

Wang L, Zeng L, Chen J (2015a) Sublethal effect of imidacloprid on Solenopsis invicta (Hymenoptera: Formicidae) feeding, digging, and foraging behaviour. Environ Entomol 44:1544-1552

Wang L, Zeng L, Chen J (2015b) Impact of imidacloprid on new queens of imported fire ants, Solenopsis invicta (Hymenoptera: Formicidae). Sci Rep 5:17938

Whitehorn PR, O'Connor S, Wackers FL, Goulson D (2012) Neonicotinoid pesticide reduces bumble bee colony growth and queen production. Science 336:351-352

Woodcock BA, Isaac NJB, Bullock JM, Roy DB, Garthwaite DG, Crowe A, Pywell RF (2016) Impacts of neonicotinoid use on long-term population changes in wild bees in England. Nat Commun 7:12459

Xing ZS, Chow L, Rees H, Meng FR, Li S, Ernst B, Benoy G, Zha TS, Hewitt LM (2013) Influences of sampling methodologies on pesticide-residue detection in stream water. Arch Environ Contam Toxicol 64:208-218

Xu T, Dyer DG, McConnell LL, Bondarenko S, Allen R, Heinemann O (2016) Clothianidin in agricultural soils and uptake into corn pollen and canola nectar after multiyear seed treatment applications. Environ Toxicol Chem 35:311-321

Yu RX, Wang YH, Hu XQ, Wu SG, Cai LM, Zhao XP (2015) Individual and joint acute toxicities of selected insecticides against Bombyx mori (Lepidoptera: Bombycidae). J Econ Entomol 109:327-333 